\title{
$37,6 \%$
}

1368

tom

63

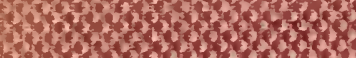

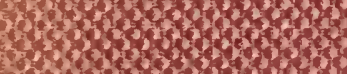



HW

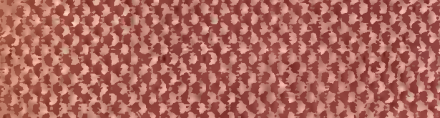

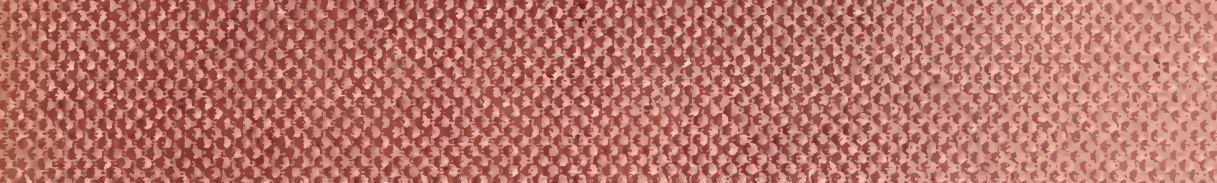

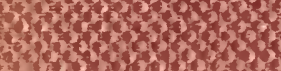

Who

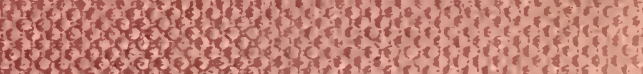

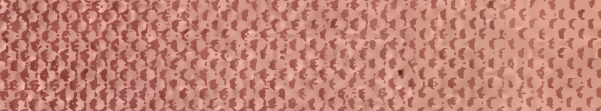




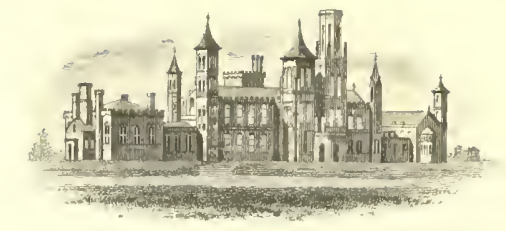

\section{COLLECTION \\ OF}

WILLIAM SCHAUS

(1)

PRESENTED

TO THE

NATIONAL MUSEUM

MCMV 


$$
17
$$





\section{Species Lepidopterorum (Pepuliosidie}

hucusque descriptae vel iconibus expressae in seriem systematicam digestae

C. et R. Felder.

Separata ertitio ex actis c. $r$. societatis zoolog.-botanicae.

TINDOBONAE.

1864. 



\section{Species Lepidopterorum}

lincusque lescriptae vel iconibus expressae in seriem systematicam dienestale

f. et his fidter.

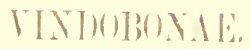

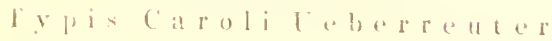


Nomina secundum jus prioris editionis rite eliguntur. Symonyma ea tantum adjiciuus, quae in cel. Doubledayi, Grayi Wakkeri et Guénéei catalogis omissa sunt, item descriptiones et icones recentiores vel illis in operibus neglectas. Observationes in appendice sub numeris appositis sequntur. Signo $t$ species distinguimus, quas in natura inspicere laud fuit concessum. Ineo laterali formas conjungimus, quarum nexum geographicum vix in dubium vocare licet. 
Pars prima.

\section{Papilionialac.}





\title{
Tribus Rhopalocera Duméril.
}

\author{
Familia I. Papilionidac Boisu.
}

\section{Genus I. Teinoprosopus Nobis. ${ }^{1}$ ).}

I. Imperialis Hope....... . Intice Eept. (Silhet, Durjeelin...)

Genus II. Leptocircus Swains. ${ }^{2}$.

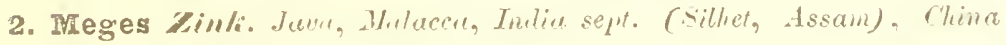
atesti.

L. Curius F. apud De Haan in Verh. over de nat. Gesch. der Nederl. orerz. Bez. Zool. III. p. 43. - I, Curius F. ja apud B! an ehard. Hist. nat. d. Ins. IIl. p. 2, 2.

3. Decius frlder. . . . . . . . . . . . . . . . Luzon. Wien. ent. Monatsehr. VI. p. 28.. - \%ool. d. Norara Exp.

4. Ennius Felder. . . . . . . . . . . . . . . . Celebes. Zool. d. Norara Exp.

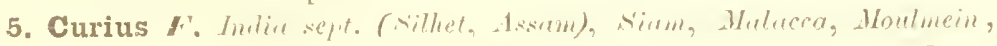
Irelu.

biancliard 1. c. pl. 2. fig. 2.

Genus III. Papilio Latr.

Sortio 1. 3).

Genithoptera lioi d. Woubldy ex parte. 
Subsectio A. ${ }^{4}$ ).

6. Tithonus He Har". ...... Nova (ruinea (lit. austio-occid.)

Subsectio B. 5 .

† 7. Victoriae Grr.y. . . . . . Ocennic (Norae Hebridue?)

Subsectio C. $\left.{ }^{6}\right)$.

8. (Priamus I. ${ }^{7}$ ). . . . . . . . Amboina, Ceram. O Seba Thesaur. t. 4. f. 22, 23. (aberr.?).

9. Richmondia (nuy. "). . . . . . . Austral. orient.

+10. Euphorion Gily. . . . . . . Austrul. sept-occident.

† 11. Pronomus (iray....... Austral. sept.orient. (Cap Tork)

† 12. Cronius Vobis. ").. . . . . Vova Guinece (lit. austro-occid.) O Ornithoptera Priamus L. var. De Haan, l. c. p. 18.

+13. Oceanus Vobis. ${ }^{10}$ ). . . . . . . . . Woodlark.

a O Ornithoptera Boisduvalii Montrouz. in Annal. des sc. plyys. et mat. de la soc. d'Agric. de Lyon VIII. p. 393.

14. Arruanus felder. . . . . . . . . Arru Ins.

Zool. d. Vovara lxp. -- Ornithoptera arruna Wall. in litt. Feld. in Wien. ent. Monatschr. III. p. 391.

+ 15. Urvillianus (nwer. "'). . . . Nove Hihernin (Port P'rastin).

+ 16. Triton Volvis. ${ }^{12}$ ). . . . . . . . . . Ravak.

P. Priamus I. var. Quoy et Gainard in Voy. de l'Uranie et Physicicune 1. 8301 . t. $\$ 3$.

† 17. Poseidon /Nowlbly. $\left.{ }^{\mathrm{k}}\right)$. . . . . . . . . Ins Darnley.

18. Pegasus Felder. . . Niva Guined (lit. nccid.-uustr. et Dore?).

Zool. d. Norara Exped. - O Ornithoptera A rchidaeus Gray apur Feld. in Wien. ent. Monat-chr. III. p. 26!. - aberr. o Snell. van Vollenh. Tijdschr. voor Ent. IIl. p. 89.

† 19. Archidaeus ('ray. $\left.{ }^{14}\right)$. . . . . . . . . Celetres?

20. Croesus VIall. i. I. (n'll!y. $\left.{ }^{15}\right)$. . . . . . . . . Batjun. Ornithoptera Croesus Wallace in litt. Feld. in Wien. Ent. Monat.chir. III. p. 390. t. 7. (0) -- riray in Proceed. of the

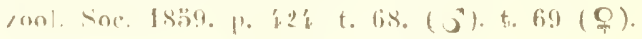

\section{Sectio $\left.11 .{ }^{16}\right)$.}

nenithoptera lioisd. Doubldy. ex pte.

$$
\text { Subnatin A. }{ }^{17} \text { ). }
$$

21. Remus ('ram. 14). . . . . Chebrs, Ambina, Ceram, Ternate. s Soba, Thesaur. t. 46. f. 11, 12. 19, 20 (aberr.?). - 5 ihid.t. f. 17. 1s, 19, a catrerr.? 


\section{Subsectio B. $\left.{ }^{19}\right)$.}

22. Helena L. . Amboina, Temate. Noua Guineu (eadem?).

Celobes!

G Seba Thesaur. t. h. f. $9,10,11,12 .-9$ ibid. t. 46. f. 6,7 . -

P. Amplimedon Cram. Boisd. - Esp. Ausl. Schmett. t. 40 C. f. 2 .

23. Criton Felder. . . . . . . . . . Batjan, Italmaheira. Zool. der Novara Exp. - Ornithoptera Criton Feld. in Wien. ent. Monatschr. IV. p. 223.

24. Darsius Gruy. . . . . . . . . . . . . Ceylon.

O Ornithoptera Darsius Gray apud Feld. 1. c. p. 97.

25. Haliphron Boisd. "2i). . . . . . . . . . . Celebes.

Ornithoptera Amphimedon Cram. O apud Doubldy et Hew. Gen. of diurn. Lep. p. et Gray Catal, of the Lep. of the B. M. I. p. Z. - Ornithoptera Haliphron Boisd. apud Felder in Wien. ent. Monatschr. IV. p. 98. t. II. f. "2a (o $2 \mathrm{~b}(\mathbf{9})$.

26. Rhadamanthus Boisal. . . . . Luzon, China austr., Cochin. P. Nephereus Gray. List of the Lep. of the B. M. p. I. $6^{21}$ ).

27. Magellanus Felder. . . . . . . . Luzon, Ins. Bubuynue.

o O Zool. d. Novara Exp. - Ornitloptera Magellanus Feld. in Wien. ent. Monatschr. V1. p. $28 \%$.

28. (Pompeus Crum.. Juva. - Borneo (eadem?). - Nova Guinea (eadem?)

o Merian Ins. Surin. t. 7\%. - Ornithoptera Heliacon l. apud Blanchard 1. c. p. 420. pl. 1. - P. Amphrysus Cram. apud Zink. in Verh. d. k. Leop. Carol. deutsch. Akad. d. Naturf. XVI. p. 153.

29. Hephaestus Folder. . . . . . . . . . . C'elébes. Zool. d. Novara Exp.

30. Pluto ficlder.

Zool. d. Novara Exp.

31. Cerberus Felder. . Zool. d. Novara Exp.

32. Aeacus Felder. . . . . . . . . . . . . . - ? O Ornithoptera Acacus Feld. in Wien. cut. Monatschr. M. p. 22:3. +33. Minos ('ram. 22). . . . . . . . . . . Sumutrom

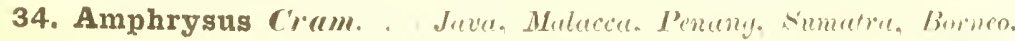


Sectio III. ${ }^{23}$ ).

35. Brookeanus I'ull.............. Borneo, sumutre. ornithoptera Brookeana Wall. in Proceed. of the ent. Soc. 1×:3:. - Hew. Exotic. Buttil. Tol. 1. gen. t. 1. f. 1. P. Trogon stell. van Vollhv. Tijelschr. roor Ent. III. p. 6s. pl. $6(1866))$.

Sectio IV. ${ }^{24}$ ).

36. Triopas Gorll..... Curme, Demerura, Pritr, Amenonia int. Lucas in Clenu, Encycl. d' Hist. nat. Lep. t. \{. f. I.

37. Chabrias Ifer............... Amazonia stl?.

$$
\text { Sectio } 1.25 \text { ). }
$$

Endopogon Boisd. olim i. litt.

38. Sesostris (rom. 26). Surinam, Canenne, Guiana, Amasonia, Nour Crimata, Ecumtor.

o Scba Thesaur. t. 26. f. 19, 20 (aberr.?) - jbidem t. 4.j. f. 2:3, 2\%. - C. Vertumnus Cram. var. c. Gray Catal. I. p. 37. pl. :i. f.

† 39. (Zestos Gruy. . . . . . . . . . . Mexico, Homheres. o P. Scsostris Cr. rar. Bat. in Trans. of the ent. Soc. of London N. S. Vol. V. p. 3ío.

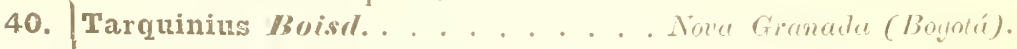
j'. Sesostris Cr. rar. Bat. I. e.

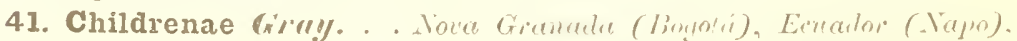
Bretsilie interior.

\& Feld. in Wien. ent. Monatschr. V. p. 73. - Zool. d. Norara lixp. j P. Sesontris Cr. var. Bat. I. c. - P. Odipus Buisd. in lift. Lueas in castelnau, Voy. dans l" Amér. du Sud E t. p. 19\%. Lep. pl. 2. fig. í.

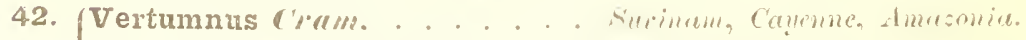
aber. F P. Ariarathes var. Esp. Ausländ. Achmett. p. 5x. t. 1', i. .3.

l. Diceros Gray.

P. Plronius Boisd. in litt. Lucas.

P. Cixins Gray.

P'. Coelus Lacord. in litt. Buisd.

(cl'. Bates l. c.) ‘).

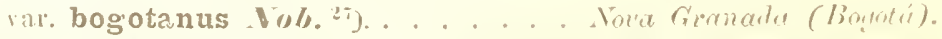

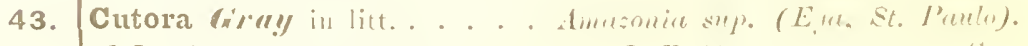

j I'. Vertumus var. c. Gray. - C. Vertumus var. Cutoral apud liaten l. c 


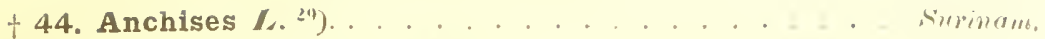
Boisd. Spec. gún. I. p. 29!l.

45. Telmosis Roisd. in litt. . . . . . . . . . . Surinum. Bat. 1. c. - P. Vertumnus j Cram. Uitl. Cap). 11L. 1. 32. t. 211. Fig. C

† 46. Erlaces friug. . . . . . . . . . . . Boliviu, P'ü.

† 47. Phosphozus Bul. . . . . . . . . . . . . . . Demerart.

Transact. of the ent. Soc. of London. N. S. Vol. V. p. 3..2.

48. Hierocles fíry. . . . . . . . . . . . . . . . I'aŕ.

abrr. C P. Aglaope Fray.

P. Thelios Gray.

P. Cyphotes Gray.

(cf. Bat. l. c. p. 3il.)

49. Zuol. d. Novara kixp.

† 50. Iycomes frrll. . . . . . . . . . . . . . . Sirinum.

51. Nephalion God. . . . . . . . . . . . Sravilin meriel. aberr. ö P. Stilbon Kollar ${ }^{30}$ ). - aberr.? ö P. II a mon Kollar in litt. $\left.{ }^{31}\right)$.

52. Idalion Feldei..

S Zool. d. Norara Exp.

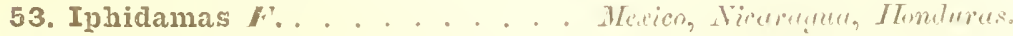

54. Polyzelus Felder. . . . . . . . . . Meviro, Ilondure. Zool. d. Tovara Exp. - P. Anclises 1. apud Cray. Catal. p. 6i? - P. Alector Boisd. in litt., Bat. Transact, ol tle int. Suc. of London. Y. S. Vul. V. p. 3'il. 3̈̈ (alsaque dencript.)?

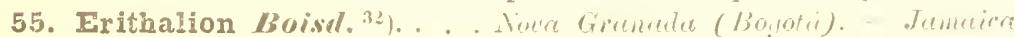
(indini?)

j P. Pyrochles 1)oubldy. Gray. - P. Phaenonkollar. S. P. Erithalion Boisd. - Feld. Kool. d. Nuvara Exp. -

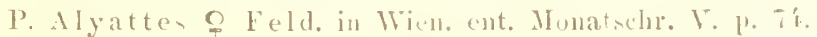

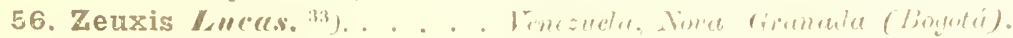
ò l.ucas in Castelnau, Voy. dans l’ Anér. du Sud Entom. lep. pl. 2. fin. :3. j- l'. Mhesus Klug. in litt. - 1'. Abilius II or.tz in litt. - S E. Erithalion Boisl. apud Fray, Catal. ऐl. Xir. í.

57. Alyattes Feleler. . . . . . None Goumbe (limenti).

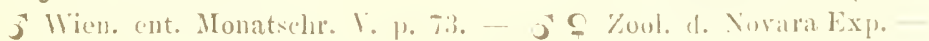

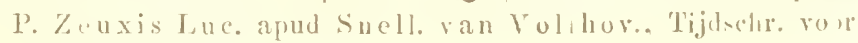
Entom 111. 1\%. S(1) no. S7?

58. Rhamases Huisd. in litt. linesuela P. Kcuxi- I, uc. apud Gray Calal. 
59. Xenares Felder. ........... Venezuela (Ormoco). O Zool. d. Norara Exp. - P. Erithalion apud Kollar, Beiträge zur Insektenfauna von Neu-Gran. u. Venez. p. 3 no. 6.

60. Arcas C'ram. . . . . . . . . . . Brasilia?

† 61. (Toxaris Nob. ${ }^{34}$ ) . . . . . . . . . . . Tenezuela. o P. Erithalion Boisd. apud Gray Catalogue. pl. $X^{*}$ f. 4 .

62. Anacharsis Felder. . . . . . . . . . . - ? Zool. d. Novara Exp.

63. Cymochles ('rr!. . . . . . . . . . Ins. Trinidad!

+64. Orbignyanus Lllclls............. Corrientes.

† 65. (Serapis Boisul. . . . . . . . Columbia (Boyotá?). O Gray Catal. I. p. 40.

66. Osyris Felder. ....... Tenezuela (Caracas). ơ Wien. ent. Monatchr. V. p. 74. - Zool. d. Norara Exp. P. Severus Moritz in litt.

67. Panares Girly... . . . . . . . . . Mecico.

$$
\text { Sectio VI, }{ }^{35} \text { ). }
$$

68. Agavus llrury. . . . . . . . . . . Brasilia.

† 69. Phryneus Larlls....... . . . Brusilia - Cayenne?

70. Proneus I/̈̈lı... . . . . . . . . . Brasilie merid.

71. Bunichus M̈̈b川............. Brasilia austral.

+72. Chamissonia Esch . Brasilire anstral. (Prov. et Ins. S. Cuthu-

rinae) et interior.

P. Echedorus Boisd. - P. Eurydorus Lucas - Isd. in Castelnan, Voy. dans l' Amér. du Sud. Lep. pl. 2. fig. 1.

73. Ascanius C'rum............ Brasilia austr.

74. Perrhebus Lacord. in litt. Boisal. L'ureunaly, Brasil. alets. (Rio

75. Gundiachianus Wob. $\left.{ }^{36}\right)$. . . . . . . . C Cuba. P. Columbus Gundlach in litt. Herrich-Schäffer. Correspondenzbl. d. zool.-min. Ver. zu Regensburg 1862. p. 14.

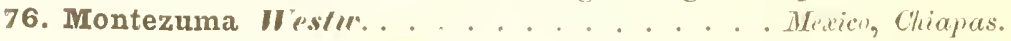
P. 'Tulana 'Tryou Reakirt, Proc. of the ent. Soc. of Philadelphia 1863. 1. 140.

77. Photinus INoulbly. . . . . . . . . . . . . Nexico.

sectio (II, $3 i$ ).

$S$ u b sectio $\left.1 .{ }^{34}\right)$.

78. Dardanug $\boldsymbol{F}$. 


\section{subsectio B. $\left.{ }^{\prime \prime \prime}\right)$}

† 79. Orellana Hew. . . . . . . . . . Amazomira suj). (E!a).

80. Aeneas L............ Surnam, Guiana, I'urú. O P. Marcius Hiibn. Gray. (cf. Bat. Trinsact. of the ent. Suc. of London N. S. Vol. V. p. 312).

81. Bolivar Mell. $\left.{ }^{40}\right)$. . . . . . . . . Anazonia sup. (Eya.) (cf. Bat. l. c.)

† 82. Gratianus I/ere. . . . . . . . . . . . Nova Granadr. o Exotic Butterfl. Vol. II. gen. t. ̈̈. fị. 13.

† 83. Aglaope (i) Príá.

† 84. Euristeus Crom.............. Surinum.

85. Panthonus Crame. . . . . . . . Surinciu, Demerare.

† 86. Callicles Bat. . . . . . . . . . . . . Butivia. Q 1. c. p. 361 . - P. Erlaces O Gray Cital. 1.

† 87. Numa Hoistl. .

O Bat. 1. c.

88. Pisander Fellel.

O Zool. d. Novara Exp.

89. Anaximander felder.

O Zuol. d. Novara Exp.

90. (Phrynichus Felder.

Nova Gramala.

u Zool. d. Norara Exp. - P. Eurymas Fodt. var. Kollar, lieiträge etc. p. 2..

91. Parsodes (uray. $\left.{ }^{41}\right)$. . . . Purá, Tocantin.. M Mitico?

O P. Anchises I. apud Esp. Ausl. Sclmett. t. 6. fig. 1. - P. Arbates Hübn. - P. Sonoria Gray. - o 9 P. Lysander Cr. var. Bat. 1. c. p. 3'í.

92.

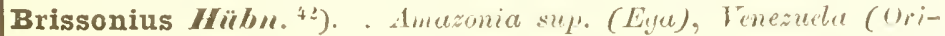
moen).

Q P. Arbates Cr. apud Kollar, Beiträge stc. p. 3. - P. Lysander Cr. apud Bat. I. C.

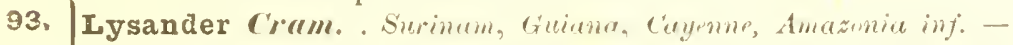
lirasilia?

j P. oblongus medius etc. Petiver Gazophyl. t. 137. fig. 7, s. - P. Aeneas L. apud Esper. Ausländ. Schmett. t. 9. fig. 1. - C sieba Thes. t. 7 . fig. $2 \pi$, 28. t. 11. fig. 11, 12. - P. Anchines L. F. Goilt. ex pte. - P. Arbates Cram. - P. Pouplejus ll ïbu. Sammlung cx. Schmett. - aberr. o* E.p. Ausl. Schmett. t. 16. tig. 1. - boisd. Spec. géu.

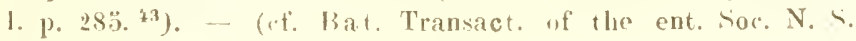
vol. Y. p. 3is. 


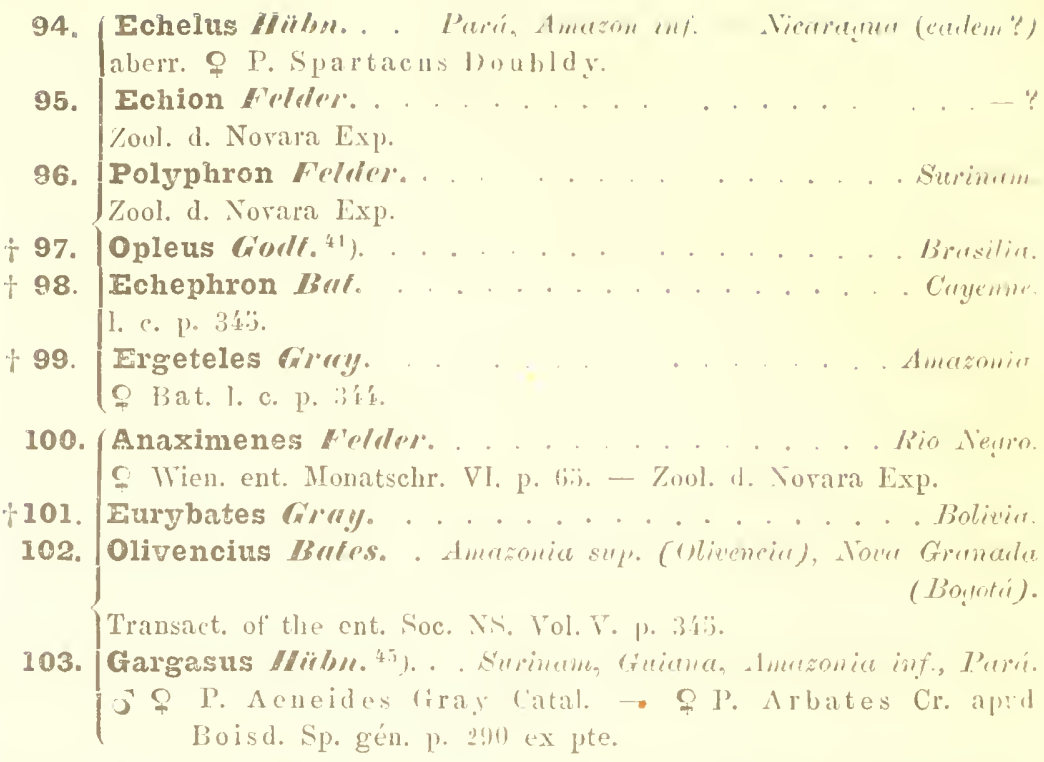

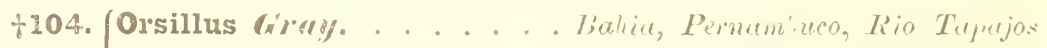

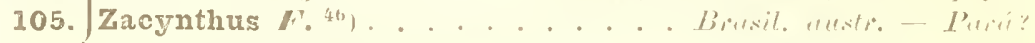
o' Polymetus Codt. - O aberr. P. Eupales riray. - var. A. Boisd. Ap. gen. p. 292.

106. Alcamedes Fulder. . . . . . . . . Tore Granalu?

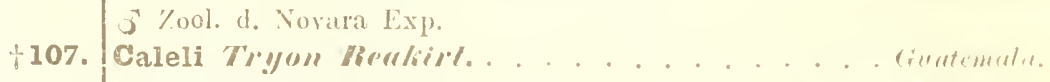

j Proce of the ent. Soc. of Philadelphia 1863 p. 13\%. - \& P. Tonila Tryon keakirt l. c. p. 1 i.0?

108. Aristomenes Frlalm. . . . . . . . . . Mérico.

o \%ool. d. Norara Exp.

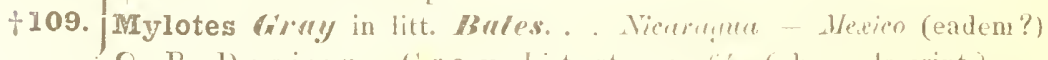
O P. Docim as (iray list cte. p. í (absy dencript.) jo Bates, Tramact. of the ent. Soc. NS. Vol. V. p. 3iti.

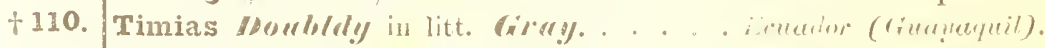

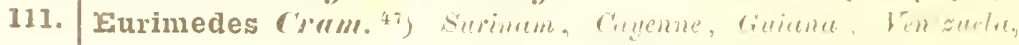

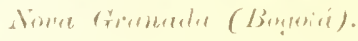

j P. oblongun niger etc. l'eturar tiazophyl. t. 1:3 fig. 4. 10.

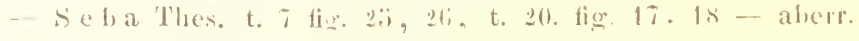
'l'. Agathocles Kollar heitrïge (tc. ${ }^{*}$ ). 


$$
\text { Sirtio VIII, +4). }
$$

$S$ u bsectio $A$. it).

\section{†112. Villiersil Ciodl.}

relue, Floride.

Lucas in Ramonde la Sagra, Historia fisica, politica y natural de la Isla de Cuba II. tom. VIl. p. Ás.).

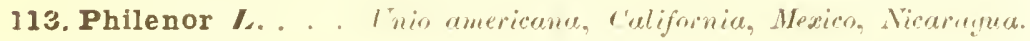
Say Americ. Entom.

$$
\text { Subsectio B. }{ }^{31} \text { j. }
$$

† 114. Copanae Tryon Ibukirt. . . . Chiapres, Guntemale. (Copun). Proceed. of the ent. Soc. of Philadelphia 186.3 p. I $1: 2$.

† 115. Madyes Moubldly. . . . . . . . . . . Brimin.

116. Archidamas Imer)d. in litt. Bojisd. . . . . . Chils. Blanchard in Gay Hist. fisica y politica de Chilw \%oul. Tom. VII. p. 8. Atlas Lep. t. I f. $1 \mathrm{at}, \mathrm{b}$.

117. Xenodamas Buist.

Siravilin mestr.

118. Neodamas Iurlls. . . . . Erlure, Guadeloupe, Juratren. Isd. in Ram. de la Sagra Hist. de Cuba t. 111. p. 4xi.

119. Polydamas L. Surium, Guiuna. Conenne, Ana:ania. Nota Gra-

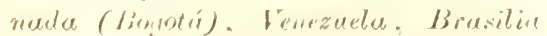

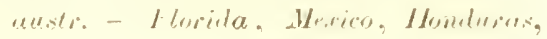

Seba Thesaur. t. if f. It, is.

Niruragere (eadem?).

t var.? Gray Catal. p. 1, T. - Drury-J, ucas in dela Sagra, Hist.

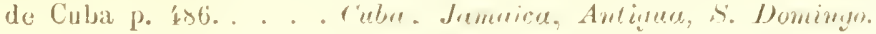

$$
\text { Subsectio ( } \therefore \text {. }) \text {. }
$$

120. Protodamas Goull. . . . . . . . . Birasilid austi. t var.? Gray List. p. Tre (absque dencr.). Honduras, qiuntemalu.

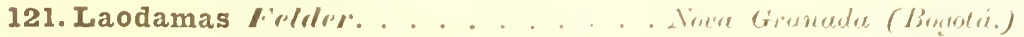
Wien. ent. Honatehr. M. p. 393. t. 8. f. 1 - Jbil. V. p. 72.

122. Chrysodamas Bul. . . . . . . . . . . C Createmulu. Proceed. of the Zoul. So: of J ondon $186 \%$.

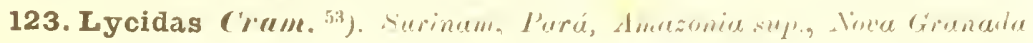
(liouritia).

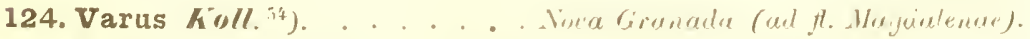
var. Bat. in Trun act. of the Ent. Suc. I. S. Vol. V. p. 228. . Amit-

†125. Amulius Esy. zonire strp. $\left(f_{i}, u\right)$. 


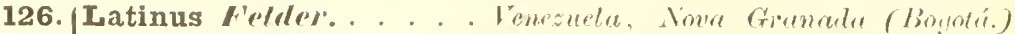
Wien. ent. Monatschr. V. P. 7 2. - Zool. d. Novara Exp, - P. Numitor apul Gray Catal. p. 6s? Bates, Journal of Ent. 1861. p. 223. ex $\mathrm{I}$, te?

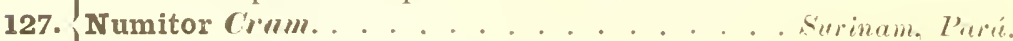
P. Belus apud Esp. Ausl. Schmett. t. 19. f. 2. - Bates Transact. of the ent. soc. N. S. Vol. V. p. 228.

728. Belus C'rum........... Surinam, Anasnire sup. Seba, Thesaur. t. 4.2. f. 1, 2.

129. (Lepidus Felder. . . . . Fenzuelu, Nova Granala (Boyotí). Wien. ent. Monatschr. V. p. 72. - \%ool. d. Novara Exp.

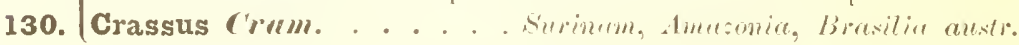

Sectio IX. 5i)

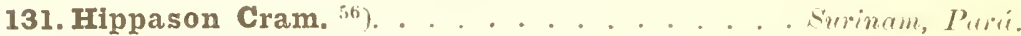
P. paraensis liates Transact. of the ent soc. N. S. Vol. Y. p.337.

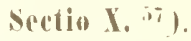

i u b s e etio $\left.A .{ }^{i n}\right)$.

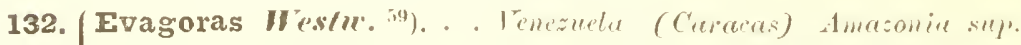
cf. Bates Transact. I. c. 1).336. (Eitu), - Rio Negro (rulem?)

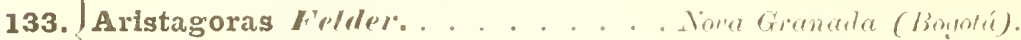
Zool. d. Novara Exp.

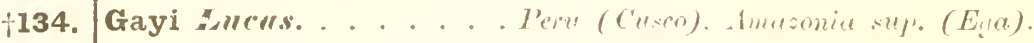
Rates 1. c. p. 337.

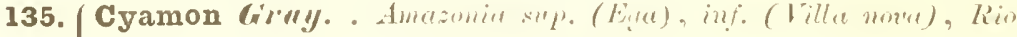
Nemo O Gray Catal. t. $i$, f. $1 .-\subseteq$ j Batest. c. p. 3336. - var. f Gray l. c. p. lit.

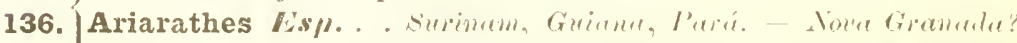
O j krichson in Schomburgks heisen in brit. Guina p. 393. - Bates 1. c. p. 336. - I'. Cyamon C Gray Catal. p. 60. t. 11. f. 3.

$$
\text { Subsectio 13. ("in). }
$$

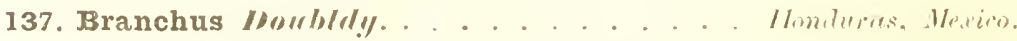
t jo var. Fira Cat. p. 62. . . . . . . . Cimedemeler. †138. Belesis Gru!y in litt. Mal. . . . . . . . . . Cimetemulu. - s Proceed. of the \%ool. Soc. Istit.

$$
\text { subsertio (". "1). }
$$

139. Hephaestion Frlder. 


$$
\text { Subsectio D. (i2). }
$$

+140. Rhetus Broisd. in litt. (irray. Createmale.

$$
\text { Siretio XI. }{ }^{63} \text { ). }
$$

Subsectio A. "17).

† 141. Aconophos Gr'ly. . . . . . . . . . . Mferico. 142. Thymbraeus Boisal. . . . . . Mexico, Guentemulu, Chiapus.

Subsectio B. $\left.{ }^{\text {bi. }}\right)$.

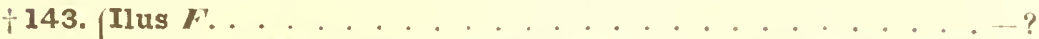

144. Hostilius Moril in litt., Felder. . . Mrezuele (Curaces). Wien. ent. Monatschr. V. p. 73. - \%ool. d. Novara Exp.

145. Farmodius Doubloly. . . . . . . . Bolina, Ecuador.

Subsectio C. (nit).

146. Earyleon Here. "i7). . . . . . . Non'u Girnala (Bo!noti). \& Felder, Wien. ent. Monatschr. V. p. 73. - \%ool. 1. Norara Exp. †147. Xenarchus I/er.... . . . . . . . . . . Mexico. Exotic Buttel. Vol. II. gen. t. .̈. f. 12.

$$
\text { Subsectio 1). } \left.{ }^{64}\right) \text {. }
$$

†148. Phaon Lacord. in litt. Bosisd. . . . . Mexico, Honduras. var.? a. Gray Catal. p. 6\%. . . . . . . . . . Tenezuele. 149. Therodamas Felder. . . . . . Sinet Cirunale (Boyoti). O Zool. d. Norara Exp.

150. Hyperion Hiibll. . . . . . . . . . Brasil. austral. †151. Ulopos Girlly. . . . . . . . . . . . . Mexico.

$$
\text { Subsectio L.6!). }
$$

152. Choridamas Hoistl. . Brasil. austral. - Demerara, India oecirl. (eatem?).

$$
\text { Subsectio F. } \left.{ }^{i n}\right)
$$

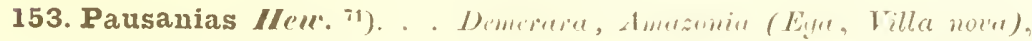

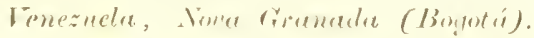
† var.? Gray Catal. p. 19. . . . . . . Itomeluras, Guctemula.

$$
\text { Sicto III. i?). }
$$

154. Harrisianus surnils. . . . . . . . . Brasil. austrul.

155. Athous Frelder. . . . . . . . . . . Bretsil. austrul. Zool. d. Novara Exp.

156. Oedipus Frlder. Brasil. austral. Zool. d. Novara Exp.

157. Lysithous //üb/. Brasil. austral. 
158. Lalus Ho!y. in litt. Boisd. ${ }^{73}$ ). . . . . . . Branil. anstral. +159. Rurikia Esch. . Brasil. austral. (Ins. S. Cutharine", Rio grande). Sectio XIII. it).

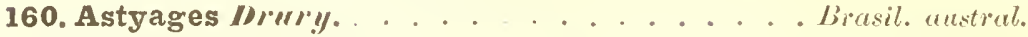
O Iphiclides $\Lambda$ sius r. apud. Hiibn.

$$
\text { Sectio XIV. is). }
$$

161. Columbus HeV.. . . . . Amazonia (Villınoua, Eiga, Jamura). 162. (Dolicaon ('rum. . . . Susinum, P'urri-tmanonia (endem?).

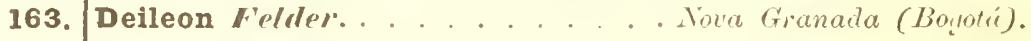
Zool. d. Novara Exp.

164. Deico on Nobis. ith). . . . . . . . . Brasil. austrul. Eurytides Dolicaon apud. Hübn. Samml. ex. Schmett. - P. Dolicaon Cr. apud Boisd. ex pte. - Lucas in Chenn, Encycl. d"Hist. nat. t. 9. Fig. 2.

165. Iphitas IÏ̈lu. . . . . . . . . . . . Bra.il. alstiul. Lucas l c. t. 11. f. 2.

\section{Sectio XY, if).}

166. Servillei (íoll, ${ }^{73}$ ). - Nova Granala (Botma). Felder, Zool. d. Norara Exp.

167. Hippodamus Hoish. in litt. Moubldy of Her. $\left.{ }^{79}\right)$. . Notu Gionmada (Bonotii), Venezuda. Gen. of diurn. Lep. tab. F. 2(18.6). - P. Columbus Kollar Beitrïge zur Insektfauna von Yeu-Gran. und Senez. p. 1. t. 1. f. $1,2(1849)$.

$$
\begin{gathered}
\text { Soetio XY. } \left.{ }^{80}\right) \text {. } \\
\text { subsectio } \left.\quad .{ }^{81}\right) \text {. }
\end{gathered}
$$

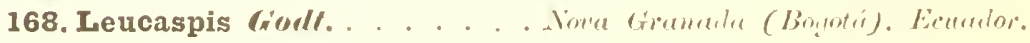

$$
\text { Subsectio } \left.13 .{ }^{2}\right) \text {. }
$$

†169. Lacandores IBut's.

Ginetemerles.

Proceed. of the Znol. Soc. 1 $\$ 6$ it.

170. Diosippus //en.

Sor'u Greenuder (Botutui).

Sertio XVII. ${ }^{x: 3}$ ).

† 171. Calliste Bufes. Ginatemale. Procerd. of the \%ool. Sice I8tit.

† 172. Marchandli Boist. . . . . . . . . . . Gilutemala. 173. Thyastes H'rry. Brotiel. unstral. 
Sectio (HIII. ${ }^{34}$ ).

174. Saloini Bules. . . . . . . . . . . Cruatemulu. l'roceed of the \%oul. Soc. 186i.

\section{Sectio IIX. ${ }^{45}$ ).}

$\mathrm{Subsectio} \mathrm{A}$. " $"$ ).

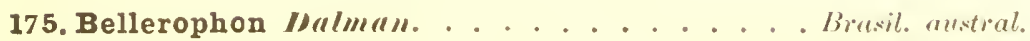

Subsectio B. ${ }^{97}$ ).

176. Agesilaus Boisd. . . . . . . Non Granada, Vencuuela. P. Conon Hew. Transact. of the ent. Soc. N. S. II.

177. Autosilaus Boissl. in litt. But. 'x). Ameznnice sup. (Eya), Mecivon Brusil. austr.?

P. Agesilaus Boisd. Sp. gén. p. 2633 ex pte? Gray. - P. Protesilaus L. apud. Esp. Ausl. Sclimett. t. 52. f. 1? - Bates Transact. of the ent. Soc. N. S. Y. p. 3is.

178. Protesilaus L. ${ }^{x y}$ ). . Surinum, Guiana, Cayenne, Amazonia, Ven-

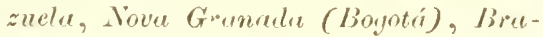
silia austial. (Bahia, Rio).

Merian Ins. Surinam. - Seba Thesanr. t. 36. - Sulzer Genera Ins. ed. Roemer t. 1i. f. : .

t var? a. Macrosilaus Boisd. in litt. . . . . . . Honduras. Gray Catal. p. 3 í.

179. Telesilaus Nobis. ${ }^{90}$ ). Amazonie, Nova Granada, Brasilia anstral. Princeps heroicus Protesilaus apudHübn. Samml. exot. Schmetr. - P. Protesilaus L. apud. Koll. Beitr. zur Ins. - Fauma. v. Neu Gran. u. Venez. p. 2. - P. Protesilaus L. var. Bates in litt.

180. Archesilaus Felder........ . Nova Grancula (Boyotii). Zool. d. Tovara Exp.

181. Penthesilaus Felller... . . . . . . . Meriro. Zool. d. Novara Exp.

Sectio XX. ${ }^{n 1}$ ).

182. Glycerion Gruy. . . . . . . Mrlia sept. (Nepal, Durjeclin!)

Sectio XXI. $\left.{ }^{92}\right)$.

Subsectio A. ${ }^{43}$ ).

†183. Alebion Gilly. . . . . . . . . . . China styto 
Subsectio B. $\left.{ }^{\prime \prime}\right)$.

184. Agetes Wes/u. . . . . India sert. (Silhet, Assum, Darjeelina).

Subsectio C. 95 ).

185. Antiphates (ram."16). . India sept. (Silhet, Bemyalia), Mulacea,

186. $\left\{\begin{array}{l}\text { Euphrateg Foldes. . . . . . . . . . . Luzon. } \\ \text { Wien. ent. Nonatschr. VI. p. 383. - Kool. d. Novara Exp. }\end{array}\right.$

187. Androcles Boisd. . . . . . . . . . . . . . Celebes.

†188. Dorcus Reimuarall in litt. Me Man!. . . . . . . Celebes.

$$
\text { Subsectio 1). }{ }^{97} \text { ). }
$$

189. Orestes F. . . . . . . . . . . . . . . . . - ?

var. ${ }^{9>}$ ). . . . . . . . . Indiu sept., (Cushmir, Darjerlin!).

†190. Anticrates IDoubldy. . . . . . . India sept. (Silhet, Durgetiny).

191. Aristaeus (rom. $\left.{ }^{99}\right)$. Amboine, Crom, liatjan. - Celebes (erdem?)

†192. Parmatus liray. . . . . . . . . . . Austreliat.

193. Pherecrates Felder. . . . . . . Nove Guineu (Dorey). Zool. d. Novara Exp.

194. Hermocrates feldler. . . . . . . . . . . Luzm 7ool. d. Novara Exp.

195. Rhesus Boisd. . . . . . . . . Celebes. - Benyalia?

\section{Sectio XXII. ${ }^{100}$ ).}

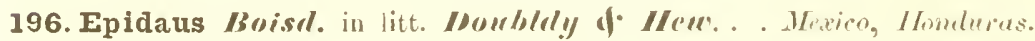
Tryon Reakirt in Proced. of the ent. Soc. of Philadelph. 1863. p. 136 .

$$
\text { Sectio XXIII. }{ }^{101} \text { ). }
$$

$$
\text { Subsectio } \Lambda \text {. 1"'). }
$$

197. Arcesilaus Lucus. . . . . . . . Venezuche (Caracas).

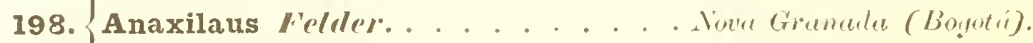
Zool. d. Novara Exp.

†199. Xanthicles IBufes. . . . . . . . . . . Guatemela. l'roceed. of the Zool. Soc. 186, i.

$$
\text { Subsectio 13. } \left.{ }^{10: 3}\right) \text {. }
$$

200. Sinon ('ramr. . S. Dominso, Culue, Jamnira. - America sept.

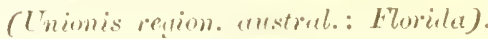
Lucas in Ramon de la Sagra llist. de Cuba t. Y'H. p. 197. 
Subsectio C. $\left.{ }^{111+}\right)$.

201. Philolaus Bnisd. . . . . Medirn, Viramume - Amerire sept. Menétriés, Enum. Corp. Anim. Mus. Petropol. Jep. 1. p. 1/0. t. 7. f. 1 .

Subsectio D. $\left.{ }^{105}\right)$.

202. Celadon Luens. . . . . . Culu, Jamairw. - Amerien sept.? Seba Thesaur. t. 37. f. 13, Ji. - L, ucas in Kauron de Ja Sagra Hist. de Cuba t. VHI. p. fis.

†203. Marcellinus Houbldly. . . . . . . . . . . Jumuiru.

Subsectio E. (10ti).

204. Marcellus Boisd. (P Lec. $\left.{ }^{117}\right)$. . Re'pinnes oecirl. et austr. Lnimis americanae (Ohio, Temmesee, Virinin. Curolina, Georgia, Florider).

Sulisectio F, ${ }^{\text {InY) }}$.

205. Telamonides Felder. . . . . America sept. (t'mio axs/rat.) Zool. d. Novara Exp. - aberr? P. Ajax 1. apul Palisot de Beaurais.

†var.? P. Ajax L. var. Dutrenx, Ent. Zeitung 18̈34. p. 142. ${ }^{109}$ ).

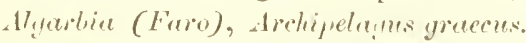
206. Ajax L. ${ }^{111}$ ). Regiones austral. Chionis amerieance (Florida, Georgia, Tirginir, Carolina). aberr. Marcellus Cran. (cf. Hoisd. Sp. gén. 1. 255.)

$$
\text { Sectio XXIY. }{ }^{111} \text { ). }
$$

207. Leosthenes $/ 10 u b / d y$. Australiee.

\section{Sectio XXY. 112)}

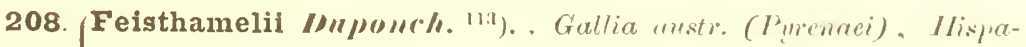
nia (Catrelomia, Ametelusin), Africa

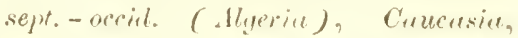
Asiat central., Atsin minor (Smyran, Ephesus).

P. Podalirius F. apud Cram. Uitl. Cap. I1. p. 8s. t. 1:i1. f. B. (cf. Koeh, leogr. Verbr. A. enrop. Schmett. in and. Weltheilon p. 33). - Lucas in Annal. de la Soce (nt) de France 18:30. P. 83. - Lovailla n t ibitem lsis. p. ini. L Ledered in Verh. 1. zoul. hot. Ver. zu Wien 1,:i2. p. 27. 
209. Podalirius. L. . Europa centr., austr. (Italia, Siritia) et nrient. (Russia austr:: Orenturu), Sibiri, (Altui), Kirgisia, Asia minor (Amasia, Brussa), Creta, Aes!nptus - Alaerin? - Imlia sept. (Mresuri) ${ }^{11}$ ).

Petiver Gazophyl. (Pap. Etruriae) t. 133. f. 2. - Seba Thesaur. t. 32. f. 11, 12.-Meigen, Syst. Bearb. d. Sclmett. v. Europa p. 1. t. 1. f. 1a. b. (aberr.) - Bla $\mathbf{n} c h a \mathbf{r}$, Hist. nat. des Ins. III. p. 421. - aberr. \& P. Podalirius var. Zancl a e us \% ell. - (ct. Le derer l. supra c. et K o c li l. c. p. 33.

\section{Sectio XXI. $\left.{ }^{113}\right)$.}

Subsectio $\left.A .{ }^{116}\right)$.

210. Policenes C'ram. Africa occil. (Guineaelit., Sien a Leme, Ashanti, Oreare, Caluliar). + var. Gray Catal. p. 32 Africe austi. (Zulu, Port Natul, Cufficeivit).

Boisd. in Delegorgue Voy. dans l' Ifr. austr. II. p. 386. - WalJengren, Kafferl. Dagtjär. p. 5 (in kongl. Vet. Ak. Handl. II.) - Trimen Rhop. Afr. austr. 1. p. 14.

Subsectio B. ${ }^{17}$ ).

211. Antheus ("ram. "1"). . Airica nec. (sierra Leone) - Mozambirger

(Inhamiane), Port Natal (eadem?) Trimen Rhop. Afr. austr. I. p. 13.

212. Evombar Buisul.

\section{sectio XXVII. 119).}

Subsectio A. $\left.{ }^{1211}\right)$.

213. Cloanthus W'es/ı). . Imlia spt. (Darjeeling. Assam, Cashmir). Kollar in H ïgel, Kaschmir u. das Reich der Sicklss IV. 2. p. 40;; t. II. F. 1, 2.

$$
\text { Subsectio B. }{ }^{121} \text { ). }
$$

214. (Sarpedon L. 122). . China atestr., India or. (Ilimalaya, Nepal,

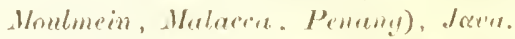
- Ins. Sandwich (redem?) Jetponice

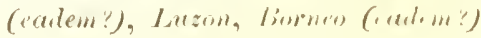

Seba Thes t. 37. F. 3, i. - Roesel Ins. Belustig. IV. 1. 1. f.' I. - Esper Au l. Schmett. t. \$. f. 2. - Hiibn. Simml. exot.

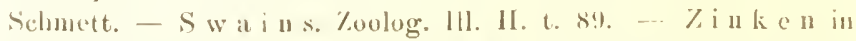
Verh. d. k. Leop. Carol. deutselı. Ikad. d. Naturfi. XYl. p. B̈̈t. - Jucas in Chenu lincel. d. Ilist. nat. Lep. pl. 20. t. 1. 


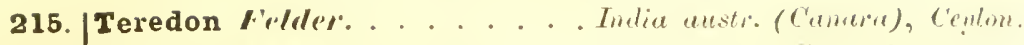
216. Moulo d. Novara Exp. - l'. Sarpedon L. var. a. (i rag l. c. p) 28

217. Anthedon Volis. ${ }^{12 / 2}$ ) Anturima. S e b a Thesaur. t. 37 . f. 3, 4. - P. S a rpe d o n 1. apud c'r a m. Uitl. Cap. - D e H a a $n$ in Verh. over de nat. ('resch. d. Nelerl. overz. Bez. Zool. HI. p. 3'́ ex pte.

218.

Choredon Boisal. in litt. 123). Australin, Noute Guinere, Ins. WhatP. Sarpedou ral. h. Fray Catal. p. 28. pl. 4. t. I.

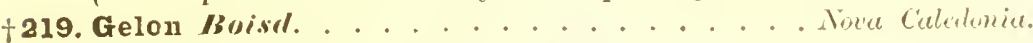
Bullet. de la Soc. ent. de France 1839. p. Cl V.

$$
\text { Siubsectio C. }{ }^{12.5} \text { ). }
$$

220. Evemon Boisd. Malucea, I'enan!, Hou'mein, Jace, Simmetra,

221. Telephus felder.

$$
\text { borneo.'- Ceylun? }
$$

Zool. d. Novara Exp.

†222. Doson Nolsis. " ??)

P. Jason L. apud Esp. Ausl. Achmett. t. "8s. f. "\%.

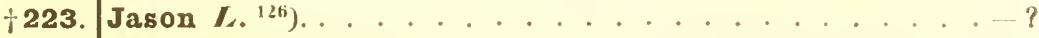

†224. Axion Nobis. 12^). . . . . . . Intia spet. (silhet). (hare?) Zetides Eurypylus L. apud Hïbn. Samml. exot. Schmett.

225.

Gordion fielder. . . . . . . . . . . Leizon.

Zool. d. Novara Exp.

P. Eurypylus L. apud. Boisd. Sp. gén. ex pte.

Pamphylus felder.

Celelies.

Zool. d. Novara Exp.

227. Eurypylus L. Amboint, Ceram, Ternate, Aru Ine, Noru Guinea. Cram. Uitl. Cap. - Esp. Ausl. Schmett. t. 33. f.'1.

228. Lycaon Buisd. in litt. Felder......... Ansticulia. Zool. d. Novara Exp. - P. Eurypylus var. a. Fray Cat. p. 2..

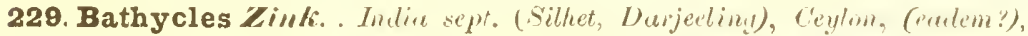
Java, Borneo, Mrlecere, P'encury.

Guér. in Belanger, Voy. dans l'Ind. or. \%ool. p. 30\%. lus. pl. ¿̈. f. 1,1 A.

$$
\text { Sulisectio I). }{ }^{129} \text { ). }
$$

†230. Wallacei / $/ \mathrm{er}$. - Nover Givinea. Exut. Buttfl. Vol. 1. g, 11. t. 2. f., 3.

231. Aegisthus (.. 1:41). Awlwinar Breljern. 
232. Plisthenes F'elded. . . . . . Amboina. - Jias. Wondlark Zool. d. Novara Exp. - P. A eg is tus apul 11 o nt to uzier i. Anal. de la Soc. d'Agric. de Lyon VIll. p. 400 .

233. Agamemnon L. ${ }^{131}$ ). . China austr., India sept. (Castemir, Nepal, Sillect, Bengal.) et austr. (Canara), Ceylm, Moulmein, Penand, Malarra, Sumatra. Java, Borneo, C'elebes, Latzom - Timor (eudem?)

Petiver Gazophyl. t. 78. f. 1. - Seba The aur. t. 3i. f. 1, 2. Sulzer rien. Ins. t. 13. f. 3. - Blanchard Hist. nat. des In.. III, p. 421.

Subsectio E. 1:3:).

†234. Arycles Boisd. . . . . . Sinumpre - India sept. (Nepal). 235. Rama feldler. . . . . . . . . . . . Mulucea int. Wien. ent. Monatschr. IV. p. 39' '. - Zool. d. Novara Exp.

Subsectio F. $\left.{ }^{133}\right)$.

236. (Codrus ('rmm. $\left.{ }^{134}\right)$. . . . . . Aminina, C'eram. Lucas in Chenu Encycl. d' Hist. nat. Lep. pl. 1. f. 2.

†237. Empedocles F. . . . . . . . . . . . . . Jav" - Bmerme? f238. Medon Nobis ${ }^{135}$ ). . . Nova Guince - Ins. Woollark (eadem?) P. Codrus var. De Haan in Verls, ov. de nat. Fescls, van Nederl. overz. Bez. Zool. III. p. 33. - Montrouzier in Anal. de la Soc, d'Agric. de Lyon VIII. p. 102?

289. Melanthus felder. . . . . . . . . Luzon. linrius. Wien. ent. Monatschr. VL p. 283. - Zool. d. Nurara Exp.

Sectio XXYIII. $\left.{ }^{336}\right)$.

240. Scottianus Felder............. Australia orient. Vertr. d. k. k. zool. hot. Ges. zu Wien. Xll. p. 4s?. - Zool. d. Novara Exp.

241. Macleayanus Lenell. . . . . . . . . Australir.

Sectio XXIX. ${ }^{13}$ ).

siubsectio $\left.\Lambda .{ }^{13 x}\right)$.

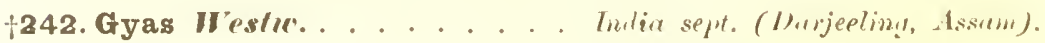

Subsectio B. (1:4).

†243. (Payeni Boisd. . . . . . . . . . . . . . . . . Jume.

244. Evan Joubldy..... . . . . India sept. (Darjeeling, silhet). jo Doubldy et II ew. Cen. of diurn. Lep. Atlas t. l'. 1. ? ibid. t. 2. f. 1. 


\section{Sertio IXX. ${ }^{140}$ ).}

245. (Pylades $\boldsymbol{F}$. . . . Africa oceident. (Sen yal, Sierra Leme). 246. Corinneus Berlol. 1'1) . Africa austral. orient. et orciel. (Tontren, An ola, Mosambique, Zulu, I'ort Nittal, Caffiraice)

P. angolensis etc. Petir. Grzophyl. t. 9. f. :. -.. Sebat Thesaur. t. 9. f. 19, 20; t. 12, f. 31,32 - P. Morania Angas il litt. - P. Pyiades var. Trimen. Rhop. Afr. aust. I. p. 2y. - P. Anthomenes Wallengr. Kafferl. Dagfj. p. 6 (Kongl. Vet. Ak. Handl. Il, nr. i.).

†247. Endochus Boisal. . Medelycerear.

\section{Sectio XIXI. 14:2).}

Subsectio A. 1's3).

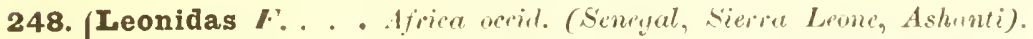
P. similis L. apud Cram. Uitl. Cap.

249. Brasidas Nobis. 14t). . Aficicr alestr. (Zulu, I'ort Nutal). P. Leonidas var. Fray Cat. t. 5. f. 3. - Trimen Rhop. Afr. austr. 1.2. $I$.

Subsectio B. 1'is).

†250. Ridleyanus Hhile............... Conyo.

Sectio XXXII. 1'ti).

† 251. Antimachus Irury. . . . . . . . . . . Sicrel Leore.

Sectio XXXIII. ${ }^{14 i}$ ).

252. Ideoides Gray. . . . . . . . . . . . . . Lunem. Hew. Exot. Buttil. Vol. 1. gen. t. 1. f. '2.

$$
\text { Sectio XXXIY. 14x, }
$$

253. Encelades Buist. . . . . . . . . . . . . Cileter.

II e W. Exot, Buttil. Vol II. gen. 1. i. f. 10.

Sirctio XIIT. 1'49).

†254. Cyrnus Buistl. . . . . . . . . . . . Mfudeyorsorer.

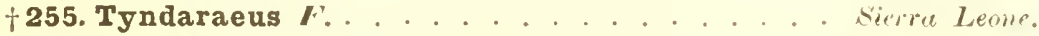
256. Latreilleanus fiodll. . . . . . . . . . Siemu Lronn. †257. Agamedes IIs/U... . . . . . . . . Ahanti, Fort Aere. P. Adamastor var. a. apud Gra! 


\section{Sectio XXXY. 1,00).}

259. Delessertil linel. . . . . . . . . . . . . . Penang.

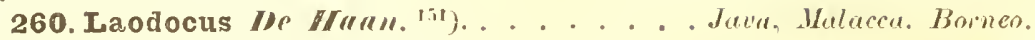
261. Deucalion Buisil. . . . . . . . . . . . Celebes. Hew. Exotic. Buttfl. Vol. II. gen. t. 5. f. I1.

262. Macareus Gorll. . Jard, Borneo, India sept. (Asisam, Sithet, Darjeelinu).

263. Stratocles Frlifr. . . . . . . . . . Mmloro.

Wien. ent. Monatsclsi. V. P. 298.

264. Xenocles Domb/dy. 152). . . . . India sept. (Silluet, l,arjeclin!). †265. Leucothoë Westll. . . . . . . . Indiu sept. - Singripore? †266. Megarus Heslu......... Indic sept. (Assem, Silhet).

Sectio IXXYII. $\left.{ }^{153}\right)$.

267. (Dissimilis L. 1.it). Chino austr, Indiu sept. (Nepal, Silhet, Assam, Bengulies) et austr. (Mulubar), C'eylon. - Austrolia? Sulzer Gescli. d. Ius. t. 18. f. 6. - Lucas in Cluenu Encycl. d llist. mat. t. 13, f. 2 .

+268 .

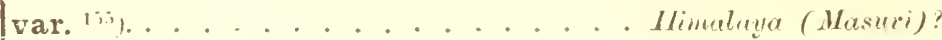
Echidna /Ne f/um! in litt. . . . . . . . . . Timor. P. dissimilis var. De Haan in Verh. over de nat. fiesch. ran Nederl. over\%. Bez. t. 8. t. 6 .

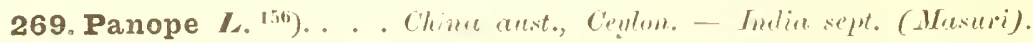
aberr.? Clytia L.

270. Palephates U'es/le. $\left.{ }^{1 i i}\right)$. . . . . . . . . . . . Lllzmu. † 271. Lacedaemon $\%$. . . . . . . . . . . . . . Malalur

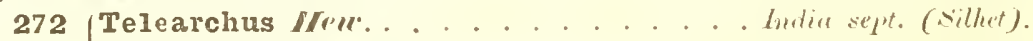

†273. Telesicles Vobis. 1.i. . . . . . . . . . Bomeo. P. paradoxa var. Hew. in troc. of the zool. Soc. 18.59. t. $6 \%$. f. 1. $\mid j \geq \mathbf{s}, 3,49$ aberr.

274. I Paradoxus Zillk. . . . . . . . . . . . . Jou'te.

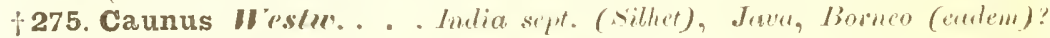

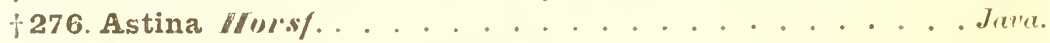
†277. Slateri Kasisal. in litt. Klew. . . . . . . . . . . Burneo. Exot. liuttll. Vol. Il, gen. t. 4. f. 9.

\section{Sectio XXXVIII. $\left.{ }^{154}\right)$.}

278. Agestor (ivol. . . . Indin sept. (Niprel, Musuri). - Sumetrut Koll. in $11 \mathrm{lig}$ el, Kaschmir ete. IV. 2, t. 3. f. 1, 2.

†279. Epycides Her................ Intlu seft. Exot. Buttl. Vol. Ill gen. 1. 6 f. li. 
Sectio XXXIX. 16it).

Subsectio A. $\left.{ }^{1+1}\right)$.

280. Demoleus L. Africa occid. (Sinegul, Guiner, Sierra Leone, Ashanti) et orient. (Aeryptus, Nubia, Alryssinia. Mozambique. I'ort Natal (Caffraria), Promont. bonar spei. Mulaylasear. India sept.? 16:).

Seba Thesaur. t. 4f. f. 6, 7. - lucas in Clienu Encycl. d'Hist. nat. Lep. t. s. f. 1 .

Subsectio B. ${ }^{(63)}$ ).

281. Erithonius Cram. . . . . . Clina anstr.. Indie or., Ceylon. Seba Thesaur. t. 4i. f. 8, 9, t. 37. f. 17, 18. - Kleemann Beitr. zur Ins.-Gesch, t. 1. f. ^, 3.

282. Sthenelus Mlnc Lelly. . Austrective.

\section{Sectio XI. ${ }^{16^{\prime}}$ ).}

†283. Zetes Hestw. . . . . . . . . . . . . S. Domingo.

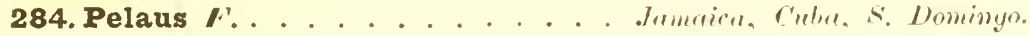
Herrich-S chäff. in Correspbl. d. zool. min. Ver.zu Regensb. XVl.p. 141. 285. Oxynius \|iulbn. . . . . . . . . . . . Cubu. Lucas in Ram. le la sigara llist. de Cuba. t. VII. 1. 183.

286. Caiguanabus Poeg. . . . . . . . . . . . Culaa. Lucas l. c. p. 465 . - P. Numicus Hopfi. Neue Schmett. des k. zool. Mus. zu Berlin. II. p. 1. t. 1. f. 3, 4. - Hew. Exot. Butttl. Vol. III. gen. t. 6 f. 17.

\section{Sectio Xh, 16i5).}

287. Andraemon H/ïln........ Cuba, Merico, Ilomiuras. L. ucas 1. c. p. i.iti.

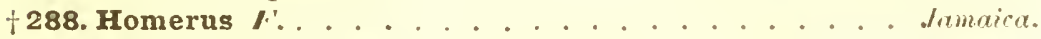
289. Machaonides Esp. . . . . . . . Cuba, s. Dominto. Lucas 1. c. p. i82.

Sectio Xlll, ${ }^{16 r i \mathrm{j}}$.

290. Daphnis Murly". . . . . Culue. S. Dominym - Amer. sept.? P. Aristodemus Esp. - Lucas in De la Sagra op. c. p. 483. pl. 14. f. 2, 2, a.

291. (Paeon Hoy. in litt. Borsol. ${ }^{167}$ ). . . . . . . . . Perel - Chile? Blanchard in Giay llist. lis. y polit. de Chile. \%ol. Tomo VIl. p. s. 292. Thrason Frlder..... Nina Grameda (Bo!ntii), Vénezmela. \%ool. d. Nusara Exp. - P. Paeon apud Doubldy, Gray et snell. v. Vollenl. Tijdschr, voor Ent. III.? 
†293. Ornythion Rog. in litt., Boisal. . . . . . . . . Yuratm.

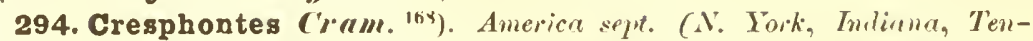
nesee, Georyia, Floridu, Carolina), (ulia, Jamaica, Mexiro, Honduras, Vonezuela, No'rt Granada (Boyotí), Brasil. austral.

Heraclides Thoas Hï lın. Samml. exot. Sclımett. - Ménétriés Enum.

Corp. Anim. Musei Petropol Lep. I. p. 111 (furma septentrionali-americana). - P. Thuas L. apud Lucas in De la Sagra Hi.t. de Cuba VII. p. 482.

295. Thoas L. $\left.{ }^{16 \%}\right)$. Surinam, Amazonir inf., Puré. - Brasilia, Tenezrela, Mexico, Iucatan, Nicaragua?

Seba Thesaur. t. 38. f. 6, 7. - Drury I. t. 22. - Princeps heroicus Thoas Hïbn Samml. exot. Sclumett.

296. Cinyras Mémelr. ${ }^{171)}$. Brasilia wust. (Bahi"), Amazonia sup. (Ega) et inf. (Villa Nova).

Enum. Corp. Anin. Mus. Petropol. Lep. I. p. 111. t. 7. f. 3. - (cf. Bates in Transact. of the (nt. Soc. N. S. Vol. V. p. 3\$7).

\section{Sectio Xlill. 1il).}

subsectio A. ${ }^{172}$ ).

297. (Torquatus C'rmm...... Surinem, Amazonia inf., I'ari. Selsa Thesaur. t. 7. f. 21, 22. - 9 P. Caudius Hübn. - (cf. Bates Transact. of the ent. Soc. N. S. Vol. V. p. 3ti).

298. Patros (iray. ${ }^{173}$ ) . . . . . . . Amazmia sllp. (Ega). 299. Polybius Nuruins. ${ }^{174}$ ). . . . . . . Brasil. austral. O P. Torquatus Cram. apud șains. \%onl. Illustr. I. pl. 94. I.ucas in Chenu Encyel. d'llist. nat. Lep. pl. (6. f. 1 .

†300. Orchamus Boissl. . . . . . . . . . . . . l'nezuela. $†$ 301. Peleides Esp. . . . . . . . . . . . . . . . . . . . . . . - ?

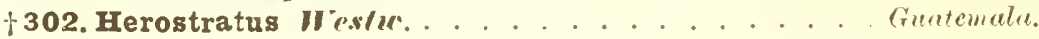
Subsectio B. $\left.{ }^{13.5}\right)$.

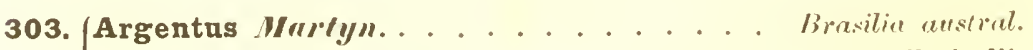
ơ P. Torquatinus Esp. - P. Pandrosus Swains. Zool. Ill. 1. pl. 93.

†304. Mezentius Doubldly..... Litus orcid. Am. austrel. (ubi?)

Sectio XIV. 1iti).

Subsectio $\left.A .{ }^{177}\right)$.

305. Mentor Buisal. Brasilia arstrul. 
306. (Lycophron M̈̈ln. . Brasilin austral., Andsonia inf., Unumey. Q Felder in Zool. d. Norara Exp. - P. Pyrithous apud fray Cital.

Pyrithous Royer. in litt. Buisd. . . . . . . . . . . Culod.

S P. Lycophron Häbn. apud Lucas in De la Sagra Hist. de Cuha. VIl. p. Ál. - O P. Pyrithous lioisd. - Lucas l. c. p \{s'f. pl. 16. f. 1, 1 a. - P. Lycophron Auctorum ex pte.

308. Theophron Felder......... Nova Granada (Boyotí). Zool. d. Novara Exp. - P. Polycaon var. apud Sinell. van Vollen h. in Tijdschr. voor Ent. HII. p. 86 ?

309. Hippomedon Fvlder............ Tenezueld. Wien. ent. Monatschr. 111. p. 393.

†10. Acamas F. . . . . . . . . . C Cuba, Jumaica. o P. Thersites F. - Lucas in De la Sagra op. cit. p. 481.

311. Oebalus Karord. in litt. Buissl. . . . . . . . . Mexico. Subsectio B. Iir).

312. Androgeus ('rum. Surinum, Guiana, Cayeme, Amaznia, Venezuela, Nov'a Gianada (Boyo'í), Brasilia austral.. Cuba, S. Dominyo, Merico, Honduris, Guatemalu.

o' Seba Thesaur. t. 39. f. 2, 3. - Merian Lus. Surin. t. 31. f. inf. - Kleemann Beitr. zur [ns. Gesch. t. i. f. 1, 2.

P. lolycaon Cram. - Sepp Surin. Vlind. III. t. 137. - var. b. Gray Catal p. 36.

S P. A udrogeus Cram.

altera forma: Piranthus Cram....... in mmilus locis? Seba The aur. t. 38. f. 13, 14. - Kleemann Beitr. t.8. f. 1. 2. Merian lns. Surin. t. 31. f. sup. - aberr.? P. Pirantlsus \& apud Esp. Ausl. Sclımett. t. 20 f. 2.

\section{sectio XW. 17!).}

313. (Anchisiades E'sp. Surinam, Coneme, Amarmia inf. et sup, (Eya).

Merian Ins. Suin. t. 17. - Bates in Transact of the ent. Soc. N. S. Vol. V. p. 338 . - var. a. ऊ゙ ibid.

314. Theramenes felder.. Venezuela, Novu Granula (Boyotii). Amazmia smp. (Eya.) (eadem?)

\& Wiell. ellt. Monatschr. V. p. Tí - o \& Zool. d. Novara Exp. - P. Anchisiades var. b. Bates l. c.?

Pandion Boisd. in litt. Felder. . . . Mexico, Honduras. P. A nchisiades var. a et P. Idaeus rar. a ex pte. Gray. Cat. l. 6.3 ? 
320. Isidorus Domb/dy. 150). Bolivia, Nove Granada (Boyoti), Amazonia sup. (Eile).

P. Anclisiades rar. c. Bates Transact. of the int. Soc. N. S. Vol. V. p. 338. - var. a. Gray Catal. p. 64 .

321. Pharnaces Houb/dly........... Mexico, Guatemala.

\section{Sectio XLY. ${ }^{181}$ ).}

322. Zagreus IDoubldy. Venezu lu, Nova Grunade (Bogotí), Amernmia sup. (Eini).

323. Ascollus frolder. . Ecuador (Quitn), Nora Gronada (Boyotii). Zool. d. Novara Exp. - P. Zagreus var. a. Gray Catal. p. \&.

324. Bachus Felder........... Nova Granada (Boprói). Zuol. d. Novara Exp.

\section{Sectio YLYII. ${ }^{182}$ ).}

Subsectio $A .{ }^{1 \times 3}$ ).

+ 325. Coristheus Boisd.

326. (Coroebus f'elder. Surinem. \& Wien. ent. Monatschr. V. p. T.j. - Zool. d. Novara Exp.

Birchalii Mere.......... Nova Granader (Boyotii). Transact. of the ent. Soc. N. S. Vol. VI. p. $\$ 17$.

328. Eurotas felder. . . . . . . . . . . Rio Neyro. Wien. ent. Monatschr. VI. p. 66. - Zool. d. Novara Exp.

+329. Bitias Givdl.

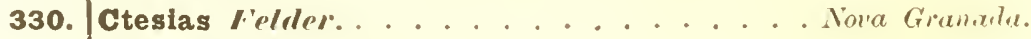
Zool. d. Novara Exp.

† 331. Lenaeus looubldy. Bolivier. P. Cleotas Gray $\$$ apud Gray Catal. p. 33 .

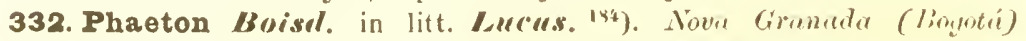
Tenezuela (biumo). - Borsilia in- 
Voy. de Castelna a dins l'Amér. du Sud. Ent. p. 197. Lep. t. 1? f. 1. - P. Cleotas fray val'. Koll. Beitr. zur Ins.-Faumar. Veu Fran. u. Venez. p.

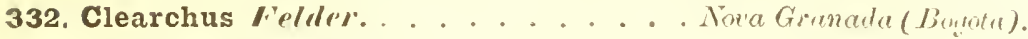
Zool. d. Novara Exp.

333. Philocleon Felder............ Coluwlic (ubi.) Zool. d. Nuvara Exp.

334. Oleotas (irry. . . . . . . . . Brasil. anstial., Lrnyuay. 335. Lycortas Felder. Tenezela (Caraces), thio Neno (Hurebiana.s). Wien. ent. Monatsedr. V. p. T3̈. - Zool. d. Novara Exp.

336. Helle il fiplder................ Heacien. Zool. d. Nuyara Exp.

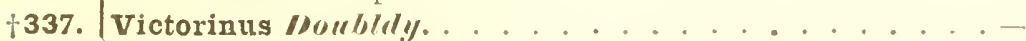

Subsectio B. 15ij.

338. Grayi Boist. . . . . . . . . . . . Brosilie "tustral. Lucas in Chen u Encycl. d"Hist. nat. Lep. pl. 1:3. 1". 2.

†339. Scamander Lacord. in Jitt. Boisd. . . . . . Brasilin intrime. Lucas op. supra c. f. 1. - Isd. in Castelnau 1. c. Lerp. pl. 1. I. . siubsectio C. $\left.{ }^{13 i}\right)$.

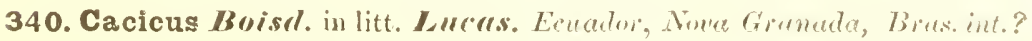
Lucas in Castel na voy. dans l" Amér. du Suฯ. Lep. pl. 1. l. 3.

Sectio XWVIII. 18i).

¡341. Electryon II Ites.

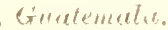
l'roceed. of the zool. Sioc. Is6't.

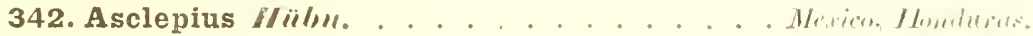
†343. Abderus //o///2/. . . . . . . . . . . Hedien Teue schmett. des k. zool. Mus. zu Berlin. Il. p. 1. t. 1. 1. 3, 4. \$34. Garamaz $/ \ddot{\prime} /)$.

Sectio NuIX. $\left.{ }^{188}\right)$.

Subsectio $A .{ }^{199}$.

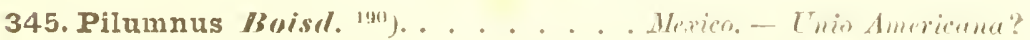

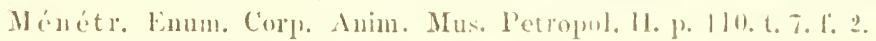

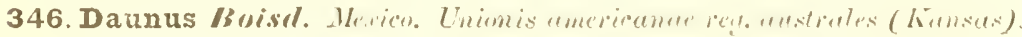

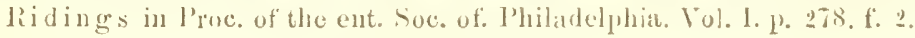

$$
\text { in bsectio B. }{ }^{111} \text { ). }
$$

†47. Antinous /Non. 1!n). . . . . . . Alestralia (... s. Winles). 348. Eurimodon Boissl. . . . . . . . . . . . . . Calijurnia. 1. Rutulus lioisd. rar. Gray Catal. p. 2í. 
349. Albanus Felder.

Crelifornice. Zool. d. Novara Exp.

350. Rutulus Bois(l. ${ }^{193}$ ).

351. Turnus L. Americe sept. (Cameda, Hledsoms Bay, X. Enulami), Enis amoricuna (N. Tork, Delumbire,

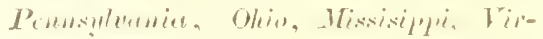

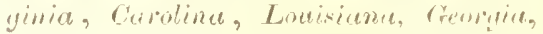
Florida), Jurutuica.

o) Say Americ. Ent. [ll. pl. 40. - Ilarris Treatise on the Ins. of Massachusets ete. ed. Flint p. 268 . f. 97.

f lorma altera: Glaucus L. ${ }^{1+4}$ ). Unionis americ. retromes austral. (ohio, Missisimpi, Gentia, Wiminia, lamisineru, Cusolina, Flovitu), -

Sameica.

Sectio L. 19i).

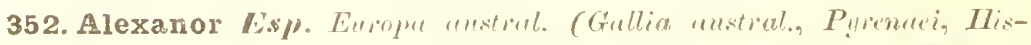

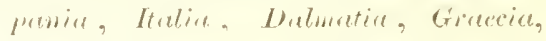

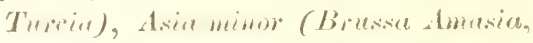
Marvi), I'sisice anstral.

Hiallhard, Hist. nat. des Ins. Ilt. p. 421. - Meigen System. Bearb. der Schmett. Europ. p. 3. t. 129. 1, 1.

sectio I.I. 19ti!.

Subsectio $\left.1 .{ }^{1 ! 7}\right)$.

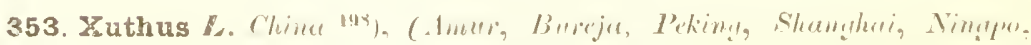

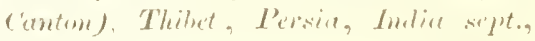
Irepinier.

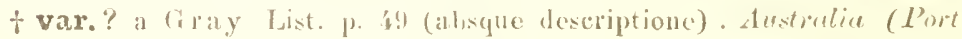
Eisinutom).

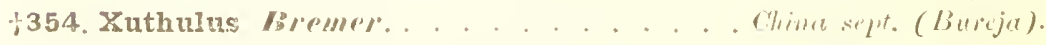
Bullet. de l'Acad. de's sc. de St. Petrisbourg. 111. p. 463.

Subsectio B. 1949).

355. Hospiton Gisme. . . . . . . . . Surdiner, Cursicer.

$$
\text { Subicedio C. } \left.{ }^{2011}\right) \text {. }
$$

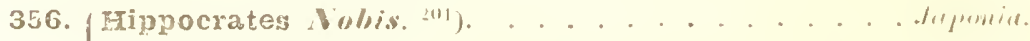

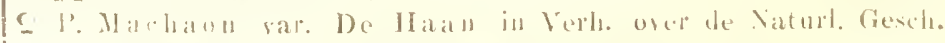
itul Nede.l. overe. 13e\%. p. i2. t. :., t. 2.

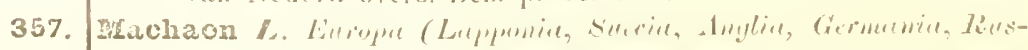

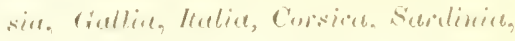

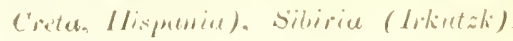




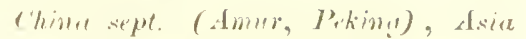

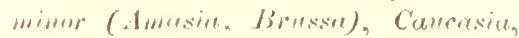

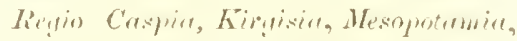

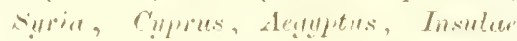

Camarires.

l'. major caudata etc. Petiv. Gazophyl. (P'. Britanniae icons t. I1. t. ̈.) - Sebal Thuaur, t. 31. t. 9, 10. t. :i9. t.. 1:, 1:3. - Meigull syst. Bearb. d. S.hmett. Europ. p. 2. t. 1. f., 2, 3 (aberr.1. - Mlanchard Hist. nat. des Ins. P. 2.21. - IV allengren Skindinav. Dagrfjür. p. 173.

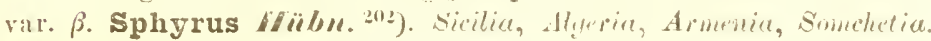
Mann in Wien. ent. Monatschr. p. 86. - Bellier in Annal. de la sic. ent. de Frince. IX. p. 67ź.

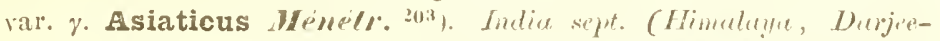
line, Biostan, Nepal, simele, Dherm,

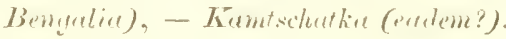

Enum. Corp. Anim. Mus. l'etropol. 1. p. 70.

P. Machaon var. Kollar in II ïgel's Kaschmir IV. 2. p. 40't.(iray List. p. ¿̈0.

358. Zelicaon Buisd. 2014)... . Crelifomia - Labrudor (erudem?) -Misisuri?

$$
\text { Subsectio D } 205 \text { ). }
$$

359. Americus Kallar. Nota Girmedu (biofota), Temezuda, Eiruder P. Sadalus Lncas. Giray.

$$
\text { (cirito), Hetico? }
$$
†360. Aristor fiorll.

Subsectio E. ${ }^{206}$ ).

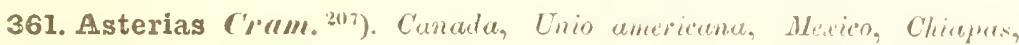
C'uluce, s. Heminifo.

1'. Carolinianus eotc. Petiv. Gazophyl. t. 6. f. 1, 2 (mutilata). Lucas in De la Sagra Hist. de Cubit. P. Áno. - Ilaris

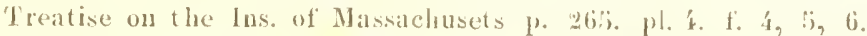
- forma $\beta$. Buind. Sp. gén. 1. p. 333. 1'. Truilus o apud Cram. Uitl. Cap. t. 207. f. A. - aberr? ampliata llévétr. Enum. Corp. Anim. Mus. P’etropol. I. p. 9!.

\section{Sirctio LII. 2or $)$.}

S u b s cet i o A. $\left.{ }^{209}\right)$.

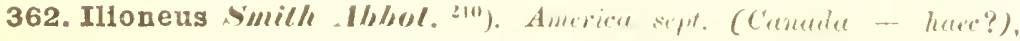

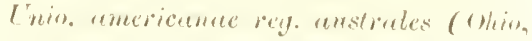
lireniniu, Curolina, Gerrigite, Lourisi- 
1'. Troilus L. apul Boisd. et Lee. Lan. des Lep. d'Am. sept. pl. 10. - Euphoeades Troilus L. apud II iibn. Samml. exot. Sclimetterlinge.

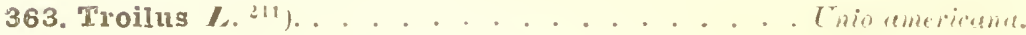
Cram. Uitl. Cap. t. 26) \%. f. B. C.

Subsectio B. "12).

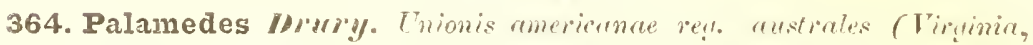
Gempia, Cromlina, Florida), Cubre. Seba Thesaur. t. 43. f. 3,6. - Lucas in De la Sagra Hist. de Cuba. VIl. p. itis.

\section{Sectio LIII. ${ }^{213}$ ).}

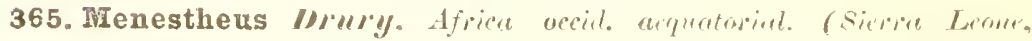
A.stenti).

$$
\text { Sectio LIV. } 214 \text { ). }
$$

Stubsectio A. ${ }^{215}$.

†366. Bromius /Dohldly. . . . . . . . . . . . Astenti.

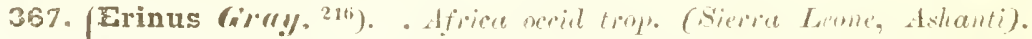
Seba Thesamr. t. 4. f. (il, 22. - P. Nireus apud ])rury, Cram. ete.

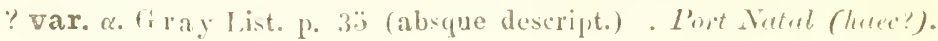
368.

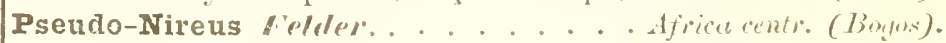
Zool. d. Novara Exp.

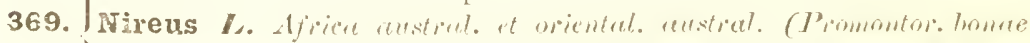

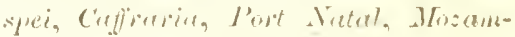

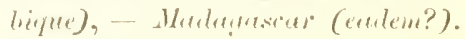
5 Sieba Thesaur. t. 9. f. 21, 22. - I'. Lyaeus Doubldy apud Wallengren, Kaflerl. Dagfjair. p. 6. (Kungl. Vet. Nk. 11 andl. III. nr. 4.) - jo l'. Nireus I. Trimen Rhopal. Ifr. allstr. p. H:

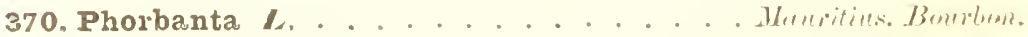

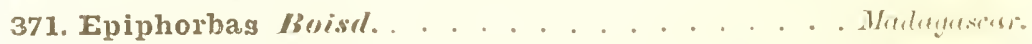

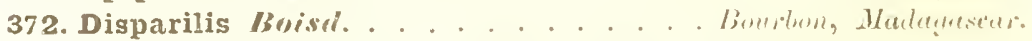
Lucas in Chenu Encycl. dllint. nat. Lep. pl. "̈. f:. 2.

$$
\text { Subsectio } 13 .{ }^{217} \text { ). }
$$

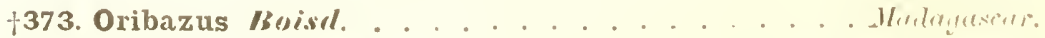

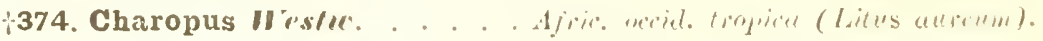




$$
\begin{aligned}
& \text { Sertio W. } 21 x \text { ). } \\
& \text { Subsectio } A . " \text { "). }
\end{aligned}
$$

375. Phoreas ('rum.......... Africe nerit. (Gieva teme). l'. Dorcus F. Lucas in Chenu. Encyel. d'Ilist. nit. pl. Hll. f. 1.

†376. Thersander I. . . . . . . . . Africu ocid. (Sicrat Lime).

377. Lalandei (iorlt. . . . Africa austral. (Cuffraria, Port Nutul). lucas iu Clienu Encycl. d'Ilist. nat. Lep. pl. 7. f. 2.

siubsectio B. ${ }^{231}$ ).

†378. Hesperus W'estu......... Africa ocrid. (Siema Leone).

Subsectio (. 2:1).

379. Meriones Felder. . . . . . . . . . Marlagacar. Zool. d. Norara Exp. - P. Brutus F. var. B. apud Buisd.

380. Merope ('rum. Africu secil. (Senegal, Sieva Lemo)? Africu

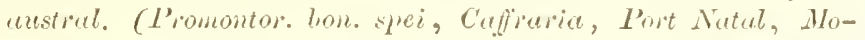
zetmloique $)$.

Trimen Rlıpal. Afr. austr. I. p. 11. - P. Brutus F. apud Wallengreu, Katlerl. Dagfj. p. 1. - Lu cas in Chenu Encycl. d'Ilist. nat. pl. 2 f. 1.

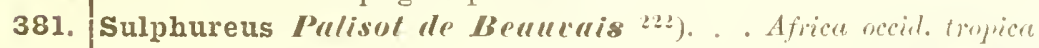
(Grineu.)

\section{Sectio WI. 223).}

382. Zenobia I'. . Ifirica occil. (Sierra Leone, Astunti) et austral. interior.

Lucas in Chenu Encycl. d' IIist. nat. I.ep. pl. 2 f. 2.

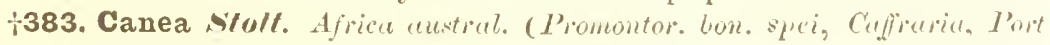
Nie(ul). o' $\&$ Trimen Rhopal. Afr. austr. I. p. 20.

$$
\text { Sictio LVII. }{ }^{2: 4} \text { ). }
$$$$
\text { s ubsectio } A \text {. 22ir). }
$$

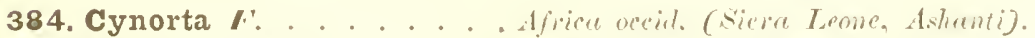

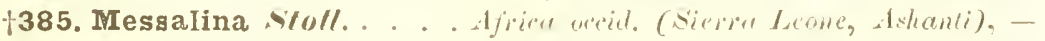
Cafiowria!

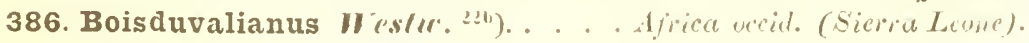




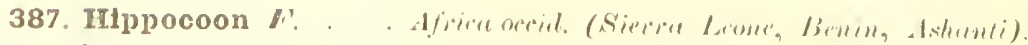

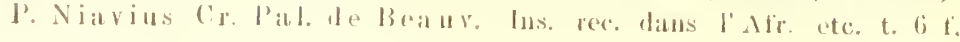
$1 \mathrm{id}, \mathrm{b}$.

388. Dionysos llomblly.

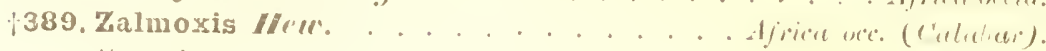

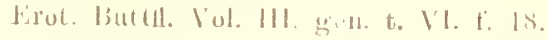

\section{Sieclio LIIII. 2?: $)$.}

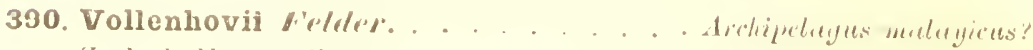
Zool. 1. Novara lixp.

\section{sertio hIX. 22!").}

subsection. $2: a 0)$.

391. Gigon tisuly in titt. Frelor, Glelues. Koul. d. Noriara lixp. g'in. 1. p. 2.21?

I'. Cresploutes f'. var. apud boist. spe. Subsectio B. 231).

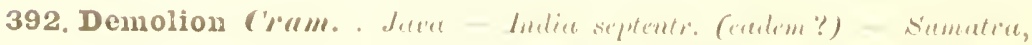

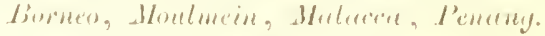
Celedes? - Centon (Tivineomali).

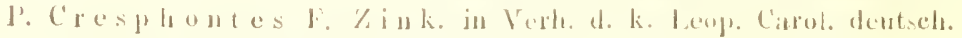

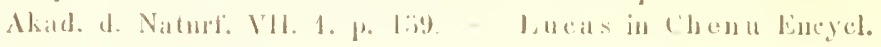
HHist. nat. Lep. pl. 1. i. 1.

\section{Seclio LX. ${ }^{232}$ ). \\ Subsection $\left.1 .{ }^{2 i 3}\right)$.}

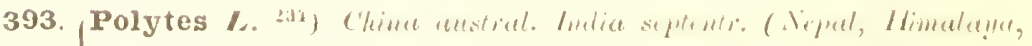

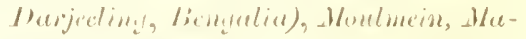
laser, l'enare!, - lus. Sundrich (eculcm?)

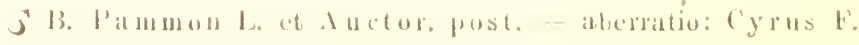

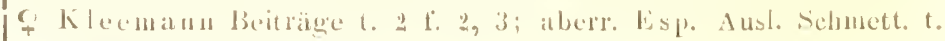
ill 13. I. I.

F altera forma: Polytes l. Mus. Lud. Uh. et Auctor. poster.

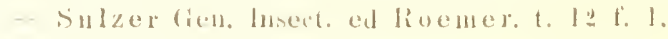

aberatio: Stivhius 11 ii bus.

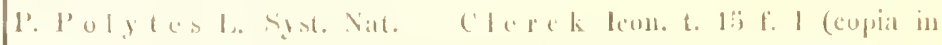

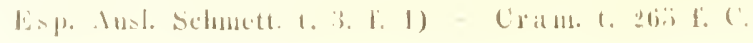


P. Alphenor. Cr. apud. Henétr. Finm. Cop. Anim Mus. I'etropol. J.e.1. I.

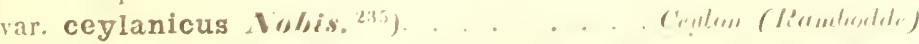

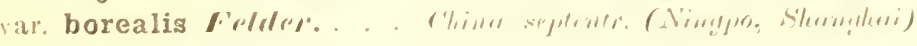

j. Wien. (ant. Minats hr. VI. p. 2.

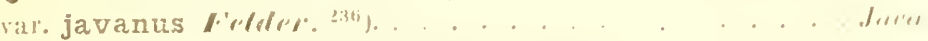

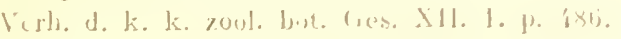

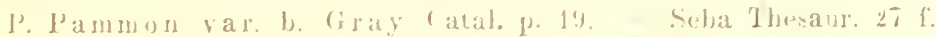
$21,22 . t$. is 1', 11, 12237),

1'. Ledebourus Esch. apud Zink. In Virh. der k. Jeop. Carol. deuterh. Alsad. d. Naturf. VIl. 1. p. Jín.

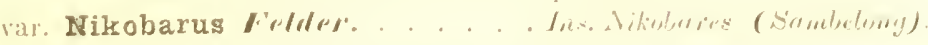

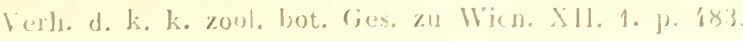

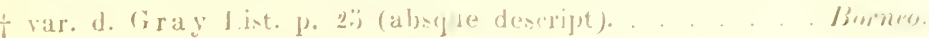

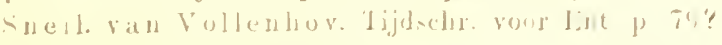

tal. timorenais lobis. . . . . . . Timet,

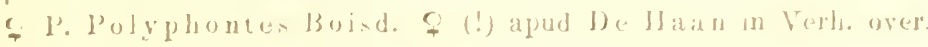

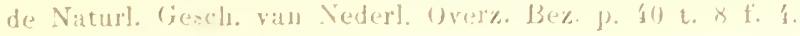

z' Suell. van Vollenhor. J. c.

val. Numa Holore.

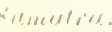

s Snell. van Voll, nhovel. e.?

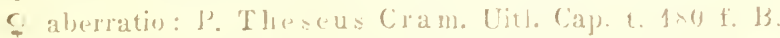

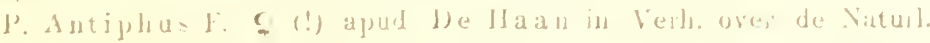

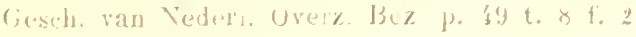

394.

Ledebouria I:sc/4. ${ }^{23}$ )

l."isul.

G felder in Zool. d. Tivaria Lixp.

395.

Alphenor ('rull, $\left.{ }^{234}\right)$. . . . .

Tirurle

396.

jo le der in Zuol. d. Virapa J.xp.

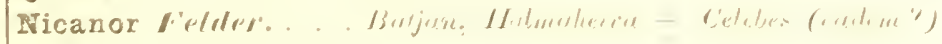

3 C Koul. d. Vordia Lixp.

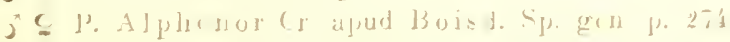

397. Melanides /J" //uUn.

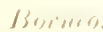

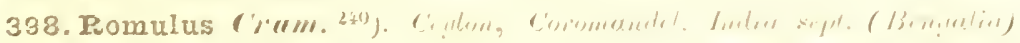

399. Sakontala M"r".

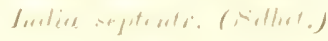

400. Canopus "Irs/r.

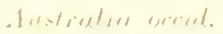

401. Hipponous Frll',

1. $4 \therefore \div 11$

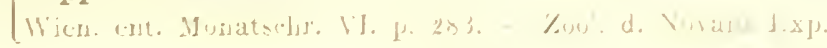

$\checkmark u b,(+\cdots, i, 1\} .2+1)$.

402. Capaneus "ris/".

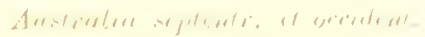

403. severus ('/lll. .

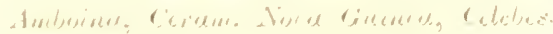

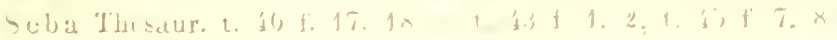

(aberabuses.) 
404. Helenus L. China metral, - India septentr. (Ilimalinga, Nepal, Darjelinely), Ceylon, Jalet. ZZink. in Verb. d. k. Leop. Carol. deutsch. Nkad. d. Naturf. VIl. 1.

405. Hystaspes releler . . . . . . . . . . . Lusm. Wien, ent. Nonatsch. V1. p. 2x:3. - Zool. d. Norara Exp.

406. Sataspes Feldel. . . . . . . . . . . . Celedes. Zuol. d. Novara Exp.

407. Araspes Feldel. . . . . . . . . . . . . . . . Luzono. Wien. ent. Monatschr. 111. p. 321. - Zool. d. Novara Exp.

408. Iswara While. . . . . . . . . . . . . Penchy, Malacert. 409. Prexaspes felder. . . . . . . . . . . . Mulacu. Zool. d. Norara Exp.

410. Chaon W'estu. "2t). . Indir septentr. (Assum, Durjetin!, Silhet), Mrelecere, Borno.

† 411. Nephelus Boisal. . . . . . . . . Celches - Molluectere?

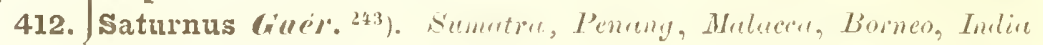

P. Nephelus var. De lla an. septento. (Assum).

\section{Subsectio (.. 242).}

413. Castor Wes/l. . . . . . . Indiu septentr. (silhet, Jarjeetimi.) O P. Pollux Westw. - Hytril.: Semper in W'ien. tent. Nonatschrift. VIl. p. 2खI t. 19.

†414. Phestus Gillir.. . Non'r Guiners.

$$
\text { Subsection. D.tis). }
$$

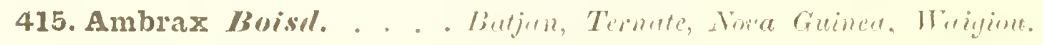
OP. Or"phanes boisd. Sp. gén. p. 2ti.

aberratio C. Blanchard in Voy. an pol sud t. 1 f. 3.

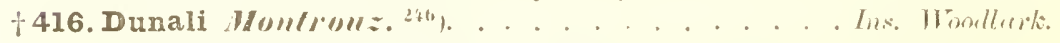
Ann. des sc. phys. de la Soc. d"Agricult. de Lyon Vhll. p. 390.

$$
\text { silusectio k. 2kit). }
$$

417. Gambrisius C'rolm. . . . . . . . Ambine, Cerem. s'seba Thesaur. t. 8 f. 7 s. - P'. Amphytrion li. Jablisot de Beauvais hos. rece dans l" Ifr. ete. t. 2 c f. I a, b.

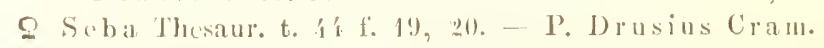

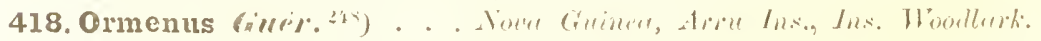

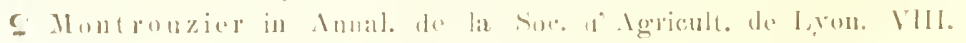

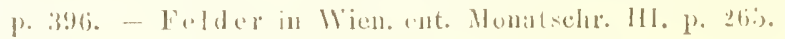

O forma altera: Amanga Boist. (an virr?

I'. Unenimus II ew. Fxotic. Butterll. Iol. H. gen. t. 3 l. 6.

1'. Godartia \& Hantrouzier l. e. p. 3!!!?. 
419. Amphytrion Cram.......... Amboina - Celeles? C Seba Thesaur. t. 8 f. 7,8 ?

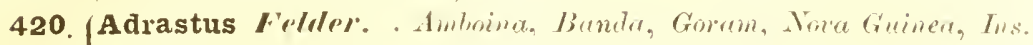
Airn.

o' O Zool. d. Nurara Exp. - P. Erechtheus Don. apud Boisd. Sp gén. p. 21:j ex pte.

S P. Gambrivius var. Aegeus Don. apud De Haan in Verh. over de bat. Cieseh. van Nederl. overz. Bez. p. 31.

P. Gambrisius rar. Erechtheus I)on. alud thell. ran linllenhor. in Trijdschr. roor Ent. III. p. Ti.

5 I. Ormenus Guér. apud Blanehard in Voy. au pol and It. p. 377. Lep. t. I f'. 1, 2. (Erechtheus var.)

421.

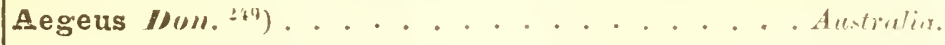

j l'. Erechthens Don. - Lucas in Chenu Encycl. d' Hist. Hat. Lep. pl. \& t. 2 .

aberr. a. Grily Cital. p. 2.2.

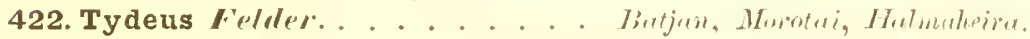

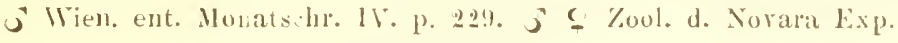

Subsectio F. 2:ib).

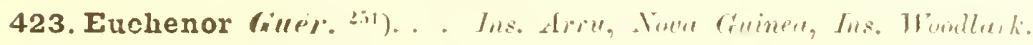
1'. ciodartii o Montrourier in Anma!. de lasoc. d'Agrice de Lyun. VIII. 1. 398.

$$
\text { Subrectio G. } 2.2) \text {. }
$$

424. Amphiaraus Vobis. ${ }^{2 i 3}$ ). . . . . . . . Austruliu. P. Rlioneus Don.

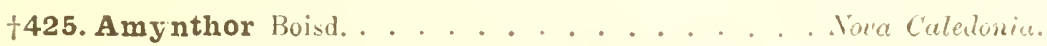
Bulletin de la Soc. ent. de France 18.5\% p. 1.j.;.

$$
\text { Sectio LII. 234). }
$$

426. Anactus Muc LIu!y. Anstruli,

$$
\begin{aligned}
& \text { Sretio LIII. 2ij). } \\
& \text { Subsectio A. 2its). }
\end{aligned}
$$

427. Ulysses 1............... Amburmu - Celebes, J Seba Thesaur. t. if 1: 9, 10. - t. 4ti 1: 4, 10 (malie).

If ibidem t. $5 \mathrm{f}$. 11. 12. - Lucas in Chenu kneycl. d' Hist. nat. 428. 1.ep. t. 12 t: 1. 
†429. Telemachus Montrouz.......... Ins. Woodlork. Anal. de la soc. d' Agric. de Lyon. Vill. p. 402.

430. Telegonus F(der. ${ }^{45}$ ) . . . . Batjan. Gilolo. - Ins. Arru? Wien. ent. Monat.chr. IV. p. 226. - Zool. d. Norara Exp. - I'. Ulyssodes Westw. in litt. - P. Telemachus Wallace in litt. - Boind. in litt?

$$
\text { Subiectio B. }{ }^{25 x} \text { ). }
$$

431. Montrouzieri Boist........... . Nova Culedonia. Bullet. de la Soc. ent. de France 18:59. p. 15\%. - Felder in Zoul. d. Novara Exp.

432. Chaudoiri frefler........... Th.s. Aru? Moluceac?

Wien. ent. Monatschr. 1V. p. 99 t. Il. f. 1. - P. Ulyssinus Westw. in Proceed. of the ent. Soc. of London 1838 et 18.39. p. 73.

†433. Ulysellus I'pstur. . . . . . . . . . Nota Culedomir. Proceed. of the ent. Soc. $18: 58$ et $: 39$. p. 73.

\section{Sectio LXIII. 25:).}

$\left.\mathrm{Subsectio} \mathrm{A} .{ }^{260 i}\right)$.

434. Peranthus F... . . Jae'l, Lombok. Bomeo. Moluceat? Timon. † var.? a. Buisd. Sp. gén. p. 203.

t var.? De 1 a a n in Verh. orer de Nat. Gesch. rau Vederl. orerz. Bez. p. 27.

435. Adamantius Fidlor.............. . Celebes.

Zool. d. Novara Exp. - L. Peranthus var. 13. Boisd. Sp. zéll. p. 203.

Subsectio B. $\left.{ }^{261}\right)$.

436. Blumei Boissl. . . . . . . . . . Celebes. - Amboina? Felder in Zool. d. Novara Exp.

437. Crino f. . . . . . Ceylon (Trineomuli), Cochin-China.

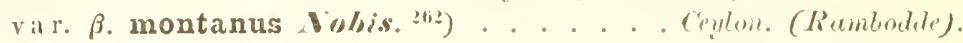

$$
\text { Subsectio C. (263). }
$$

7438. Daedalus Iousd. in litt. Felder.......... . Lusm. Wien. ent. Monitichr. V. p. 298. - Zool. d. Novara Exp.

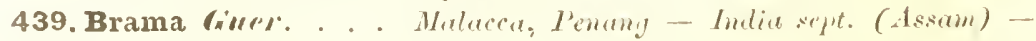
Stumetrit.

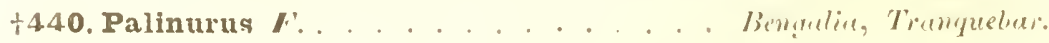




\section{Sectio ICIIY. ${ }^{263}$ ).}

Subsectiu A. 20is.

441. Arjuna Horsf. . . . . . . . . . . . . . Jach. 442. Karna Frlder. . . . . . . . . . . J Jeva. Zool. d. Novara lixp.

443. Paris L. Clina austral. (Conton, Hometom!l), India septentr. (Ne-

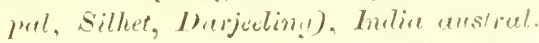
(Cimence.)

Blanchard IIst, nat. des Ins. 11I. p. 121.

444. Krizhna Moorp. . . . . India septentr. (Boctan, Darjeclin!.) Catal. of the Lep. His. in the Mlus. of the hon. E. 1. C. 1. 10s. t. 2 a f. 6 .

445. Arcturus Hestur. . . . India sept. (Silhet, Assirm, Dherjeding.)

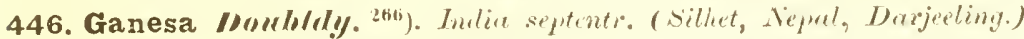

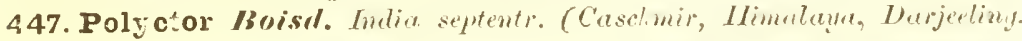
Nivel, Penjat, Beregrelice.)

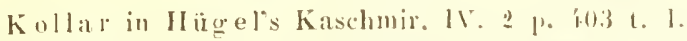

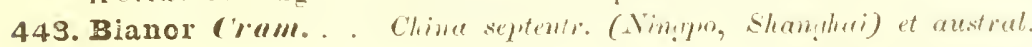
(C'ention), Jisunice.

\section{Subsectio B. ${ }^{267}$ ).}

4i9. Raddei Brem........ . Chime septentr.-orientulis (Burejit) Bulletiu de I' Icad. des sc. de St. P'etersbourg. III. 1) 4tiz.

450. (Maackii Menstr...... Chince septentr-orimetulis (Amur). in Schrencli's Reisen im Amurlande. 11. 1. p. 10 t. 1 f. 1.

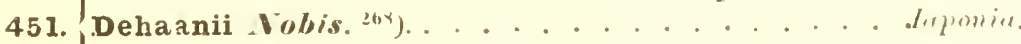

o S P. Bianor Cer var. apud De llana in Verh. ored de nat.

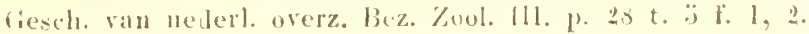

\section{Sertio LIV. $20 \%$ ).}

\section{Sub sectio A. 271).}

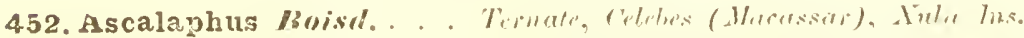

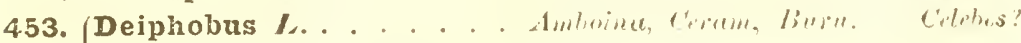
j Seba Thesaur. t. it f. ";. 6 .

C ibid. t 4ti. f. 16, 17.

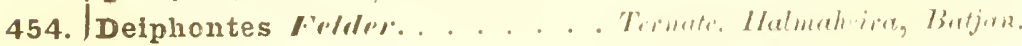

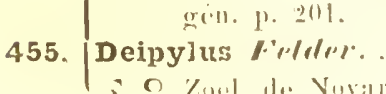


456. Emalthion //ïl)/................ LAtion.

J'. Luzoni،us etc. Petir. Gazophyl. t. II f. 8.

C formil altera: Rumanzovia Esell.

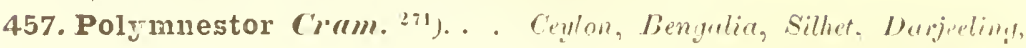
Costmitio

Lueas in Chenu Eneycl. d"II st. nat. Lep. t. 3 f. 2. - Blanchard Hist. nat. des Ins. IIl. p. 121.

Subsectio 13. 27?).

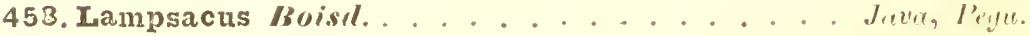

$$
\text { Subsectio C. }{ }^{273} \text { ). }
$$

459. Bremnon L. ${ }^{274}$ ). Jace, Stmatia, Bornen, Maluesa, Penand, India septentr. (Nepul, sillet, Assum, Darjectin!), China austral. - Japmin (eudem?) - Latzon?

Seba Thesar, - Sulzer Gen. Insect. ed. Roemer t. 1: f. "̈. abritr. J Indrogeus Cram.

f forma a maris celore.

Wemnou var. f. Giral Cintal. p. 13.

Jamedourar. De Hain.

Memourar. d. liray l. c.

forma $\beta$. \ genor $\mathrm{L}$.

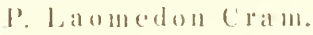

l'. Inceus Cram.

forma $\gamma$. Ac liates rar. I) 11 a al 11 .

I. Arhates cram.

J'A Alatiades Esp. - deliates Sulzer l. c. t. 12 f. ?.

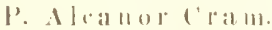

460. Oenomaus Godl. ${ }^{275}$. . . . . . . . . . . Thmor

$$
\text { Subsectio 1). } \left.{ }^{2 i b}\right) \text {. }
$$

461. Protenor ('rom. China septentr. (Nimenn, Shanghai) et anstral. Indiat septentis. (Mecsuri, Asstm, (Boetin).

462. Demetrius ('rmm. . . . . . . . . . . . Jupmin.

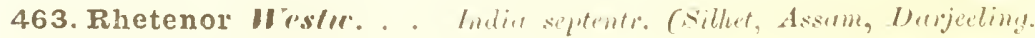

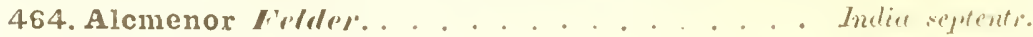
\%oul. d. Novari Exp.

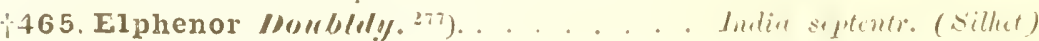




\section{sectio LIII. $2 \pi x$.}

466. Varuna Ihile. . Intire septevits. (Sillet, Durjeclim!, Asirm), l'enan!.

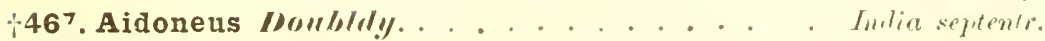
4E8. Semperi feldrl. . . . . . . . . . . . Luzon. Wien. ent. Nonatsclur. Y. p. 297. VI. p 282. - Zool. d. Novara Exp.

$$
\text { Sectio LIIII. 2in). }
$$

469. (Nox Strrills. . . . . . . . . . . Jave, P'enmu! l.ucas in Chenu lingcl. d' II.st. nit. Lep. $t$ it. 1.

†70. Noctis Hell.................. Bormen. P. Nox var. De II a n in Verh. over de Nat. Gesch. van nederl. overz. bez. t. "̈ f. 3.

\section{Sectio LIIII. $\left.{ }^{281}\right)$.}

471. Priapus Boisd. . . . . . . . Jinneo, Jater, sumetir.

Sectio LXIX. $2 \times 1$ ).

†472. Icarius IIes/ $/ \%$. . . . . . . A 1 . .

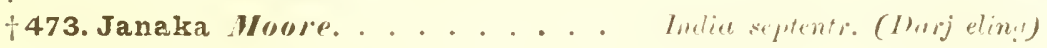
Proceed. of the zonl. Soc. - Catal. of the lep. Bns. in the Cinll. of the E. I. C. P. 97.

†474. Bootes II

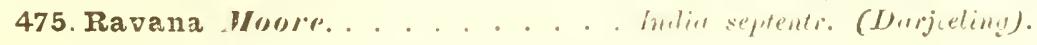
Catal. etc. 1.96.

P. Philoxenus Gray var. We-tw. Cab. of the or. Eut. t. 40 t. '́. - Gray Cirtil. p. 9.

476. Dasarada HourP. .

lietire reptertis. (Assam, sillet).

I. c.

P. Philoxellus liray var. Wentw. l. c. f. : ;.

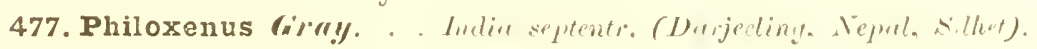
aberr. Polyeuctes 1$\left.)_{0}, b\right) l d y$.

†78. Minereus Gra!. . . . . Jutlie septents. (Neprel, Darjelin!).

$$
\text { Sectio LXX. 24:2). }
$$

479. (Aicinous Alll!). "*3). . . . . . . . . . . . . . Jripmia.

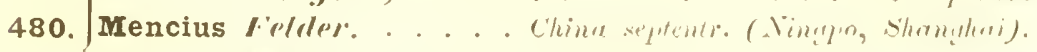

Wien. ent. Monatuclur. VI. p. 2.

P. Alcinous rar. liray. Catal. 


\section{Sectio LXXI. $\left.{ }^{2 s+1}\right)$.}

481. Neptunus firrer. 245). . . . . Pénany, Malaced, Bornen.

Sectio I.XXII. ${ }^{206}$ ).

482. Coon F. . . . . . . . . . Java, Borneo, Moulmeir. Zink. in Verh. d. k. Leop. Carol. Nkad. d. Naturf. VIl. 1. p. 1 k6 t. 1: f. 35 - Lucas in Clienu Encycl. d'Hist. nat. lep. t. 13 f. 1. Blanchard llist. nat. des Ins. 1II. p. 420. t. 21. 1 9. + var.? a. Firay Catal. p. 16. Intle septentr. (Assam). - Chinn australis?

\section{Sectio IIXIII. ${ }^{287}$ ).}

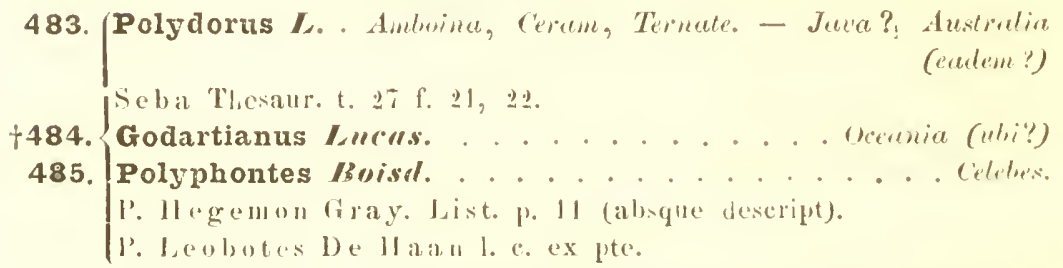

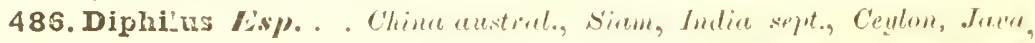

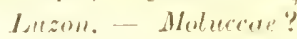

P. I d a mas Z in k. in Verh. d. k. Lemp. Carol. deutsch. Akad. d. Naturl. III. 1. p. I í.

uberatio il, b, e liray Cat. p. lo.

aberatiol)e II anal.

487. Antiphus f. . . . . . . . Jeete, stumetra, lomel ok.

tvar? b. Gray catal. p. 11. . . . . . . . Burmero.

488. Kotzebuea Esrh. . . . . . . . . . . . Luint.

t489. Jophon Girmy. . . . . . . . . . . . . Cẹtm.

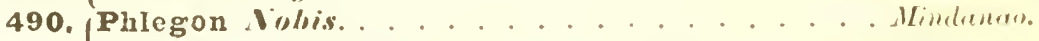

1'. A nnine G Felder. in Wiem. ent. Momatichr. V. p. 297.

491. Annae simp. in litt. Folder. . . . . . . Mineloro. IVicn. ent. Munatochr. V. p. 29?7. - Zool. d. Novara Jxp.

$$
\begin{aligned}
& \text { sectio liXXIY. }{ }^{2 \times 4} \text { ). } \\
& \text { Siubsectio } 1.2 \times 1) \text {. }
\end{aligned}
$$

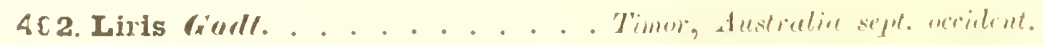

Subsectio $\left[3,{ }^{2911}\right)$.

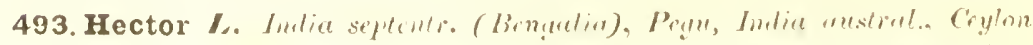

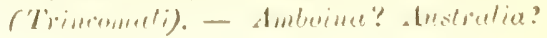


Seba Thenaur. t. 27. 1. 23, 2:i. - I, cas in Chenu Encycl. d'Il int. nat. Lep. t. \& f. 1. - Sulzer Gen. Ins. ed Ruemer. t. 12.. f I.

Sectio LIXY, 201).

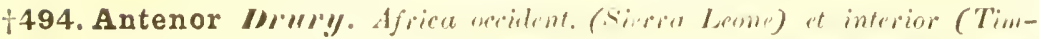
leceti1), Merdayrescerr.

\section{Genus IV. Euryades Nobis. ${ }^{29 !}$ ).}

†495. Duponchelii Luens. . . . . . . . P"raynuy, Lu P"utu.

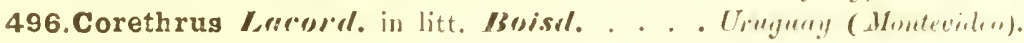
Lucas in Chenu Encycl. d'Hist. nat. Leje t. 9 f. 1.

\section{Genus V. Eurycus Boisd. ${ }^{293}$ ).}

497. Cressida $1 \%$

Jila nclua rd. Hist. nat. des Ins. HI. p. 12:3.

\section{Genus VI. Parnassius Latr.}

$$
\text { Sectio I. 29'). }
$$

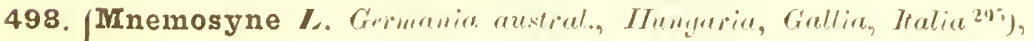

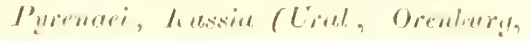

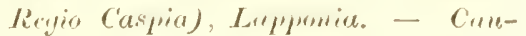
carees (cadew?).

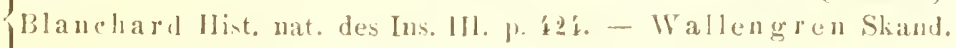
Dagfjär. p. 167.

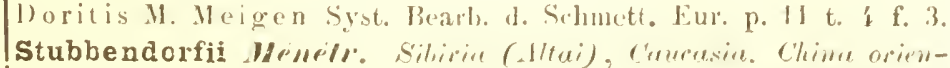
1 tali-sept. (Aluer).

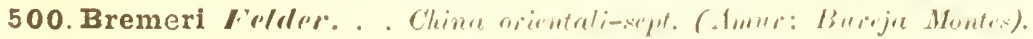
\%ool. d. Novara Fixp.

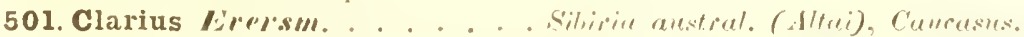

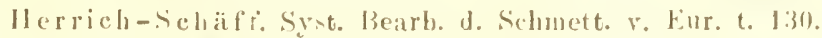

†502. Nordmanni Senrils. in litt. Norlm. . . . . . Caucusus. I'. I'at al'aeus Nordm. in litt. - Giray Jist. p. 89.

503. Clodius Mrurle. ${ }^{2+6}$ ). . . . . . . Clifornin, Ltah. Enum. Corp. Anim. Mus. Petrepul. I. p. 73.

I'. Clarius Er apud Boisd. in Annal. de la Loc. ent. de France $18 ., 2$. p. 20.3.

t504. Wosuesenskii Mrmell. Sillivire (Oolorisk).

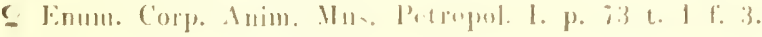


†505. Eversmanni Menell. . . . . . . sibiria (Kinsk). 1. c. f. 2.

+506. Tenodius Elersm. . . . . . Silvivin orirnt (Irkutzk. Lena). †507. Simo Gílly. . . . . . . . . . Torturia chinensis. †508. Acco Gruly. . . . . . . . . . . . Turturia chinensis. †509. Charltonius Gray. . . . . . . . . . Tarturia chimensis. 510. Hardwickii firay. . . Indiet septentr. (Nepel, Himeleya, Musuri). Tartarie chinensis. P. Jacquemontii Boisd. apud Kollar in Iligel's Kaschm. IV. 2. p. \{117. t. II. I. :3, i.

taberratio? Charino Gray . . . . . . Therteria chinensis.

\section{Sectio II. 297 ).}

†511. Felderi Bremer.. . . . Chime septentrionali-orient. (Bureja). Bulletin de l' load. des se. le St. Petersbumg III. p. kli:;.

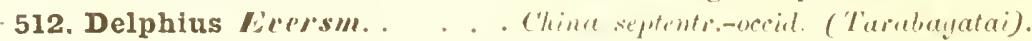
11 crr.-Selätf. Syst. Bearlo. d. Schumett. Europ. t. 132. f. 638, 639.

513. Actius Eeressus. . Chime septentrionati-aceident. (Theraluegetai).

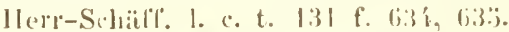

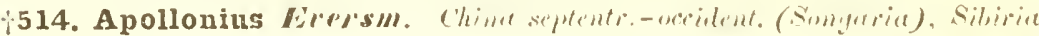
acestiellis.

Herr.-Schïfl. l. e. t. 1:32 l: 6i36i, 6i37.

515. Nomion Fisch. . Siberie, (hine septo-orient. (Amer) et meridert.

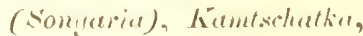
f var. P. Corybas Fisch. alud Il err.-Schäll., Syst. Bearb. Vl. 1. 3i;.

516. Jacquemontii Boissl. . . . . . Indine stptentr. (ITimalun!u). t var. a. (iray. . . . . . . . . . Theftrine rhinemsis.

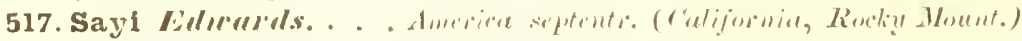

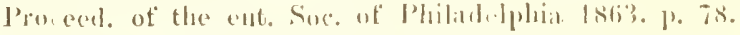

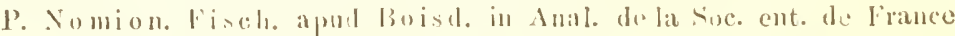
18:3. p. 2as. Criay Catal. 1. p. 7i:.

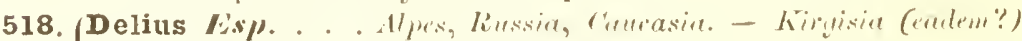
lila lleliard llist. nat. des lns. p. 42k.

aberatio? Il err.-Sclätl. Syst. Bearl. t. 66 f. 317, 31 s.

519.

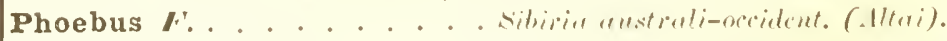
P. infermedius If énétr. Enum. Corp. Animal. Mus. Petropul. I. 1. 72.

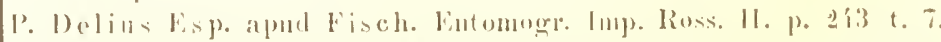
1?. Delius vale Smintheus loubldy aput bederer in Verb. d. zoul. bot. Gresellsch. zu Wien. Y. p. I00).

l'. Phoebus yar. infermedia. forma a. altaica llonitr. in

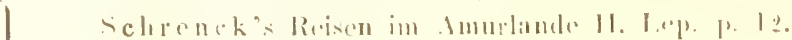


†520. Corybas F'isch. . . . . . . . . . . . . . . . . . . . . . . . P. Phoebus rar. intermedia. forma c. Kamtschatica et $P$. Phoebus rar. Corybas Minétr. I. c. p. 13.

†521. Uralensis Iolsis.... . . . . . . . . Uial. P. Phoebus var. intermedia forma b. nlalensis Ménétriés 1. c. P. I?.

†522. Smintheus Houbldy of Hor. . . Amriere septenti. (Rosky

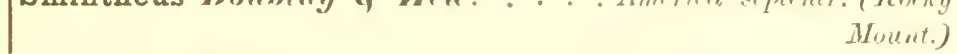

+523. Sedakovii Menelr. . . . . . Sibrive misntalis (Tikutzk). Enum. Corp. Anim. Mus. Petropol. 1. p. 71. t. 1 f. 1.

624. Apollo L. Germania, Anelia, Gullia, Itulia. Suesia. Russia, Bulmeria, Gerigia, raucasus.

P. alpinus etc. Petiver Gazohyl. t. 32 . f. 8 .

Doritis A. Meigen ryt. Bearb. p. 9 t. 3 f. 2.

Blanchard Hist. nat. des IDs. III. p. \{2' t. 3 f. \&. - Wallengren Skandin. Dagfjär. p. 168.

aberratio? Felder Zool. d. Novara Exp.

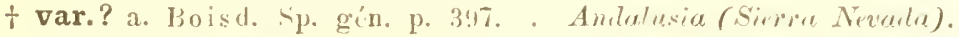
var. stbiricus Nordm. Sibiria (Kriacleta, Likutzk, Altwi). Smmaria, ISaschkiria.

† var.? Hesebolus Nordm. . . . . . . . . Mmmolic. var.? P. Ploebus De Brunner? ?42). . . . . . . Tetuetic. Meigen 1. c. p. $\{0$ ?

Genus VII. Doritis F. $x^{1, t}$. Boisd. ${ }^{299}$ ).

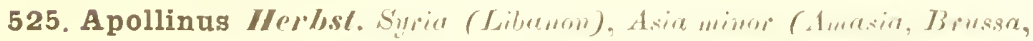
Suluma). Aichipulayms groucus.

Meigen Srst. Tearb. d. Schmett. r. Furopa p. 8 t. 12' f. 2. Blanchard IJist. wit. des Ins. III. p. 423 pl. 2 r. \&.

\section{Genus VIII. Thais F.}

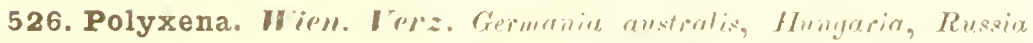
austral. Groersen. Itulia, Caurasia, Asin iminor (Brussa).

Roesel Ins. Belust. t. if f. 1. 2. aberratic Meta Meig. I. c. p. o. Mann in Stettin. est. \%eit. 18 it p. $3: j 8$ t. adj. f. 1. aberratio orhiracea Sta ud ing. Catal. 1. 1... Aforer, Bulgaria. var. b. Buoind. Sp. gein. 1. p. 38.;.

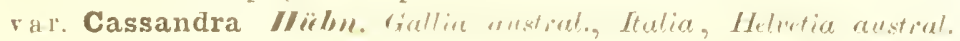
(Vatevia), Sirilier. 
T. Crensa Meig. 1. c. I. p. 162 t. i2 l. 1. - Mann I. c. t. allj. f. 2 .

T. Demnosia Dahl in litt. - Mann l. c. p. $359 \mathrm{t}$ adj. f. 3.

627. Rumina L. . . . . . Hisprenia, Lusitania, Russire australis.

P. ulisiponensis ete. Petir. Gazoph. t. I f. 8. - Meig. Syst. Bearb. p. 7 .

var. Canteneri Reyalemreich. lin litt. . . . . . Algeria.

T. Rumina I. var. apud Lucas in Explor. d'Alg. Zool. IIl. P. 3 ít pl. I. f. 1 .

528.

Medesicaste IIl. ........... Gallia austral.

Meig. l. c. p. 6. - Blanchard Hist. nat. des Ins. III. p. 4.23.

var. Honoratii Boisl. . . . . . . . . . Diniae.

529. Cerisyi Coull. . . Archipeley. giaeces, Constantinopolis, Asia minor (Alimesia, Brussa), Syria (Libanon).

Meig. Syst. Bearb. d. Schmett. v. Eur. III. p. 26 '.

var. I, ederer in Wien. ent. Monatschr. III. p. 1\%. . Balcan. var. caucasica lederer ibid. VIll. t. 3 f. 1, 2..... Cucasus.

\section{Genus IX. Sericinus Westw.}

630. Telamon IDon. . . . . . . . . . Chind septentr. (Peking). Bremer et firey Beitr. zur Schmett. Fama des nürdl. China's p. 1. - Ménétr. Enum. Corp. Anim. Mus. Petropol. 1, 1. 70. t. 6 f. 2.

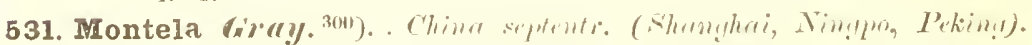
O S. fasciatus Brem. et firey 1. c. - Ménétr. 1. c. p. 71 t. 6 f. 1.

†532. Telmona (ád!y. . . . . . . . . Chind septentr. (l'ekim!). \& S. Greyi Brem et frey 1. c. p. 2. - Ménétr. l. c. P. i? t. 6 f: 3 .

Genus X. Fypermnestra Ménétr. in litt. ${ }^{311}$ ).

533. Helios Vickerl. . . . . . . . Turn (I)jan Dirin). Parnasius II. apud loubldy. Fenera of diurn. Lep. Doritis 11. apul standing. ('atil. 1. Lep. Eur. p. I. 


\section{Ippendis observationmm.}

1). Pristinum nomen .. Teimplalpers" vox lyelorida. Hane ob ren: novm

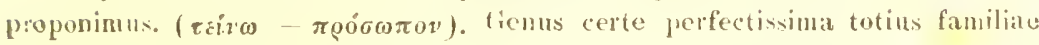
forma.

2). Miximam analggiam cum sechone Papilimis Protesilai, Setrperdmis, Coulvi etc. habet hoc genus renarum distributione ab ommibus reliquis familiae aeque remotum.

3). Genus Ornithotern Boisduralii a pluribus jam offensum (De Haan, Verh. over de nat. Ge ch. der Nederl overz. Bez, Zool. Ill. p. 18. - Westwood, Arcma entomologica 1. p. lï. - Snellen van Vollenhoven, in Tijdschr. voor lintom, III. p. 6s), a cel. Fray reliquis Papilionibus sed subgenus proprium aggregatum duas valde distinctas turmas, eximia P. Brookeani Wallace forma cum caeteris congeneribus junctas

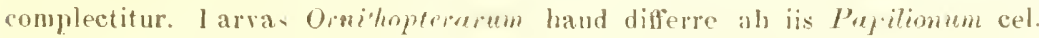
Wallace Tranact. of the ent. Sos. of I ondon N. S. Vol. :3. p. 348 demonstravit.

Sectio nostra primia species l'ritmo l. affines continens distinguitur valva anali marum latissima, capitis fronte villo multo breviore tecta, quam in sequentibus, magis deo deplanata collari multum exerto, cellula discoidali alarum anticarum latia, ob venam subcostalem et medianam arcuatam apice orali, quae res ramos medianos bueviores efficit, rann tertio venat subco-talis medio inter secundum et cellulae finem, quarto in plerisque mox post cellulam. in nonnullis in cjus extimo oriente. antemnis longioribu., palpis br. vioribus. multo minus setosis, pedibus longiorihu-g tibis tarsi-que quoad femora multe longioribus, tibiis inp imis porticis incrassatis, longius spmnlosis, margine interno alarmu postirarum in maribus valde dilatato et apuil plic:m int ruam involuto. involucro hoc extms evius :quamato, nitide brunnescente, juxia renam internam, contra abdomen, setarum patularum brunnescentium juba vestito. dimidio ejus basali iterum inroluto, cum superlicie interna totius limbi nigro squarata, absque pilis. Thorax dorso squamato, pilis dinudato.

4). Alae posticar angutatae, prorectae. Alae anticale sericeo-virides. vittis duabu, atris, juxta marginem cxternum confluentibus. Fenina ignota 
i). Alae posticae feminae sat elongatae, cellula earum (se undum iconem) angustior. Alae anticae maculis duabus vittaeformibus e basi. Color macularum pure albus. Mas ignotus.

6). Alae anticae maris supa atrae, vitta costali sericeo-riridi, cyanea vel ignea, manula interna laevigata vittaeformi. Alae posticae sat latae, plus minus abbreviatae. Femina maculis vittaeformibus interruptis pone cellulam, albidis supra cinereo-, subtu ochraceo atomatis, plerumque fasciola olligua in cellula anticarum.

7). Mas alas anticas in margine interno magis elongatas habet. quam affines, macula interna earum in extimo inferiore apud incur:um plicae internae semper incisa, usque ad ramum medianum secundum tantum exten:a et supra hunc nacula aequali minuta rotunda terminata. Alae posticae magis elongatae, quam in affinibus, supra mox pone cellulan serie macularun nigrarum conforniun ornatae, subtus sat late nigro marginatae, margo introrsum profunle sinualus, angulus analis hic aterrinus. Femina difutius colorata, absque ulla macula in cellula anticarum, maculis cuneatis posticarum semper distincte separatis, a margine magis distantibus. Decem specinina masculina et duodecin fuminina ante oculos habemus.

\). Species haec quoad patriam a Piremo remotissima proxima ejus aftinis. Alae posticae in joe distincte nigro margintale, margo vero integer, celhula earum sulstus late nigro cincta, maculae aluatale sat magnae ante marginem in pagisa mfera. Femina macula cellulari in anticis, sed angustatia, maculis cuneatis posticarum brevibus. Onnium minima. Specinen maris in collectione nostra vix l'. Crassum Cran. expansione aecquat. Ino l'riamum Amboinae cel. Doleschal collegit. Rimmomline maribn: hind majorem.

"). Man serundum De lla a ui descriptionem P. Pronomo Gray valde affinis, sed diversus absen ia macularum nigrarum in pagina superiore alarum posticarum, maculis rxterioribus viridibus paginae inferioris anticarum multo latius interruptis, disco inlero alarum posticarmu flavido tincto, absentia punctorum aureorum in hrum pagina infua et maculis nigris lric aprarentibus minoribus.

$\left.{ }^{10}\right)$. Secundum descriptionem auctoris l. e. a praecedente macula cellulari alarum anticarum paginae inferioris multo longiore posticinque supra nimro punctatis, subtus ad marginem flavido tinctis discrepat. Nomen mutindum fuit, quia longe antea Papi io a cel. Westwood "Boisderraliumus nominatus fuerat.

11. Femins ignota. - Pagina inferior ei l'. Areani maxime similis, sicut et vitta costalis superma alarum anticarum.

12). Inde furmae incipere videntur, guarum maribus macula nigra analis in pargina inferiore alarum posticarum deent. quod discrimen ralibe constans. A $P$. Pos illone Doubldy pagina superior hujus speciei sola tabulac mandata, diflert vitta costali alarum nuticarum haud incia. vitta

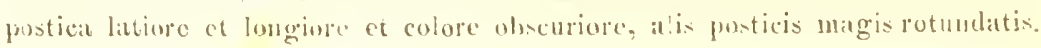


${ }^{13}$ ). Nescimus, quo jure cel. Gray leminam a cel. Westwood icone expressam ad Pronomum summ retulerit.

$\left.{ }^{14}\right)$. Dintincta certe forma, secundum iconem feminite nullo modo cum illa Peatasi confundenla. Alae posticae multo breviores, macula cellulari alarum anticarum multo minore. minus obliqua. macula parrula in cellulac ponticarum apice apparens, maculae cuneatae harum multo breviores, multo lic:ins coloratie.

1.5). Fenina 1'. Primmo, Richmomeliae et Euphorimti similior est, quam illae praecedentium. In alis anticis macula cellularis aepius in duas minutis reducitur, nonunuquan omnino abest.

iii). Cellula discoilalis alarum anticarum multo angustior propter venam subcostalem in medio suo cursu venae costali multo magis approximatam el medanam magis sursum directam, alam supra medium persceantem; ramus subcostalis tertins proxime ad cellulae extimum oritur, in nomullis in extimo ipso. in aliis e. g. Irelena pone illud, venula discoccllularis superior multo brevior et sat recta, rena discoidalis infer or et rami mediani multo longiores, ramus medianus secun fus et tertius leviter arcuati, primus rectissimus. Cellula alarum pont carum multo brevior. Palpi frontem aeguant et longe setosi. Antenate breriores. Tib ae haud incrassatae. Aldomen brevin, valva analis masculina minor. Thorax doino semper villoso. Margo interuss alarum porticarum inter plicam et renam solum leviter brumeo squamatus. pars involuta praecipuc ad basin haud iterum involuta, sed revoluta. Superfiries interra involucri et spatium ab ea tectum brumeo-alba, margaritaceo paullum nitentia et tomento densu concolore obsita.

17). Alarum ponticarum rami subcostales valde breves, vena primaria apud originem rami secundi fortiter fracta, rena discoidalis luevis, a ramo ultimo mediano at remota, venis mediana ipsa apud originem rami primi valde infracta, praesertim in maribus. hic a basi longe disians. Sexus sat discrepant in venis. Mas cellulam posticarum multo latio em habet, venam discoidalem et ramos medianos valde abbreviatos; int ratitia ramorum cum trunco basali renae angulum distisctum formant et interstitium secundi et tertii rami fore transrorsum, venula quasi discocellularis. Rami meliani valde divergentes.

In signaturis et coloribus species muica lirino et aflinibus paulfubum approximatur.

i). De nomine cf. Wallace. P'rocesd. of the ent. Soc. of london.

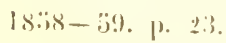

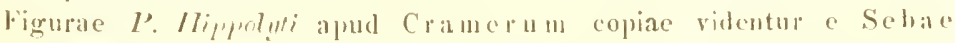
Thesauro t. it f: 11. 12 et 19, 20. Figurae posterioses (apul ('ram. t. 11 f. $\Lambda, B$ falos videntur abdomine instructae; secundum alarmm postiearum signaturas certe masculimu pecimen sistunt. Omne- colore inpsimis a typ., recedunt. Aberationes putanus. lece un utrinsque sexus specimina in col- 
lectione habemus. In duabus feminis maculam albam parvulam intra cellulam alarmm posticarum invenimus.

1"). C Ilula discoidalis alarum posticarnm multu brevior, vent carum subcostalis paullum fracta, basin versus multo minus arcuata, ramus e.ju, primus a basi alae multo longius remotus, rena discoidalis et ramus medianus tertius valde approximati, hic autem a secundo magis distans, rena mediana primaria leviter fracta. Vonae in utroque sexu conformes. Mares plurimarum areis magnis aureo-flaris apud discum alarum po-ticarum.

211). Specimina masculina sacpius maculam parram aureo-1latram intra cellulae extimum alarum posticarum girunt.

21). Cel. Gray sub nomine "Rlurdamanther Boisd." specem "x India continenti (Nepal, Canara, Mulmein) enumerat, a vero Rlludumantho (Nephoreo Gray) Jistinctan. Cel. Moore Catal, of the 1.ep. Ins. in the Coll. of the E. J. C. I. p. 88 fortasse eandem ante o ulos habuit. Quum nulla descriptio exstet et specinina nobis desint, speciem in praesens excludimus.

22). Similes sunt feminae Cerberi Indiae septentrionalis, se I Mims secundum iconem Crameri alas anticas latiores, apice minus productas et posticas multo breviores habet.

23). Cum sectione prima, cui facile adscriberes. levem habet affi itatem. Alarum forma value peculia.is. alae anticae angustac, margine interuo valde abbreviatae, apice autem nultum productac, posticae sat lreves. l'alpi frontem aequantes, dense setosi. Caput et oculi majora. Collare latius, supra ounino rubrum, thorax magis convexus et robustus, quam in (1ruithopteris genuinis. Intennae iis sectionis primae longitudine anduales, se multo graciliores. Pedes gracillimi, tarsis multo longioribus. I musa exim longiora, quam in sectionibus anteedertihus. Tibiae portica. femora paulum superant, mediae coutra femoribus subaguilongate. Ahdomen maris colius sexus noti) rohustius, crassius, cum thorace concolor, sicut ralva analis, guale modican tantum habet latitudinem (cf. Sinellen van Vollenlarenl. c.). Venarum distributio sat discrepat. Cellula alarum anticitum longior, multo angustior, obliqu" clause, ramus primus venae subcostalis mox pont ajus medium egrediens, secundus in ejus extimo, vena discoidalis et ramus medianus t"rtins multo magis distantes rami mediani breviores. Celh.la praccontalis alarum posticarum latior, cellula antem discoidalis brevior et angustior, rames primus subcostalis basi alae sat appreximatus, vena subcostali primaria leviter tantum fracta, vena discoidalis et ramus medianus tertius ralde alproximati, rami ommes mediani alarum multo breviores. Alace anticale sula fiscia macularum sericeo-viriclimm margini parallela, pusticase fascia lata discali ejusdem coloris. Pagina inferior alarmm anticarum sectionem primam, ea vero posticarum seetionems secundau revocat. Frons captis, paullo longins villosa, quam in sectione secunda.

24). Antennae gracillimae, clava valde elongata sed distincta. Mbdomen (feminac) alas posticas paullulum superans. Vena subcustalis alarmm anti- 
carum pone ramum secundun deflexa. cellula quare ad extimum coarctata. Venula discocellularis earum extrorsum distincte angulata, vena disco dalis superior in Triopa in medio renulae discocellularis, in Chebria anpra iliud rmisa. Vena discoilalis alarum posticarum ramo tertio mediano ralile approximata. Alae anticae sat elongatae, posticae valde abbreviatae, apud augulum analem sat profunde sinnatae. Frons longius villosa videtur, quam in sectione antecedente. Feminas tantum ante nos habenus. Hic Ormithoptore americanae incipiunt. Omithopteris enim proxime adjungendae ab que dubio sunt laec et subsequentes tres Americise tropicae copiona. sectiones (cf. elegantem descriptionem Batesii Transact. of the ent. Soc. of Lonton N. S. Vol. V. p. 339), quibus (eel. Boisduval nomen aeque perspicuum olim imporuit. Antemae longae, extmo modice clasatae, areuatae, abdominis forma, margo internus alarum posticarum late involutus, cellularum discoidalion et alarum forma, palporum vestimentum. pedum formatio, thorax apud lumeros coecineo maculatus et analozac sexum diversitates, hunc verum exse locum dictarum sectionum plane confirmant, guamquam species amplitudine et robustitate a maguificis oricutalium affininm formis longe superantur.

2.5). Antennae sat validae. sid clava angustiore, quam in sectione praecente. Abdomen lem nimm alarum po-ticarum margine interno triente brevius. Alae posticue marum apud angulum analem profunde sinuatie, margine interno dilatato, a plica interma involuto, basi autem involucri reversa, superticie tota obtecta albido-brunnescenti sfunmata, usque ad renam iuternam tomento denso serice-albido obsita. Vena discoidalis superior alarum anticarum venae subcostili magis approximata. quan inle iori. Tena discoidalis alarum posticarum in plurimis ramo mediano tertio sat approxinata, interstirim hoc sat arrectum. Froms longius villosa, guam in sectione secunda et tertia.

feninarum tres obmervantur typi: 1. Alace anticae macnla allida interiore a cellula longe distante rel plurimum in trienten ejus infimm extensa. 2. Alae anticae absque macula ulla, is maris plane concolores. 3. Alae anticae macula per cellulam nimine usque ad venam subcotalcm extensa, ideo laceiolae forman assumente.

26). Specimina s'esostritis genuini omnino cum surinamensibus congruentia Dom. Lindig ex Andibus bogotanis reportavit, ubi juxta l'. Chitdrence et Tarpumim boisl. volant. Hanc ob causam species propria nee geographicas formas put'umus.

27). Dom. Lindig duo specimina masculina prope Bogotan cepit. A surinamensibus alis latioribus, anticis multo minus productis, posticis brovioribus, levins dentats maculisque coccincis harum mul o brevioribus discrepant. Unum in pagina sperna supra ramum medianum tertiun maculans quartam minutam gerit.

Hoc factum clare demonstrat, P. Fyromlem Doubldy minime cise 
formam bogotanam Tertumni, ut cl. Bates Transact of the ent. Soc. N. S. Vol. V p. 341 censuit.

2x). Fentina quam maxime variat. Nondum dno vidinus specimina conformia

$\left.{ }^{24}\right)$. Haud potuimus comparare iconem Clerckii, sed cf. Bates 1. c. P. $3 \% 8$.

3*). Recte cl. Gray hanc cum Prote conjungit. In Museo Caes. Vienn. transitoria specinina asservantur.

31). Alae anticae sat falcatae, fosticae multo angustiores. Macula alarum anticarum inter ramum medianum secundum et tertium sita multo miljor, macula cellularis sat grossa apud rami mediani primi originum apparens. - Unum specimen in Museo Caesareo.

32). Descriptio Boisd 1 vali a n a multo melius quadrat in plurimas feminas Pyrochlis Doubldy, quan in eam a cel, Gray sub nomise "Erithalien * expositam. Maguan copiam specininum ex Andibus bogotanis, ubi in altitudine $6-7000$ ped. volat, Dom. Lindig reportavit. Duas feminas jam tempore, quo $P$. Alyuttem diagnosi exposumms, ante oculos habuimus. L'. Erithatim ab onnibus speciebus vicinis - Erlare, Telmosi et Zerride solis exceptis - differt alis anticis ungis porrectis, obtusis et posticis brevioribus. Praenumptio cel. Batesii de gradu hujus specei supra memorata jan propter magnam diverstatem feminae a Crommi feminis arbitraria nobis videbatur. Mas Erithaliomtis multum varıt. I ntitudo maculae grisene internae alarum anticarum valde nutabilis. Pauci tantum atomi nomunquam derelicti sunt. Ln collectionibus Lindigianis duo specinina inverimus, in quibus macula interna sat diffusa et supra eam inter bamum medianum secundum ct tertimm macula parvula thavida bene ab ea separata appret. L'. Zéteili I.uc. jan paullum approximatur haec aberratio. Alase posticae non minus variabiles. In nonnullis specininibus quatuor in is apparent maculae coccineae multo longiores, quam in typicis. femina latitudue maculae cellularis alarum anticarum a vicinis distinguitur. Poxima quidem illi $P$. Zeuxidis, a cel. Gray sub denominatione "Erithalion" depictae accedit, sed stricte discrepat ab ca faccia etian alarum posticarum latiore, margini quare extemo magis approximata et lunulis ciliaribus multo latioribus, ut in $\ell^{\prime}$. I, helemer et P'anure. Fascia illa extrorsum, ut fere fit, sat profunde crenata (..palmée en arricre" Boisd.) cellulae clausum tantum stringit vel ab eo paulum distat (.,en arrière de la cellule discoidale” Boisd.). Macula prima fasciae inter ramos subcostales semper vena sat lata nigra separatur (nterminće extérieurement par une petite tache, la seule, qui soit separce par une nervure noirest Boisd.).

:3:1). Valde affinis certe haec species pracedenti, sed mas lacile dignoscitur alis anticis angustionbus, sempr macalan ocluacean inter ramm medianum secundun et tertiun exhibentibus maculisque coccineis alarum pesticurum cellulae multo magis approximatis. Specimina venezuelana minura 
sunt et apud plagam internam alarmu anticarum duas maculas ocluracea habent. Specimen incertie originis posidemun paulmm discrepans. In alis anticis sola macula ochacea quadrangula et multo minor conspicitur it alne posticae magis elongatae sunt. Similitudo hac re efficitur quim maxima cum I'. Almutte nostro, sed manifeste d llirt lic nitore cyanco in alarum posticarun pagina superiore.

${ }^{3}$ ). Apecies a Zencolde I, u c. omnino diversa. C'f. iconom apud de Castelua u op. cit.

a5). Ditlert a sectione priore alis anticis nargine interno multu hrevioribus, posticis magis elongatis, sat profunde sinuato-dentatis, ad ramum medianum tertium candatis. vena earum subcostali multo magis fracta, $r$ n: discoidali semper optime a rano tertio mediano distaute, collula idea multo latiore. In omnibus speciebus nobis notis, solo P. Montesume Westw. excepto, cellula discoidalis alarum anticarum multua angustata est. In pherisque rani duo primores mediani alarum posticarum sat approximati et rami subcostalis primi earumdem alarum origo a basi alac magis remota, quam in sectione antecedente. Antennae et margo internus alarum pusticarum dense alho pellitus affinitatem cum hac clare demonstrant. Sixus ommino concolores. Valra analis masculina multo minor, quam in sectione primi. Mirum factum. quod species in America centrali et Bra-ilia anstrali habitant, in regionibus autem interjacentibus plane abesse videntur.

"w). Duo jam papilione. longe antea descripti nomen "Columber" forunt, hac ex causa in norum mutandum illad fuit.

37). Antennac graciles, clava valde angustata. Alarum posticamu margo internus in superticie ab involucro tecta farinose albi 'o squamatus, juxta venam internam solum parce albido floccosus. Valsa anali marmm ut in sectione Aluret.

" $)$. Alae posticae sat profunde sinuato-dentatae, apud ramum medianum tertium caudatae. Venae ut in suctione $\mathrm{V}$.

34). Alae posticae sinuato-dentatae, derte ad rammm medianum tertium obtuso rel acute prominente. Cellula discoidalis alarmm anticarum plus minus angustata. Vena discoidalis alarum ponticarum in plerisque a ramo mediano ultimo bene remota. Lunulace eiliates in phrimis rubate. Feminae in signaturis tres constitum typos, iis sectionis $\mathrm{V}$ omnino respondentes (deneas - l'millonus - Eurimedes).

411). Lemina adeo diversa ab Aenea, ut cel. Batesii opinionm de hac specie ad praesens recusare debemus. Specimen nostrum ab tcone cel. Grayi discrepat maculis alarum ponticarum multo brevionibus, a collula longe distantibus, margini externo autem magis approximatis. - Mas etian mulum diflert ab Aeneu.

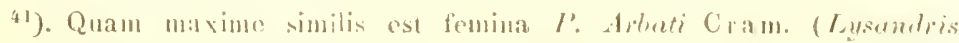
fem.) et facile cum ea confundenda. soul certe dignoscitur alis (praecipue anticis) angustioribus, cellula discoidali alarum anticarum extimum rersus, 
magis attenuata, fiscia posticarmm magis currata, cellulae extimum plum minus stringente. Collula alarum posticarmm sapius multo latius appares. Saepius maculae albae in anticis onmino desunt. Figura Ciray aberrationem sistere videtur. Dentium alarum posticarum forma non minus variabilis, quam in mare.

42). Feminam solam noscimus. Valde similis speciminibus immaculatio 4.butis est. sed primo aspectu dignoscitur colore alarum et alis anticis apice obtusioribus. $P$. (Vivencio similior est. Specimen renezuclanum in . Ilusow Caesareo maculas rubrescentes nulto breviores habet.

4.1). Specimn surinamense in collectione nostra maculas omnes alarum posticarum supra pallilissimas ostendit.

Longitudo macilarum rubrarum feminae multum rariat.

44). lalsa fortasse descriptio, cilia enim sappius multum prllescunt. Specimen nostrum $P$. Brissmii a cel. Bates communicatum cilia fere albida habet. Alarum pos! icarum foma secundum descriptionem cel. Godartii certe affinitatem cum Echelo indicat. (Cf. Bates, Transact. of the ent. Soe. N. S. V. p. $34 \%$.)

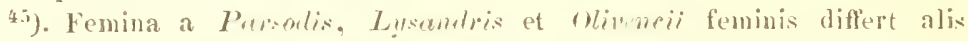
anticis cellulinque earum scilicet anguntioribus et posticarum fascia magis curvata et cellulae multa magis approximata. ('ol. Esper etiam sub nomine "tencides" duas confudit species.

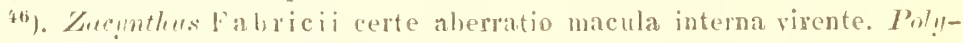
metus est ordinaria forma. Museum Caes. Viennense specimen femininum possidct, cujus alae anticae inter ramos medianos tantun maculis (duabus) subaequalibu; notatie sunt. Sat simile est (n; silli fem. secundum Swaiusonii iconem.

47). Valso nostra opinione cel. Bates Trausact. of the ent. Sior. N. S.

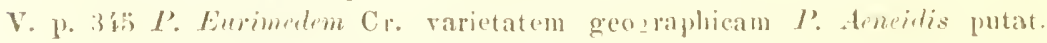
Ut multa discrimina marum practermittamns, guae abogue dubio speciem propriam indicant, feminae ad liversos typos apud sectionem V jam memoratos pertiment, femina enim Enrimedis (.1miphes Boisd.), P. Erithalionti et affinibus accedit, illa contra deseetlis, sisut ea Lysandris (drbates), eis llieroclis et lertumi similis est. Idem de $I$ '. Zurmtho F. monendum, quem cel. Bates etiam varictatem Ameidis recensuit. Mares Furimedis bogotani a surinamensibus alis ant cis latioribus obtunioribus et plaga alarum postirarum minore recedunt. Alae anticac sacpissime omnino nigrae sum. Mares a Venezueda septentrimali-oceidentali (Caracis) omnium maximi, I laga alarum posticarum plesumque multo major et longins in cellulam extensa. lancia in alis posticis feminarum lujus formae multo pallidior.

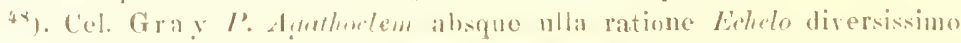
aljungit, sed certe aberatio tantum Erromedis (oolumbise nientalis est, macula integua alarum ant carum angustiore, bipartita obsoletiore et plaga dincoli posticarmu superna multe minope, expallescente diversi. Sperimen 
cum typico in Musco Caesareo omnino conforme I'rot. Ulicoechea prope Muzo Novae franadac legit. De similibus Lumerlois aberationibus. (ft: supra.

49). Ab omnibus pracedentibus sectionibus diftert antennis sat brevioribus, validioribus, in clavam subovalem ohtusam rectam incransatis, occipite albo himaculato, collari rufo rel tlare macula o, abdonine multo robustiore, marginis intemi alarum puticarum bitrientom vix acquante, vena subcostali alarum anticarum haud deflexa, sed modice arenata, vena rarum discoidali superiore in medio renulae discoellularis, sappius etian inlia illud exeunte cellulaque discoidali alarum pesticarm breviure, Jatione, rena discodali harum a ramo ultino mediano scmper optime remoto, interstitio perobliquo, liand transvero, alarum posticaium margine interno levitor involuto, superticie involuerata reliquis alac partibus concolore, involucro extus dense nigro jubato. Valva amalis ma um minor et acutiur apparet, quam in anterioribus anericanis sectionbus. frons longius villosa, in nonnullis subcomosa.

50). Antennae breviusculac. Iblomen Jimidum marginis interni vix superans, aeneo-virens, maculis latralibus et rentralibus lavis. Alae fosticate apud ramum medianum frimum caludatae.

$\left.{ }^{51}\right)$. Abdomen colore thoracis, striga laterali lateritia vel lutescente. Alae posticae repandu-dentatae, ecaudatae.

52). Abdumen marum supa, amulo basali exeepto, dilute sulphureum. Alae anticae sat elongatae, po-ticae plus minus abhreviatae.

53). Specimina a Dom. Lindig in Andibus bogotanis lecta ommino conveniunt cum surinamensibus, expansione multo majore excepta. Color saepius multum in chalybaeum vergit.

5it). Cel. Bates 1. c. hanc féminam Beli esse suspicatur. Feli autin forma columbica nobis $P$. Latinus videtur et hujus soctionis feminae non multum discrepant a maribus.

5.5). Antennae longac, fere ut in sect. Vill, sed clava crassiore. haud arcuata. Collare sat longum grosse rufo maculatum. Thorax robustus, valde convexus. Abdomen multo rohustius, quan in pratecedentilus, marginis inteni bitrientem superans. Ilae anticae sat elongatise, apice valle proInctac, posticae ad ramum me lianum tertium angulatace, dente apud hune et co apud ranum primum aeque prominentibus, limbo interno laaud dilatito et laud involuto, sed leviter revoluto. juxta venam intermam nigro piloso, in sexibus confumi. Cellula alarum anticarum costae dimidium superan, busi sat altenuata, dein vero latior fuam in quatuor sectionibus antecedentibus, ramms subcostalis tertius sacpius paullum gone cellulate clatusum emi sus, fruncus

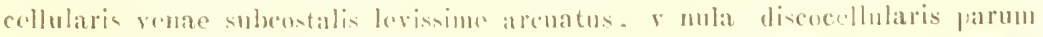
fracta, in medio ventun discoidalem superiorem enuittens, rema mediana sat flexa, ramus primus et secundu- ejus multo magis appoximati, quam roliquate venace. Cellula alarum pesticarum fore ut in sectione lol.. sed multo latior. 
apud ramos subcostales multo magis angulati, ramus subcostalis secundus basi multo magis approximatus, interstitium venae discoidalis et rami mediani tertii (i. e. Fenula discocellularis inferior) breve, minime transversum. Valva analis marum ut in sectione $\mathrm{V}$, sed minor. Collare maculis cingularibus coccineis, ut in sect. I - IV, occiput albo bimaculatum. Frons minus villosa.

5it). Feminne etiam surinamenses saepins maculan albam in alis anticis germut. Haud discrepant specimina paraensia.

57). Antennae breves, validae, in clavam vix suboralem, sed distinctan tet arcuatam incrassatae. Collare multo brevius, quam in sectionibus antecedentibus. Abdomen breve, vix dimidium marginis interni aequans. Alae anticae sat elongatae, sed angustiores, quam in sectione Vlll et ajice minus productae, posticae margine interno fortiter plicato, sed haud involuto, parce piloso, in sexibus conformi. Cellula discoidalis alarum anticarum costae bitrientem subaequans, sat lata, vena subcostalis ante cellulae clausum modice arcuata, ramus ejus primus multum pone cellulae medium emissus, venula discocellulari recta vel levissime fracta, extrorsum saepius subconcava, vena discoidai inferiore apud plurimas species in medio, nonunguam rero paullum supa medium renulae transversat nata. Rami mediani ut in sectione VIII. Cellula alarum posticarum ei sectionis praecedentis similis, sed angustior, ramus subcostalis primus a basi magis remotus, truncus renas subcostalis ideo longior, renula discocellularis superior multo brevior, interior fore longitudinalis. Color et signaturae scction $n$ I multum revocant. Valva analis marum minus distincta, acuta.

$\left.{ }^{i r}\right)$. Alae posticae obtuse repando-dentatac, donte apud ramum medianum tertium phu minus prominente, cellula discoidali angustiore, unque in medium alae porrecta, interstitio ramorum subcostalium leviter deflexo. Frons subeomora. Sexum diversitates, ut in sect. V, Vill et IX. Cullare et oceiput albo maculata.

5\%. Cel. liates varietatem Arimathis putat, sed forma alarum posticarum constanter diversa et cellula anticarum distincte angustior.

(ii). Alae latiores, anticae maregine interno longiores, posticale acute repando-dentatae, margine costali multo breviore, celluba discoidali latiore et breviore, interstitio ramorum subeostalium sat deflexo. Collare et occiput rubru maculata. Sexus concolores.

6). Alate posticae profunde et acute repando-dentatae, cellula latiore, quam in sub-ectione praecedente, interstitio ranorum subcostalium minus defle xo. Cullare et oreiput rubro maculata.

"?). Alae longiores et latiores, quam in prioribus. Alae ponticae (aulatae.

wi). Valde affinis sectimi anteriori, sed facile dignosenda antemarum alasi multo crassiore, subpryitormi, fortiter areuata, fronte longius hirsutim corpere robustiore. vena subcostali ante cellulac cxtimum magis arenata. 
angulo superiore cellulae multo magis producto, venula idcirco discocellulari multo rectiore. candatae.

(it). Alae latiores, quam in sectione praecedente, posticac longiores.

6.3. Cellula discoidalis alarum anticarum angustior. Alarum forma. ut in sectione Ariarathis. Plicae cellulares ditinctissimac. Sexus concolores? Collare et occiput indistincte albo maculata. Intennae?

6i). Forma alarum ut in priore. Venula discocellularis inferior alarum posticar'um longior, quam in praecedentibus subsectionibus. Sexus (omniun?) valde diversi, similiter, ut in sect. V et VII. Abdonen fasciolis lateralibus rubris.

6i). II Iultum variat mas. Latitudo plagae griseae internae alarum anticarum ralde mutahilis. Saepius macula coccinea intra cellulae extimum in alis posticis. Longitudo et numerus macularum coceinearum aeque mutabilis. Nomnunquam multum confluunt oh colorem nigrum venarum percurientium eranescentem. Alae posticae non raro denten apud ramum medianum tertiun caudulae instar prominentem exhibent. Sat vulgaris est species in Andibus bogotanis. Plus quam quinquaginta Dom. Lindig masculina specimina inde reportavit.

$\left.{ }^{6}{ }^{2}\right)$. Cellulae alarum angustiores. Alae posticae trunco subcostali breviore. Abdomen fasciolis lateralibus posticis rubris. Antennae bicriores, quan in subsectione piore. Sexue concolores. Alae posticale maculis griscis, nec cuccin. is.

"y). Venula discocellularis alarum anticarum extrorsum magis concava. Alae posticac latiores et breviores. Abdomen ritta laterali ubsoleta ocliracea. Sexus concolores.

7"). Alae anticae elongatae, magine externo vix levitel concavo, cellula discoidali extimum versus latiore, quam in praceedentihus, posticie leviler repando-dentatae, conta perlonga, limbo interno antem adhuc breviore, quam in Cheridame, margine toto externo et postico hanc ub rem in una linea truncatis. Abdomen vitta distincta laterali ochnacea.

7). Specimna loggotana et venezuelana nisi statura majore haul disecepant a brasiliensibus.

72). Valle similis acetioni pracedenti, sed differt alis anticis brevioribus, posticis sat longe audatio, vent subcustali alarum auticarum a cona contali magis distante, pone rami secundi originem minns arcuata, renula earum discocellubri interiore flexili cellulaque alarum ponticarm hreviore ot latiore. Fons comosa. Relatio analoga ei inter sectionem I ef VI. Forma

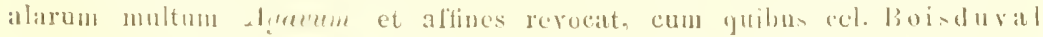
nustran sectionem conjunxit, sed antemarum et abdoninis formationon minus quan marginis interni alarum ponticarum comditio et venarum distributio (venulace disencellularis inlerioris diversissinal directio et hanc ob causinu renate discoidalis aliena positios lunge als his can rejiciunt. 
73). An varietas sequentis?

${ }^{74}$ ). Discrepat a sectione XII antennis brevioribus, clava latiore, magis abrupta, alis anticis margine interno longioribus, apice nulto magis productis, costa alarum posticarmm multo longius projecta, angulo antico ideo multo acutiore, regione postica porrecta attenuata, sinubus marginis apicem versus sensim levioribus, cauda multo longiore, per totan longitudinem aeque angusta, vena subcostali alarum anticarum pone rami secundi originesu cellulae extimo multo magis appoximatam parum sed subito detlexa, cellulae angulo superiore nagis prominente, venula discocellulari rectissims, minus obliqua, vena disco dali inferiore alarum anticarum paulem areuata, veria costali alarun posticarum a costa magis remota, cellula discoidali multum ultra alae medium extensa, multo angustiore, vena discoidali earum ramo media: o tertio multum approximata, venula discocellulari magis longitudinali, ramo mediano primo a secundo multo longius remoto, abdomine strigis binis lateralibus or ato, valva anali masculina magis acuminata. Frons minus como:a.

75). Antennarum clava bene abrupta, ovalis, contorta, fulvesenti colorata. Frons comosa. Abdomen maris crasiunculum, sat breve, dimidinm marginis interni aefuans, vittis duabus lati-simis, strig duabus lateralibus vittisque totidem ventralibus cum valra anali angustiore, acutiore ochraceoalbis. Collare, lumeri et pectus albo maculata. Alac latiores, anticae margine cxterno magis concavae, yuam in sectione antecedente, ponticae angulo apricali minus acuto, regione anali multe minus producta, margine interno a vena interna fortiter involuto, involucro supra dense jubato piloso. superticie intema ab involucro terta villo denso brumbeenti-abo obsita. Cauba bevior, tenuis, versm apicen paullo latior. Collula discoidalis a rum anticarum latior, vena earum subcostalis pon ramum necundun magis deflexa, lere fracta, ramus hic cellulac extmo propior, primus antem abbreviatus, in venam costalen excurrens, venula discocellularis multo magis obliqua, angulus fuare superior cellulae haud prominens. Ramus medianus primus rarum lem alarum a basi magis remotus. Ramms suberstalis primus alarum posticarum a basi multo magis distans i. e. Irunems subcostalis multo longrior, quan in sectione antecedente, interstitium ranorum subeostalium magis curvatum. Vemula discocellularis inferior multo longlor, magis obliqua. Liami mediani aequa'iter inter se distantes.

*\%. File dignoseitur a l'. Molicante surinamensi alis et cellulis earum multo latioribus, anticis matgine externo minus concaro, posticis in regione anali multo minus productis, colore paginas superionis pallidiore, limbu externo lusen alarum anticarum introrsum semicirculariter sinualn, juxtar malginem penticum a plica mediana secundal multu anguntiole, decresconte, ramis medianis primoribus venaque interna anticarmm, ramis subcostalibus medianis et vena discendali posticarmu ante limbum lisce coluratis, lis funde inter rames subcustales supra prolunde inciso ibique matcula 
fun li colore sat grossa notatis, anticis sulutus plaga fasciaeformi in linum multo latiore, margine finses pune eam jacente a vena diseoidali superiore valde anguston posticarum striga inlera discali basi multo magis approximata, latiore, angulum multo acutiorem formante limbogue luaco ibidem angustiore. Venula discocellularis alarum anticirmm multo obliquior est et Jane ob causam lasciola macularis superna pone ean jacens magis oblique directa. P. Iflutae, juxta quem in Brasilia australi vulat, propius accedit, quam casterae varjetates geographicae Dolicamtis.

77). Valde allinis praecedenti, sed distincta thorace immaculato, abdomine longiore, cum thorace concolore piloso, valva anali marum latiore, obtusiore, alis anticis apice magis productis, posticis in regione anali multo machis porrectis, caudis alarum bitrientem longitudine acquantibus. multo latioribus, cellulis discoidalibus longioribus venague subcostali alarum anti"arum pone rammu secunduni cellulae extimo magis adluc approximatum fere fracta, rano etiam secundo in venam costalem excurrente.

$\left.{ }^{7}\right)$. Valde similis sequenti, sed constanter discrepans secundum multa specimina comparata. Descriptio fodartiana nagis in hauc speciem quadrare videtur (,.janne d"ocre pile depuis la base jusque rers te milieu"), qualm in Hiprociamem.

79). Absque ulla descriptione omnino nomen hoc editum in tabulat, ut videtur, exempli calusa typis mandata, sed plane consentimus cum cel. liuérin i dictis, Voy. de la Coquille Texte Ins. Avant propus p. XI.

"). Affinissima sectimi priori, diversa solum statura corporis ninore, antenuarmm clava crassiore, scapo coucolore, abdomine strigis lateralibus et ventralibus ornato, vena subcostali alarum anticarmm pone ramum secundum a cellulae extimo magis distantem multo minus fractir, ramis duobus subcustalibus primoribus omnino liberis ali-que angustioribus.

"i). Caput et collare supra fusca, imnaculata. Cauda alarum posticarum latior, quam in llippodamo. Vena subcostalis alarum anticarum a rena costali magis distans, quam in sectione praccedente et subsectione sequente, apud insertionem venulae diccocellularis fracta, ramus ideo subcostalis tertius a celiulac extimo remotus. Angulus apicalis alarum posticarun multo magis propectus.

\$2). Corpus gracilius. Occijut flavido bistrigatum. Collare obsolete sul-

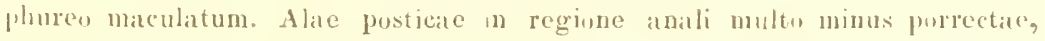
ad anguhm ani multo levius sinuatae, cauda e justem batitudinis, ut in /lifperemon. Ramus subenstalis secundus alarum anticarum cellulac extimo multo magis approximatus.

\$a). Dignoscitur ab antecedente fronte multo brevius villosil, antenuis brevioribus, thorace supra bistrigato, abdomine bresiore. vittis duabus lateralibus totidenque ventralibus ornato, alis sat augustiuribus, anticis apice magis productis, josticarum costa magis projecta et regiome anali carum multo magis angustatit. 
צ'). Antennae longiores, quam in pracedente, clisvi multo minus. abrupta, multe breviose. Valva analis marum latior. Alate multo latiores, anticate apice multo mimus productae. Cellula barum discoidalis brevior, multo latior, vena subcostalis primaria apud insertionem venulae disencellularis fracta, ita ut ramus ejus tertius a cellulae extimo paullum distet, rami duo subcostales primores sat deflexi, in venam costalem exeuntes, ut iu sect. XV, a qua jam discrepat capitis corporisque restimento el colure. Venula discocellularis superior et inferior alarum anticarum paullo obliquimes. Maculae thoracis et vittae abdominis albidae. Facies sectionem P'. Dnlicamtis revicut.

4.5). Diflert ab antecedente antennarum clava longiore, crissiore, froute longius pilosa, alis pellucidis, posticis in regione anali magis protractis, rena subsostali alarum anticarum ante cellulae extimum vix arcuata, saepius vero apud rami subcostalis secundi originem fracta, venula discacellutari obliquiure.

*6). Frons comosa. Ramus subcontalis secundus alirmu anticarum a cellulace extimo sat distans. Ramus subcostalis quartus et quintus e trunco longiore emissi et magis arcuati, jdeo longius inter se distantes, quam in sequentibus.

$\left.{ }^{47}\right)$. Antennarum clava longior. Frons brevius pilosa. Alate anticile apice multo magis productae, cellula quare longior. Vena subcostalis pone ramun secundum saepissime fractil, venula pseudu-discocellularis i. e. interstitium rani tertii subcustalis et insertionis renulae discocellularis superioris silepilus conspicuat. Raums subcostalis secustus in plurimis speciminibus cellulae extimo sat approximatur. Cellulia macustalis alarum posticarum latior. Alae posticae in regione anali minus productae, quam in subsertione anteriore.

"a). Ab tresilao, cui valde affinis, facile differt striga secunda alarum posticarum ramum medianum tertiun stringente, apud maculam analem demum cum striga mima unita. Sat mutabilis videtur species. Tria ante nos lıabemus specimina. Unum e reguo Mexicano allatum in Musco Caesareo Agesilai venezuelani specimina magnitudine superat, strigas alarum anticarum sat latas labet, limbum fuscum extermu paullatim decrescentem, fasciam byalinam in eo sensim angustatam, plicam medianam priman haud excedentem. In pagina alarum posticarum superiore striga prima sola distincta est, in inferiore auteu seculda etiam, sel ultra ramum medianum secundum non extensa. Margo fuscus harum alarum utrinque latior est. Basi alarum anticarum virescit. Alterum specimen in collectione nostra minus est, strigas supra multo obsoletiores praebet, limbum fuscuu externum angulum versus internum multo magis angustatum, sed venam intermam vix excedentem, Pascia angusta aequilata, usque ad ramum medianum primum currente divisum. 'Tertim specimen, originis aeque incertale, majus est, l'ascióas alarum anticarum et strigam primam posticarum multo latiores et distinctiores 
habet, limbum terminalem nigrescentem omnimm alarum latiorem, in anticis intus recte fere limitatum maculasque duas nigras confluas supra angulun a aalem posticarum supra etiam optime distinctas. Alae antieas apice 4 agis jroductac sunt, posticae in regione anali multo magis porrectae, candis brevioribus et latioribus instructae.

Minime dubitanda est dirersitas Ayesilai et Autosilai a Protesilon 1., nt Dom. Weidemerer in Proceed. of the ent. Soc. of Philadelphia Vol. I. p. 1'9 fecit. Permulta specimina Auesilui et P'otesilai Dom. Lindig ex Andibus bogotanis reportavit absque ullis transitoriis. Venula discocollularis inferior alarum posticarum in Protesiluo et succedentibus duabus speciebus sat longior, quam in Ayesilan et Autrsilno. Ramns subco-talis secundus alarum anticarum in plurimis Protesilai speciminibus rano tertio magis approximatus et interstitium hoc magis fractum.

say). Specimina bogotana omnium maxima sunt. Specimina Braviliate australis minima sunt et lunulas submarginales alaruol posticarum mults angustiores habont.

Inter magnam copiam speciminum hujus et Aypsilai sequentisque speciei e diveris lucis nullam invenire potuimus feminam.

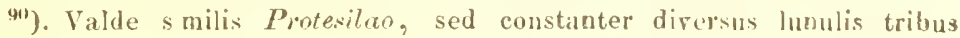
analibus alarum posticarum ochraceo coloratis fasciaque terminali hyalina anticarum latiore. Ptrmulta ex diversissimis locis comparavimus specimina. Ubique juxta Protesilaum volare videtur, sed multo magis va iat. Specimina hogotana magnitudine omnia reliqua superant. Alac anticae in iis multu angustiores sunt, guam in Protesilao, margine externo magis concavate. apice hanc ob rem usulto magis productae, posticae acque anguntiore's et in regione anali multo magis porrectae, longius caudatae, cellula discudali longiore et angustiore, quam in P'rotesiluo. Striga submarginalis alarmu anticarmm nigrescens, quae tasciam terminalem byalinam introrsum limitat, in hisce speciminibus semper mayis arcuata ent, quam in Protesilao et quare cun fasciola discocellulari connexa. Specimen perpulchum in Museo Catesarew ad ripam fluminis Magdalenae in Nova Granada captum, de quo cel. Kollar Beitr. zur Ins. Fama von Nen-Gran. und lenezuela pro metionem fecit, alas anticas latiores, margine txterno vix concavas, fere ut in Protesilae, exhibet; alac posticae ejus etiam latiores sunt, in regione anali minus porrectae, lunulis analibus ochraceis multo maxis dilatatis. Caudate hreviores sunt. Specimina e Brasilia australi in Mus. Caesareo memoratis multo ninora sunt, alae anticae eornm ninus falcatae, posticae breviores, cellula latiore et breviore, strigate earum angustiores, multo magis intel se distautes, lumulae ochraceace plerumque multo angustiores (ut in forma brasiliensi l'mtesilai). In uno specimine ejustem collectionis striga subnarginalis fusca alarum anticarmm minus arcuata et hanc ob rem a finsciula discocellulari bene remota (ut in Protesilan) et lunulate ochraceate posticarmm haul fusco 
intus limbatae, sed in fundi colorem transhuentes. Alate anticate latiores i. e. venue discuidales et rami mediani longiores apparent caudaque brevior. 91). Capnt fortiter comosum. Antennarum clava magis abrupta, obovata. Alae et cellula anticarum breviores, posticae ad costam multo magis projectae, in regione anali sat attennatae sed minus productae. Vena subcostali alarum anticarum pone ramum secundum sat arcuata sicut et basis rami ejus tertii. Ramms subcontalis primus et secundus sat approximati, primus mox post originem in venam costalem excurrèns et cum ea connatus, lace in lovo receptionis fracta. Truncus rami quarti et quinti longior, nagis deorsum directus, guam in sectionibus praecedentibus. Venula discocellularis paullulum flexilis. Rami mediani carumdem alarum multo magis deorsum directi, sub angulis ideo multu obusioribus egredientes. Cellula praecostalis alisum posticarum multo lation.

92). Antenuarum clava minus determinata, quam in antecessoribus. Frons breviter pilosa. Vena subcustal.s alarm anticarum cellulae extimum rejsus modice arcuata, ramus ejus primus et secundus valde approximati, ille cum rena costali connatus, haec vero in locu incursus haud fracta.

93). Facies Podulirii. Alae anticae sat abbreviatae, posticae in regione anali multum productae. In figura Grayi falsa videtur venae subcustalis nlarum anticarum ramificatio. Sinus ommes alarum posticarum, analibus exceptis, levissimi.

94). Facies sectionis Protesilai. Alae anticae extimo pellucidae. Vena subcustalis alarum anticarum apud originem raui secundi fere fracta. Cellula praecostalis alarum posticarum latior, quam in sectione XX. Alarum po-ticarmm sinus apicales levissmi, ut in Protesiluo.

4i.). Alae lungiores, apice magis productae, posticae in regione anali multo minus porrectae, apud costam vero multo longiores, quam in subsectione praecelente. Cellula alarum anticarum latior. Ramus subcostalis secundus earum a cellulae extimo multo longius remotus, quam in subsectione priore. Alae posticae aequaliter repando-dentatae.

96 ). Specimen in insula Borneo captum in Museo Caesareo multo majus est, quam specimina ehinensia.

${ }^{97}$ ). Alae multo angustiores, cellula quare discoidalis alarum anticarum multo angustior, quam in antecesoribus, margo internus alarnm anticarnm et costalis posticanum breviores, quam in subsectione $\mathrm{B}$ et $\mathrm{C}$, regio analis posticarum vero magis producta. Vena subcostalis apud ramum secundum a collulate extimo, ut in Antiphate, bene distantem, fere fractio.

$\left.{ }^{92}\right)$. Fitscia secunda alba praesertim in alis posticis multo angustior, limbus externus niger quare latior.

"19). Sat rari videtur haec specics. Cel. Doleschall eam haud cepit in Amboina. Museum Caesareum unicum specimen vetus incertae originis conservat.

$\left.{ }^{100}\right)$. Facies sectionis $\mathrm{X} \mathrm{X}$. Alae anticae niagna ex parte hyalinae. 
fere cjusdem formae ut in sectione dicta, sed margine interno multu breviores et apice magis productae. Antennae fere ut in P'rotesiluo, sed clava crassiore. Rami mediani alarmu anticarum magis deorsmm directi Vena subcostalis earum in nonnullis speciminibus pone ramum secundum a cellulau extimo sat recedentem vix arcuata, in aliis pone ramum hunc cellulas clausui sat approximatum fracta. Alae posticale fere ut in I'rotsilan, sed angustiores et ab omnibus praecedentibus cellula multo latiore, interstitio ramorum sulscostal um nulto magis arrecto, lraud thexili venaque discoidali ramo mediano tertio valde approximata, vemula discocullubri inferiore hanc ob rem brevissina, multo magis longitudinali discrepantes.

101). Antennae breviores, quam in sectionibus quinque anterioribus, clava plus minus abrupta, arcnata. Cellula alarm anticarum fere ut in sectionis XXI subs. D, venula autem discocellulari ut in sectione SIX et XXII, multo magis arrecta, angulus superior cellulae ideo magis promineus. Ramus subcostalis primus anticarum a secundo sat longe remotus, ut in sectione XIX. Vena discoidalis alarum posticarum ramo mediano tertio sat approximata, venula discocellularis inferior plus mius longitudinalis. Fo.ma alarum fere ut in sect. XXI subs. D

10:). Antennae graciliores. Forma et signatura alarum ut in sect. XXI. subs. D, alae posticae autem aequaliter acute repando-dentatae. Ramus secundus subcostalis anticarum cellulae clausui magis approximatus, quan in subsectionibus sequentibus.

803). Alae anticae margine interno, posticae costa breviores, quam in antecedente. Antennarum clava crassior, antennae paullo breviores.

${ }^{10 \%}$ ). Ramus subrosta is tertius alarum anticarum cellulate extimo magis approximatus. Venula discocellular's earum magis ubl qua, cellula ideo ad angulun superiorem luand prominens.

10.5). A praecedente differt alis anticis margine intemo, posticis costa multo longioribus, apice anticarum multo minus producto, cellula earum breviore, ramo subcostali prino a cellulae extimo multo magis remoto, cellula posticarmm multo longine angustiore, venula discocelhula in is longiore margineque carum profundius dentato.

$\left.{ }^{1065}\right)$. Alae multo latiores, quan in subsectionibus pracedentibus, posticae profundius dentatie, multo magis porrectae, longius cardatac, angulo apicali multo minus producto, costa convexil, venula discocellularis inferior alarum anticarum minus flexilis, posticaram cellula latior, vemula discocellularis inferior in iis longior, magis longitudinalis. Antennae rufofulvae, clava magis ab.upta.

${ }^{107}$ ). Fasciarum albo-virentium latitudo multum variat. Saepius maculis secunda sanguinea in alis posticis inter rammm medianum primum et secundum apparet.

10`). Alae anticie in apice minus productar, cellula (arum brevior; alae posticae costa longineses, reginne anali autem multo minus productae. 
quam in Marcello. Veluula discocellularis superior et inferior alarum anticarum extrorsum paullum concava. Cellula alarum posticarum multo brevior, venula discocellularis inferior minus longitudinalis, quam in subsectione priore. Caudae angustiores, breviores. Antennae rufo-fulvae, sed clava graciliore. Frons comosa.

109). Alia videtur species secundum nbservationes Dom. Dutreux. Auctor eam cum $P$. Marcello Boisd. (,Ajax" nominato) comparat, sed et in verum Ajacem L., cui certe affinior, haud omnia quadrant adnotata. Narcello.

110). Caudae longitudo variat, sed semper brevior est, quam in

111). Antennae longiores, quam in sectione antecedente, clava multo crassiore, optime abrupta, contorta, excavata. Vena subcustalis alarum anticarum pone ramum subcostalem tertium leviter arcuata. Kamus ejus tertius paullulum ante cellulae clausum emissus. Vena discocellularis earum inferior vix flexilis. Cellula alarun posticarum nulto brevior, ramus earmm medianus secundu, et tertius non multo longius inter se remoti, quam ille a vena discoidali. Alae anticae fere ut in Ajuce, posticae vero in regione anali multo magis productae, longius candatae.

112). Alate latiores, quam in sectione antecedente, anticae ad apicem magis productae. Frons comosa. Cellula alarum anticarum costae dimidium parum excedens, ramus subcostalis secundus earum cellulae extimo magis approximatus, vena primaria apud ejus originem dintincte fractia, venulia discocellularis superior et inferior extrorum sat chllavae, hatec Hexilis. Vena mediana apud ramorum origines magis fracta. Ahe posticae in regione anali valde protractae, ut subsectio A sectionis XXl, aneculo anali profunde sinuato, cauda multo breviore, quam in sectionibus antecedentibus. Cellula discoidalis earum sat abbreviati, multo latior, quam in Leosthene. Vena earmu discoidalis ramo mediano tertio valde approximata. Margo interus bene plicatus, sed minime involutus. Thorax et abdomen suprit tonuter sed dense pilosa. Valva analis marum valde acuminata. Caput minus, quam in mmibus pracedentibus. Antennae paullo breviores, quam in sectione anteriore, clava paullo angustiore.

${ }^{113}$ ). Alae maris angustiores (i. e. rami venae medianae breviores), posticae ejusdem sexus in regione anali minus porrectae, quam in l'olulirii maribus. Alae leminate antem latiores, quan in Podaliri feminis et posticae ejus non minus productae, quam il ae maris. Anticarum apex in utroque sexu magis productus et margo extermus saepe flexilior. Venula discocellularis superior alarum anticarum plenumque longior, quan in Podalirio. l'raecipue vero distinguitur haee geographica varictas ramo subeostali d!arto et quinto alarum anticarum e trunco multo breviore emissis.

11'). De lisce patriis ef. Koch Geograph. Verbreitung d. r europ. Schmett. in anderen Weltheil. p. 33 ct 11 ut tou in Transact. of the ent. soc. of London V. p. is. 
115). Protesilai africani. Dignoscuntur ab onuibus sectionibus antec.dentibus antennarum clava fortiter arcuata, alis anticis angustioribus, ramis medianis earum ideo brevioribus et nulto magis deorsum directis cellulaque praecotali alarum posticirum latiore. Cellula discoidalis alarum anticarum ut in sectione $X \mid X$, sed rami subcostales tres ultimi magis arcuati, quartus et quintus e petiolo longiore nati. Venula discocellularis superior alarum posticarum multo longior. Ramus subcostalis primus alarum anticarum ut in sectione sequente in venam costalem excurrit hancque ob causam brevissimus apparet. Margo internus alnrum posticarum optime involutus, ut in sectione $\mathrm{X} / \mathrm{X}$.

Haec sectiones antecedentes cum sequente connectit. Alie formam habent praecedentium, colorem et ignaturam rero paginae superioris sequentium sectionum Asiam solam incolentium.

116). Alalum anticarum rani mediani valde deorsum directi. Vena discoidalis superior earum infra venulae di-cocellularis medium nata. Ramus medianus primus a secundo sat remotus. Alarum posticarun ranus medianus secundus et tertins sat approximati. Costa earum sat projecta.

117\%. Alae latiores, posticae angulo apicali multo obtusiore, regione anali multo minus producta. Vena discoidalis alarum anticarum superior in medio venulae transversae oriens. liamus medianus secundus eirum a tertiu magis distans, quam a primo. C'ellula alarum posticarum multo longior, renula earum discocellularis inferior longior et ramus nedianus secundus et tertius multo magis remoti.

115. Speciem possidemus Anthei, cujus alate posticae supra strigan et fasciam in cellulae medio conlluntes ostendunt.

119). Frons dense comosa. Antennae loneriores, quam in sectione antecedente, clava multo magis determinata. Vena contalis alarum anticarum ante exitum deflexa et ramo subcostali secundo quam maxime approximata, ita ut ab hac perforata videatur. Ramus subcostalis primus abbreviatus, in venam costalem excurrens. Tiuncus rami quarti et quinti minus deorsm dircetus, brevior, rami ideo multo longiores. Alae ponticae ecaulatae vel breviter caudatae. Margo earum internus late involutus, parte involua (xtus dense pilosia, rena interna sub involucro juba compresia sat longa pilo: um tecta.

160). Alae posticat cauda breviuscula, subspathulata, anticae apice sat acuto. Vena subcostals anticarum remae costali sat approximata. Ienula discocellularis earum sat arrecta, cellulae ide reo anguln superiore magis prominulo. Vena dicosidalis inferior magis deorsum dicecta, quau rami venae medianae. kanus suberstalis quantus ot quintus sat flexiles, brevius petiolati, quan in sequentibus. Thorax haud vittatus, ut in duabus sequentibus subsectionibus.

121). Alae posticae ecaudatale rel dente ad ramum metianum tertiun caudae instar producto. Ramus subcostalis secundus alarum anticarum a 
cellulae extimo multo magis renotus, quam in Cloantho. Venula discocellularis earum magis obliqua, vena discoidalis smperior in medio ejus egrediens. Vena discoidalis inferior ramis medianis omnino parallela. Alae fascia communi, anticae maculis nullis cellularibus.

122). Fasciae latitudo variat, praesertim in speciminibus javanicis.

${ }^{123}$ ). Constanter differt haece geographica varietas a Sarpedune alis anticis multo latioribus i. e. vena discoidali inferiore ramisque medianis longioribus posticarumque regione costali et anali multo magi producta et limbo fundi colore pone fasciam in omnibus alis multo latiore. In speciminibus Au-traliae alae posticae profundiu dentatae apparent; dens apud ramum medianum tertium saepe acute prominet. In specininilus contra e Nova-Guinea septentrionali insulisque adjaccntibus (Waigiou) alae posticae levius adhuc dentatae sunt, quam in Sarpedone genuino.

124). P. (horedoni proximus, at major, fascia multo angustior, in anticis magis macularis, in posticis magis divisa, lunulae submarginales larum multo majores, multo magis angulatae, margo costalis earumdem alarum minus projectus et regio analis minus piodncta, quam in ip-o surpedone; striga lunularum submarginalis albida in pagina inteiore alarum anticarum bine conspirua.

125). Alae latiores, posticae in regione anali minus porrectae, quam in sub.ectione praecelente (rani quare mediani multo breviores), plane ecaudatae, dentibus subaequalibus. Venula discocellularis alarum posticarum multo minus arrecta, quam in subsectionibus duabus primoribus.

126). An aberratio alicujus speciei absque maculis sanguineis in alarum post carum pagina inferiore?

127). Differt ab Eurymlo secundum iconem statura minore, fancia magis maculari multo anguntiore maculs submarginalibus mu'to majorihus, sere magis fl xili digestis, macula basali coc inco notata paginae interioris alarum po-ticarum haud maginem costalem pertingente, fascia hujus paginae argentea angustiore, extus magis sinuata maculirque posticis coccineis angustioribus.

12x). Ab omnibus pracedentibus Eurypyli formis haec differt secundum iconera jam fascia multo latiose, ab Evemome insuper macula basili paginae inferioris alarum posticarum a striga basali separaca et coccineo notata. Maculae cellulares alarum anticarum et submarginales multo majores sunt. Macula fasciae anticarum inter ramum medianum secundum et tertium jacens non magis a sequente separata, quam haec a tertial, fascia banc ob rem magis macularis, et macula inter ramum medianum tertium et venam discoidalem inferiorem omnino absens.

A P. Lycane Boisd. fascia insuper alarum posticarum multo angustiore discrepat.

12:0). Vena subcostalis alarum anticarum minus arcuata, quam in anteecdente, npud ramum medianum secundum faullulum fracta, ramus ejus 
tertius ad basin multo mingis arcuatus, venula discocellularis magis arrecta, cellulae discoidalis hanc ob rem angulus superior magis prominens. Alae supra maculis in fascias digestis, subtus hand argenteo nitentibus. Alac posticae dente aul raum medianun tertium plus minus prominulo, saepius caudatae. Thorax supra indistincte birittatus.

130). Fasciae alarum posticarum latitudo multum variat.

131). Forma alarum posticarmm sat mutabilis. Specinina javanica ef malayica dentem saepissime sat latum et obtusum alasque angustiores labent. In speciminibus Indiae continentis et Philippinarum paullo longior solet, saepius in caudam distinctam transformatur.

In ceylanicis (Rambodde) alae distincte caudatae sunt. Specimina insulae Celebes omnium maxima sunt, alas sat latas habent. ut indica sed regio apicalis alarum antiearum multo magis porrecta, costa magis arcuatil et margu externus onnium profundius sinuatus et acutius dentatus. Cauda nt in indicis. Maculae virides alarm anticarum multo minores, quam in caeteris. In varietate javanica macula tertia et quarta strigae secundae alarum anticarum saepe contluunt. Museum Cacsareum specimen continet incertae originis a cel. de H ii gel lectum, quod caudam distinctam et valde dilatatam gerit. Maculae alarum ejus anticarum extra venam medianam sitae, multo latiores, tertia et quarta seriei secundae conflua. Color in Havescens parum vergens.

132). Differt a subsectione anteriore vena subcostali alarum anticarum a costali magis distante, apud rami secundi originem extimo propiorem multo minus fracta, vena discoidali inferiore multo magis deorsum directa, quam rani mediani, ramo subcostali primo a secundo multo longius distante. quam hic a tertio, tertio ad basin minus arcuato, margine costali alarum posticarum multo magis projecto, apico earum quare multu minns angulat", regione anali magis angustati.

${ }^{133}$ ). Ab omnibus praecedentibus haec discrepat statura multo robuntiore, alis posticis semper di-tincte candatis, in regione anali multum porrectis, utrinque immaculatis, cellula earum ad alae longitudinem breviore. A subsectione priore, cui proxime accedit, differt etiam rena subcostali alarum anticarum costali magis approxinsata et apud rami secundi originem magis fracta venaque discoidali inferiore ramis medianis parallelit. Cellula ei subsectionis Ayumemnonis similliua. Margo etiam costalis alarum posticarum, ut. in hac, minime projectus, sed declivis.

${ }^{134}$ ). Mas rarior vidutur, quam femina. Haec discrepat colore paginae superioris fusco, nitore aeneo-viridi carente.

13.5). Magis a Codio discrepare videtur, quan Empelorles secundum observatione, cl. De Haan l. c.

$\left.{ }^{136}\right)$. Frons valde comosa, ramus primus venae subcustalis alarum anticarum brevis, in venam costalem excurrens, ut in sectione antecedente, sod multo magis arrectus et secundo saepe quam maxime approximatus, venis subcostalis primaria pone rami primi originem sat deflexa, venula disen- 
cellularis alarum anticarum multo obliquior, quam in sectione praecedente, cellula hanc ob rem extimo superiore multo magis retracta; venula discocellularis superior alarum anticarum strictissima, inferior bene arcuata. Vena discoidalis superior infra medium venulae transversae exiens. Rami mediani earumdem alarum magis sursum directi, multo magis et aequaliter approximati. Truncus rami subcostalis quasti et quinti longior. Antennarum clava brevior, magis decisa. Rami mediani alarum posticarum ut in $P$. Codro. Alarum anticarum nargo externus magis excavatus, quam in sectione antecedente.

137). Antennae breviusculae, clava sat elongata, sed fortiter arcuata. Frons valde convexa, brevissime hirsuta. Thorax valde convexus. Abdomen longius, ut in sectionibus antecedentibus, valva anali marum sat acuminata. Alae anticae sat longae, falcatae, margo earum internus eum posticarum superans. Cellula discoidalis anticarum sat brevis, costae dimidium haud aequans, rami subcostales omnes liberi, secundus et tertius sat approximati, ante cellulae extimum assurgentes (in subsectione B), quartus et quintus longe petiolati, venula discocellularis superior perobliqua (in subsectione 13), inferior valde flexilis, extrorsum concara, rena discoidalis superior longe supra medium venulae discocellularis oriens, vena mediana a rami primi origine sur-um arcuata, rami ejus et vena discoidalis inferior paullulun arcuati. Alae posticae acute repando-dentatae, similiter ut in sectione antecedente caudatae, cellula discoidali longa (in subsectione B), medium alae transgrediente, interstitio ramorum subcostalium vix deflexo, venula discocellulari multo longiore, quam in antecedentibus affinibus. Margo intemus alarum posticarum profunde plicatus, sed liaud involutus.

13^). Alarum anticarum apex obtusus, posticarum sius anaiis sat profundus. Secundum cel. Westwoodii iconem renae etiam discrepant a sequente. Fortasse propriam constituit sectionem.

139). Alarum anticarum apex ralde productus, acuminatus, falcatus, sinus analis posticarum levissimus.

${ }^{140}$ ). Antennae clava brevi, flexili. Occiput, collare et thoracis latera inferiora grosse albo maculata. Abdomen multo gracilius, quam in praecedentibus sectionibus (post $X$ ), valva analis uasculina brevis. Venae ut in subs. D sectionis XXVIl, venula discocellularis alarum anticarum vero multo strictior, a ramo suhcostali tertio haud distans, inferior multo longior et minu, arrecta, ramus medianus secundus et tertius magis inter se remoti. Margo internus alarum posticarum hand dilatatus, marum involutus, jubam pilorum seri ceorum apud venam internam tegens, feminarum plicatus solum. Alae bene ciliatae, latiores, quam in Ayrememne, anticae plus minus falcatae, margine interno longiore, posticae aequaliter repando dentatie, apud ramum medianm tertium plus minus angulatae, dente boc prominulo.

141). Diffirt a Pylude statura minore, alis anticis apice minus productis, fascia earum interna giba nunquam ultra ramum medianum secundum 
extensa alisque posticis angustioribus, multo levius dentatis et minus angulatis. Specimen in collectione nostra, fortasse cx Africa occidentali, maculas duas cellulares in alis anticis ostendit, juxta venam medianam fasciae internae adnatas, ut in Pulade et in pagina inferiore maculam ad originem rami mediani secundi. P. Anthomenis Wallengr. duo specimina typiea cel. Boheman benigne nobis communicavit.

142). A praecedente sectione haec differt statura multo robustiore, antemis longioribus, clava subovata, leviter areuata instructis, fronte haud albo bivittata, sed bimaculata, longius pilosa, capite punctis minutis albis ornato, abdomine longiore, vitta sericque macularum ochraceo-albis apud latera, valva anali marum multo magis acuminata, longe pilosa, margine interno alarum posticarum infra apud venam intermam densits hirsuto, alis anticis magis elongatis, posticis multo magis abbreriatis, ramo subcostali primo alarum anticarum (aeque in renam costalem excurrente) longiore, vena earum discocellulari magis obliqua, rena discoidali superiore infra cjus medium emissa, ramis duobus ultimis subcostalibus brevius petiolatis posticarumque trunco subcostali breviore.

${ }^{1}{ }^{43}$ ). Alae sat latae, anticae margine externo bene excarato, posticae leviter dentatae.

144). Valde similis Leoniulae, sed diversa maculis alarum anticarum minoribus, paucioribus, albido tinctis, alis posticis longioribus (i. e. ramis medianis renaque discoidali Iongioribus), maculis earum magis a margine distantibus.

Figura in cl. Grayi Catalogo aberrationem sistit, in cujus alis posticis maculae posteriores biseriatae desunt.

Figura Crameriana Leonidae falsa videtur. Ceilula alarum posticarum nimis lata et renae posticae nimis longae.

${ }^{145}$ ). Alae anticae secundum iconem multo magis productae, extus vix concavae.

1'ti). Praecedenti sectioni certe valde affinis, sed secundum iconem Druryi jam abdomine alas posticas superante, collari valde cxserto, antennarum clava multo minus detcrminata, alirum firma et statura robustissima discrepans. Cum Omithoteris nullau artiorem labet affinitatem. Caput et thorax dilute punctata jam longe ab iis miram lane spe(iem removent.

${ }^{147}$ ). Sequenti sectioni proxima, sed antennae breviores et abdonen longius. Juba apud venam internan longior.

14y). Antennac sit breves, clavia bene determinata areuatia, sed longiore, quam in sectione XXXY. Ablomen brevius, vitta lata laterali ochraceo-allsa, ralva analis marum latior et obtusior. Cellula anticarum latior, venula discocellularis carum magis ohliquat, vena discoidalis superion

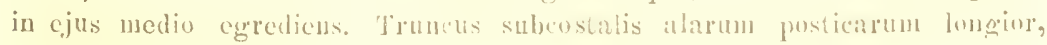
interstitium ramorum subcostalium hanc ob causan brerius, venula disco- 
cellularis inferior sublongitudinalis. Plicae cellulares omuium alarum coloratac. Alale anticae apice multo magis porrectae, posticae multo longiores, quam in sectione $\mathrm{XXXV}$, cellula carum vero brevior, medium alac laad excedens.

14"). Facile differt a praecedentibus antennarum clara tenui, male determinata. Alarum forma fere ut in sectione XXXV, sed alae posticae subintegerrimae, longiores. Abdomen brevius, lateraliter fasciolatum, marginis interni alarum posticarum dimidium parum superans. Venula discocellularis alarum anticarum magis fracta, truncus subcostalis posticarmm multo longior, cellula praceostalis enrum multo major. Statura gracilior. Picare cellulares alarm posticarum subtus coloratae.

151). Antennae ut in sectione anteriore, a qua dignoscitur haec abdomine lateraliter vittato, alis anticis multo latioribus (i. c. ramis medianis et rena discoidali inferiore longioribus), vena earum subcostali pone rami secundi uriginem minus arcuata, renula discocellulari (praesertim superiore) multo whliquiore, multo magis fracta, venula discocellulari inferiore plus minus convexa, cellula discoidali posticarum valde angustata, ramo subcostali primo basi alae multo magis approximato, interstitio ramorum subcostalium ideo multo longiore. Alae inter renas longitudinaliter striatae, pusticarmo cellula striga transversi a ramo subcostali primo ad ramum medianum tertium ducta.

1:1). Alia videtur species. Discrepat a $P$. Delessertii secundum hujus iconem alis posticis multo angustius vittatis, striga cellulari multo minus expressa, vittulis limbi postici multo magis interruptis, ita ut series submarginalis macularum quatuor perangustarum formetur.

152). Nullo modo varietas Macarei. Alase anticae apice multo magis prodactae, posticae in regione postica multo breviores, striga cellulari earum supra oblitterita.

15:3). Antennarum clava longior, quam in sectione antecedente, optime arcuata. Aldomen multo longius, pallo brevius, quam margo internus alarum posticarum, seriebus duabus latcralibus totidemque ventralibus albis, plus minus distinctis. Valva analis marum multo magis acuminata. Ramus subcostalis primus alarum anticarum omnino liber, secundus a cellulae extimo multo magis recedens, vena primaria apud ejus originem magis fracta, truncus rami subcostalis quarti et quinti brevior. Venula discocellularis apul venae discoidalis originem multo magis fracta. Tena mediana multo magis sursum flexa, ramus tertius et vena discojdalis inferior distincte aruati. Alarum pusticarum cellula latior, propter venulam discocollularem superiorem multo longioren, alae medium in plurimis vix attingens. Margo interms alarum posticarum in maribus bene plicatus, sed hand involutus. l'rous cappit is in plurimis brevissime pilosa. Rami subcostalis tertii alarmu anticarmu positio mutabilis saepe in una eademque specie; mox paullulum ante, mox fone collulae (lausum oritur. In (o)loribus et signaturis magna 
cum Danaidis quibusdam similitudo, e. g. P. paradorus cum Ëploea Midamo L., Palephates cum Euploee Su'ainsonii eandem regionem incolente, Panne cum Euploca Core ete. Species antecedentiun ruatuor sectionum magis genera "Danais" et "Hestic" in colore et signaturis revocant.

154). Minime mas Panopes, ut anglici auctores putarunt. Feminas et mares utriusque speciei in collectione habemus. lemina hujus maculas albas radiiformes latiores et magis diffusas habet, quam mas. $\Lambda l^{\prime}$. P'conofe non solum colore et signaturis, sed etiam forma alarum ista species recedit. Alac enim posticate in regione anali distincte longiores sunt, rami mediani et rena discoidalis ideo longiores. Ramus subcostalis primus alarum posticarum a basi magis distat et interstitium a ramo secundo longius est, qua res ambos ramos breviores efficit. Venula discocellularis superior alarum anticarum in P. Panope saepissime multo magis arrecta, et multo brevior apparet.

155). Minor, alae breviores, anticae apice minus productac, maculis latioribus, posticae maculis sagittatis brevioribus lunulisque submarginalibus minoribus, magis transversis.

156). Specimina a cel. Bar. de Ḧ̈gel in montibus IImalaya (Masuri) lecta minora sunt, saturatias colorata, maculae marginales flavidae paginac inferioris minores, lunulae sulmmarginales levins cxcavatae, maculae sigittatae plerumque breviores et a lumulis magis distantes.

${ }^{157}$ ). Species indubitanda et nullo modo forma Punopes. Jam alarum discrepat forma, ei $P$. parculoxi similiore.

${ }^{154}$ ). Cel. II ewitson 1. c. Telearchum etiam sum reducit. Halec forma secundum iconem in signaturis Telourcho similior est, in lorma alarum rero $I^{\prime}$. paradoro. Femina valde mutabilis videtur. Fig. 21. c. magnam cum Euploca Midamo O habet analogiam, fig. \& t. 66 similis est Euploene Melinae Cram. et Climenae Cram.

15!). Caput minus et abdomen brevins, quam in sectione $P$. discimilis. Alae multo angustiores. Cellula discoidalis anticarum multo longior, costae bitrientem atequans. Tena subcostalis eartm pone ramum secundum cellulace extimo multo magis approximatum distincte fracta sed multo minus deflexa, ramus ejus tertius magis areuatus, quartus et quintus e petiolo longiure wati, venula discocellularis fortiter fracta, inferior multo magis obliqua (introrsum directa), rami mediani multo breviores, quan in sectinne dicta, aequaliter inter se distantes, duo primores sat deflexi, margo externus quare multo obliquior, margo internus brevior quam in posticis. Alace posticae multo breviores, quan in sectione XXXVII, feviter sinuatice, cellula discoidali multo latiore, suburata, plicis duabus coloratis divisa, medium alie superante, trunco subeostali lomgo, strictissimo, ramo subcostali primo parum arcuato, bane ob rem paullulum pone nediun alac oriente, interstitio ramorum subeostalium multo breviore ot obliquiore, reunla discocellulari superiore, multo magis arrecta, inleriore nagis longitadinali, rena discoidali et ramis modianis magris distantibus. Abdonien firsciolatum. 
$\left.{ }^{160}\right)$. Antennae sat robustae, clava elongata, arcuata. Occiput flavido quadrimaculatum. Ab eo juxta scapulas duae vittae flavescentes currunt. Abdomen brevius, quam in sectione paenultima, supra cum thorace dense sulphureo aspersum, vitta lata laterali, striga infra eam vittaque angustiore ventrali ochraceis. Valva analis marum multo latior, sed etiam obtusior, quam in sectione $P$. dissimilis. Thorax subtus fasciis latis oclraceis, cum iis alarum contiguis. Alae anticae multo minus elongatae, vena subcostalis earusn pone rami secundi originem sat arcuata, sed non fracta. Venula discocellularis sat conrexa, distincte fracta, in medio venam discoidalem superiorem emittens. Ramus medianus tertius et vena discoidalis inferjor multo longiores, quam in sectionibus septem anterioribus. Alarum posticarum cellula absque plicis coloratis, fere ut in sectione pracedente formata, sed vena subcostalis apud originem rami primi multo magis fracta, lic ipse a basi alae minus remotus, interstitium ramorum subcostalium paullulum deflexum, vena mediana minus deorsum flexa. Sinus analis bene distinctus. Macula magna analis ocellata.

Hic Metheonis affines incipiunt.

$\left.{ }^{161}\right)$. Alae posticae sinulito-dentatae, dente ad ramum medianum tertium prominulo. Cellula alarum posticarum medium alae non attingens.

${ }^{162}$ ). Cf. II utton Transact. of tlue ent. Soc. T. p. 48.

$\left.{ }^{163}\right)$. Alae posticae levius dentatac, subrotundatae. Cellula earum diseoidalis angustior, usque ad medium alae extensa, truncus subcostalis brevior et interstitium ramorum subcostalium multo longius. Margo costalis earum longior, quam in Demoleo, regio analis rero multo minus producta (i. e. vena costalis longior et rami renae medianae venaque interna breviures).

16t). Antenua sat graciles, in claram elongatam, arcuatam sensim transcuntes, abdomen multo brevius, gracilius, quam in sectione praccedente. Valya analis masculina angustior et multo obtusior, remula discocellularis alarum anticarum superior multo magis arrecta, cellulae hanc ob rem angulo superiore unagis producto, quam in sectione priore. Vena subcostalis prinaria pone rani secundi originem minus arcuata. Alae posticae semper caudatae, jnterstitio ramorum subcostalium strictiore, cellula discoidali alate medium haud pertingente. Alae posticae leviter sinuatodentatae, lunulis in sinnbus marginis plus minus dilatatis. Cauda immaculata, plus minus lancoolata. Antenmarum clara ommino nigra. Oceiput et collare maculis rufis vel flaridis. Abdomen unicolor.

16.3). Collare longius, quam in sectione priore, cui valde affinis. Alao posticae acute repando-dentatac, longius candatae, cauda subaequilata, sat longa rel dilatata, subspathulata, sinu anali profundiore. Antennarum clava plus quam dimidio basali fulrescente. Vittae duae angustae, voluracollarae juxta scapulas ultra fronten ductae. Abdomen lateribus rentreque ochraceis. Ramus guatus et fuintus subcostalis alarum anticarum longius 
petiolati, quam in sectione praecedente. Margo internus alarum posticarum multo magis excisus (i. e. spatium post plicam internam nulto angustius). Alae posticae maculis submarginalibus.

166). Antennarum clava longior, quam in sectione antecedente, nigra. Alae anticae multo longiores, ramus subcostalis primus earum a cellulice extimo multo longius remotus, ramus quartus et quintus e petiolo multo breviore emissi, vena discoidalis superior supra renulae discocellularis medium nata, inferior et ramus medianus secundus et tertius paullulum arcuati, ramus medianus primus et secundus sat deorsun directi, ferc omnino paralleli. Alae posticae multo breviores, quam in sectione anteriore, ce'lula discoidali multo latiore, rena subcostali apud rami primi originem magis fracta. Maculae lunulatae in earum margine ipso. Margo abdominalis alarum posticarum multo latior, quam in praecedente. Corpus subtus totum ochraceo-flarum. Sexus concolores.

167). Collectio Mrusei Caesarei Viennensis specimen continet a cl. Ida Pfeiffer in Andibus Perurianis lectum.

${ }^{163}$ ). Certe propria species, minime cum sequente confundenda. Multa specimina utriusque compararimus. Constanter differt a Thocule fascia alarum anticarum multo obliquiore (cf. Cramer Uitl. Cap. II. p. 109) et margine earum nigro in pagina superiore pellucente latiore. Cel. Ménétriés (Enum. Corp. Anim. Mus. Petropol. p. 111), sicut et Cramerus, formam Americae septentrionalis et insularum ante se labuit. Speeimina Americae septentrionalis alas latiores, anticas multo minus productas labent. Ea Indiae occidentalis ab his discrepant serie submarginali unaculari alarum anticarum paginae superioris maculis tribus aucta. Proxima veniunt specimina mexicana, quae omnium minima sunt. Specimina columbica a pritecedentibus differunt alis angustioribus, anticis apice multo magis productis, posticis longius caudatis, fascia anticarum magis maculari maculaque distincta semper in earum cellula apparente. His accedunt surinamica et cayennensia, sel statura majore, fiscia multo latiore (ut in Thocule), candis longioribus maculaque cellulari alarm anticarum obsoleta dignoscuntur. Brasiliensia ab lis discrepant fascia alarum anticarum angustiore, macula cjus tertia a fundi colore multo magis perforata maculacque cellulari omnino ubsente (in femina saepius macula minuta in cellula apraret). NI sseum Caesareum specimen continct formac brasiliensi proxime acedens, sed alis anticis angustioribus, pusticis in regione costali brevioribus, in regione anali multo magis porrectis lisciaque superna multo angustiore diversum. Specimen in collectione nostra bogotanum maculam fundi colore in macula tertia fasciac supernae alarum anticarum obsoletan liabet.

Aberatio formac mexicane coloren ochraceum subtus pracdominantem ostendit, anticarum maculas exterioses a maculis subuarginalibus linea tenui irregulari nigra separatas, lunulas grisescutes alarum po.ti- 
carum multo angustius nigro cinctas marginemque externum nigrum a lunulis sinumn interruptum.

$\left.{ }^{164}\right)$. Specimina duo surinamica ante oculos habenus, quormm alae anticae maculam fuscam in macula tertia fasciae ostendunt, fere ut in Cresphonte. Siuul a macula inter ramum subcostalem tertium et quartum ad bases eorum jacente paucissimi tantum relicti sunt atorui, vix conspicui. Nihilominus primo intuitu dignoscuntur haece specimina a $P$. Cresphonto Cram. ab omnibus auctoribus sequentibus lucusque cum Thoade confu:o. Nondun certi sumus, utrum juxta occurrant hae species an diversas incolant regiones.

171). Specimen in collectione nostra a Balianis speciminibus differt statura majore, fascia discali alarum anticarum minus obliqua, margini subparallela, maculis quatuor ochraceis atomariis in limbo postico apparentibus, alis posticis angulo apicali minus projectis et in regione anali magis productis longiusque caudatis.

171). Frons magis comosa, quam in sectione antecedente. Antennae longiores, clara earum multo gracilior, acutior. Abdomen longius et multo gracilius, in mare fascia laterali anglustiore, in femina striga tantum ornatum. Valva analis marum fusca, acutior. Venula discocelhularis alarum anticarum longior, superior magis obliqua, vera discoidalis inferior et rami mediani earum strictissimi, prinus magis deorsum directus. Cellula alarum posticarum angustior, vena subcostalis minus fracta. Thorax subtus ochraceo fasciatus. Alae anticae multo obtusiores. Sexus in coloribus, signaturis et forma alarum posticarum diversissimi.

172). Alac posticae sinuato-dentatae, dentibus obtusis, in mare cauda sat lata, subspathulata, in femina cauda multo angustiore. Femina is sectionis quartace similis.

17.3). Mas etiam certe differt a Torquato typico. Feminas solas in collectione habemus.

174). Multa specimina collectio Musei Caesarei servat. A P. Torqualo surinamensi, eni simillimi, constanter discrepant alis anticis cellulaque earum latioribus, apice mimus porrectis, fascia alarum posticarum multo latiore, supri cellulam fore totan occupante, limbo fundi fusci earum quare anguntiore caudisque longioribus.

17.5). Alace posticae profunde repando-dentatae, in regione anali multo magis productae, cauda sat longa, fere acquilati, dente ad ramum medianum secmdun caudaformi. Femina sertionem I'. Aque revorat.

126i). Ablomen robustius, quam in priore, ut in sectione XLII coloratum. Ramus subcostalis primus et secundus alarum anticarum longius a "elfulace extino distantes, quartus et quintus trunco breviore emissi. Vena discoidalis inferior, ramus medianus secundus et tertius distincte arrati, ramus medianus primus secundo parallelus, apice deflexus, omnes multo 
longiores, quam in sectione XLH. Venula discocellularis carumdem alarum magis fracta. Sexus in coloribus et signaturis ralde diversi.

${ }^{177}$ ). Cellula discoidalis alarum anticarmu in pluribus sat angustata. Vena mediana carum stricta. Alae posticae iis sectionis XLII conformes.

$\left.{ }^{179}\right)$. Alae anticae longiores, apice magis producto, posticae in regione antica longiores, in regione anali autem haud productae. Vena mediana alarum anticarum paullum sursum flexa. Truncus subcostalis alarum posticarum multo brevior, interstitium ramorum subcostalinm deflexum. Alae posticae profunde repando-dentatae, dentibus acutissiruis, cauda lerangusta. Statura multo robustior. Femina in duabus formis.

$\left.{ }^{179}\right)$. Collare supra et thorax subtus rubro maculata. Abdomen fuscum, maculis basalibus rubricantibus. Alae anticae angustiores et breviores, posticae in regione anali plus minus productae, repando-dentatae, saepissime ecaudatae et dentibus obtusis, venula discocellulari inferiore breviore, quan interstitium rami mediani secundi et tertii. Sexus conformes. Ficies sectionis $\mathrm{X}$ et affinium.

${ }^{130}$ ). Duo specimina Dom. Lindig ex Andibus bogotanis reportavit. A boliviensi apud cl. Gray illustrato discrepant maculis tribus alarum posticarum cellulae multo magis approximatis, prima integra, dente ad ramum medianum tertium sito longiore. In uno specimine supra in alis posticis macula subapicalis infra venam costalem ochraceo-alba obserratur. Cauda hujus longior et multo angustior. In pagina inferiore alarum anticarum maculae duae atomariae grisescentes inter ramos medianos totidemque apud angulum internum conspiciuntur. Maculae tres primores alarum posticarum et maculae anales grossae. In altero specimine alae anticae supra in disco maculas duas atomarias ochraceas habent, primam in cellula, secundam inter ramum medianum secundum et tertium. In codem maculao tres alarum posticarum latiores sunt et cellulam attingunt. Ante maculam priman atoni concolores apparent. Pagina inferior alarum anticarum fasciolam discalem irregularem tripartitam griseo-ochraceam praebet.

[3I). Antennae in clavam angustam sensim incrassatae, basi excepta, ochraceo coloratae. Caput et collare albo naculata. Thorax maculis duabus ochraceis scapularibus strigaque dorsali concolore, subtus fasciis tribus lateralibus ochraceis. Abdomen alas posticas subaequans, robustum, fisciis lateralibus perlatis in regione ventrali postica plus minus confluis. Alate elongatae, colore et signaturis IIeliconionem et Deneiderem quarumdau. Alae anticae margine interno jubato-pilosae, cellula discoidali lata, dimidium alae aequante, vena subcostali modice arcuata, ramo ejus tertio ante ccllulae extimum egrediente, vena primaria pone illius originem paullum fracta, ut in sectione I, ramo quarto et quinto petiolo longo emissis, venula discocellulari fortiter fracta, superiore strictissima, sat obliçua, inferiore longiore, paullulum arcuata, vena discoidali et ramo mediano nltimo bene remoto paullulum areuatis, ramis medianis inter se fere aequi- 
distantibus. Alac posticae leviter sinuato-dentatae, in regione anali abbreviatae, angulo apicali vix ullo, margine interno (marum) dilatato, apud renam internam dense et longe nigro jubato-piloso, spatio circa venam medianam supra breviter sed dense flavo piloso, vena costali a costa sat longe distante, cellula discoidali ultra medium alae extensa, venula discocellulari inferiore et interstitio rami mcdiani sccundi et tertii magis longitudinalibus, quam in sectionibus praecedentibus.

192) Antennae nulto validiores, quam in praecedentibus. Thorax et abdomen alaruu posticarum marginem internum plus minusve superans robusta, omnino nigra. Costa alarum anticarum serrata. Alae anticae apice acutiores, multo latiores, quam in sectione priore, margine externo distincte concaro, posticae repando-dentatae, in plurimis specicbus sat productae. Venaruu distributio fere ut in sectione antecedente, cellula discoidalis anticarum autem angustior, vena subcostalis pone rami secundi originem multo minus arcuata, ramus tertius a cellulae extimo emissus. Cellula discoidalis posticarum latior, alae medium haud superans, venula discocellularis inferior multo magis sursum directa. Alac posticae costa sat arcuata, angulo apicali quare nullo.

${ }^{183}$ ). Alae posticae dente ad ramum medianum tertium solo prominente. Ramus subcostalis tertius alarum anticarum in plurimis interstitio brevissimo obliquo a cellulae extimo separatus.

${ }^{184}$ ). Permulta specimina ante nos habemus, a Dom. Lindig in Andibus Bogotensibus lecta et a $P$. Cleote Gray alis anticis apice multo minus productis, fascia maculari earum fere semicirculari, alis posticis longioribus fasciacque earum maculis confluentibus constanter discrepantia. Saepius fascia alarum posticarum in cellulae apicem se extendit. Petiolus rami subcostalis quarti et quinti alarum anticarum brevior, quam in Cleota et Lycorta.

$\left.{ }^{135}\right)$. Alae posticae dentibus duobus prominentibus caudacformibus, angulo anali acute producto, ramus subcostalis tertius alarum anticarum paullulum pone cellulae clausum oriens.

156). Alac posticae caudatae, cauda angusta, ad basin paullulum attenuata, dente ad rasuum medianum secuudum caudaeformi, angulo anali dentem acutum introrsum directum sistente. Frons capitis sat comosa. Costa alarum posticarum minus decliva.

${ }^{137}$ ). Valde affinis sectioni praecedenti, sed margine costali alarum anticarum land serrato, alis posticis subspathulato candatis, angulato dentatis anguloque earum apicali distincto facile diversa.

${ }^{1 \times x}$ ). Diflert a sectione anteriore statura minus robusta, antennis paullo brevioribus, clava carum crassiore, collari minus exserto, capite thoraceque supra flavido bivittatis, hoc subtus flavido fasciato, abdomine marginis intorni alarum posticarum dimidium haud attingente, vittis duabus lateralibus unaque ventrali flavidis ornato, valva anali masculina maxima 
ex parte flarescente, alis anticis acutis, cellula carum longiore angustiore, vena mediana minus sursum flexa, rano ejus primo et secundo longius inter se distantibus, quam secundus et tertios, alis posticis multo magis excisis i. e. margine abdominali multo angustiore, vena interna parce pilosa, cellula discoidali breviore et multo latiore, ramo enim subcostali primo a basi alae multo longius remoto, secundo sat approximato, interstitio eorum multo magis arrecto, renula discocellulari superiore multo longiore, inferiore autem multo breviore ramisque medianis duobus ultimis magis approxiuatis.

$\left.{ }^{139}\right)$. Venula discocellularis alarum anticarum et forma posticarum fere ut in sectione XLVIII.

19or). Ninime femina $P$. Dauni, ut Dom. Teidemeyer Proce of the ent. Soc. of Philad. Vol. I p. 149 putarit. Furma alarum jam plane diversil. Plures feminas Dami in collectione habemus; discrepant in maribus alis latioribus et saturatius coloratis anticarumque margine externo recto. Truncus subcostalis alarum posticarum multo brevior est, quam in Dauno.

191). Cellula discoidalis alarum anticarum angustior, quam in praccedente, renula discocellularis superior brevior et magis obliqua. Alace posticae ad costam longiores, in regione amali magis porrectac, multo lerius dentatae, dente ad ramum medianum secundum reliquis conformi, angulo anali lobum rotundatum sistente, ramis subcostalibus sat arcuatis, primo venae costali fere omnino parallelo.

${ }^{192}$ ). Species ralde dubia, in hanc sectionem secundum iconem certe pertinens, sed nimis diversa a Tumo, ut cum eo conjungi posset.

${ }^{193}$ ). Forma alarum jam facile distincta a Tumo. Femina primo intuitu ei 1 . Dueni sat similis apparet.

19'). Signaturae flarae restigia specimina nostra distincte praebent.

19.5). Frons magis comosa, quam in sectione antecedente. Antennae clara sat crassa et longa, recta, subtus fortiter impressa, dimjlio fere apicali ochraceo colorato. Valra analis marum brevior et latior, fuseo coloratia. Alae multo breviores, anticac angustiores, venae carum fere ut in subsectione A prioris sectionis, ramo autem subcostali primo ccllulae extimo magis approximato et secundo quam maxime inter se approximatis, fere appressis, paullum deflexis. Alae posticae costa multo magis decliva, rena costali ideo breviore, cum ramo subcostali primo haud parallela sed fortiter cum ea convergente, cellula multo angustiore, alae medium pertingente, vena subcostali nulto minus fracta, ramo primo basi multo magis approximato, interstitio ejus et socundi paullum deflexo, multo magis longitudinali. Sinus analis levior, margo analis inter caudam et ramum medianum primum integerrinus.

196). Antennarum clava bene abrupta, multo crassior, quan in scctione XLIX, semper arcuata. Abdomen ut in sectione $I$, sed ralva analis masculina longior, acutior. Nlae et cellulac earum longiores, quam in sectione 
dicta, anticae venula discocellulari obliquiore, cellulae hac ex causa angulı superiore haud prominente, ramis duobus primoribus renae subcostalis distincte separatis, secundo a cellulae extimo magis remoto; ramis medianis longioribus. Alae posticae multo levius dentatae, costa multo ninus decliva, vena costali quare ramo primo subcostali subparallela, vena subcostali multo magis fracta.

$\left.{ }^{197}\right)$. Antennarum clava longior et angustior, quam in sequentibus, minus arcuata, supra plus quam dimidio basali albido. Collare magis exsertum. Valva analis masculina obtusior. Alae anticae angustiores (i. e. ranus medianus secundus et tertius brevior). Ramus nedianus primus sat arcuatus. Alae posticae venula discocellulari superiore magis obliqua i. e. angulo ad rami subcostalis secundi originem obtusiore.

19я). Cf. Ménétriés in Schrenck's Reisen im Amurlande II. 1. Lep. p. 11.

Specimen masculinum aberrans in collectione nostra ordinariis multo minus est, maculae vittaeformes ochraceac multo longiores, limbus niger hanc ob rem multo angustior fasciaque nigra irregularis externa paginae inferioris alarum posticarum valde angustata. An transitus ad Xuthulum?

1!19) Antennarum clava brevior et crassior, quam in sequentibus. Abdomen brevius. Alae anticae breviores, cellula earum brevior, posticae levissime sinuatae, ecaudatae, caudae instar dente acuto ad rami mediani tertii extinum, cellula discoidalis earum brevior venaque subcostalis apud rami primi originem magis fracta, truncus ejus plerumque brevior, quam interstitium ramorum. Venula discocellularis alarum anticarum paullo obliquior, quam in sequente.

2100). Rami duo subcostales primores alarum anticarum sat approximati, venula discocellularis superior earum sat obliqua. Thorax vittis duabus flavis ultra frontem ductis. Abdomen vittis perlatis lateralibus flaris.

201). Duas feminas e Japonia accepimus. Differt a Machaone statura multo majore, fascia superna multo angustiore, pallidiore, alis angustioribus, anticis apice, posticis costa brevioribus, in regione anali multo magis porrectis, longius caudatis, maculis submarginalibus minus distinetis, macula anali a lunula atomaria caerulea optime separata, obscurius colorata, fascia maculari nigra paginae inferioris alarum posticarum multo latiore, distinctiore, lunulis atomariis caeruleis apud eas multo latioribus, in medium fere macularum nigrarum positis, extus multo minus ab atomis sulplureis limitatis, fascia submarginali paginae inferioris increscente. Petiolus rami subcostalis quarti et quinti alarum anticarum longior, quam in Machaone et cellula discoidalis omnium alarum longior.

2012). Sphyrus Lederer Verhandl. d. zool. bot. Ges. zu Wien 18:32 p. 28 aberratio Machaonis typici est. In icone Hübneriana Sphyri macula tertia alarum anticarum (inter venam subcostalem et discoidalem superiorem) nullam maculam nigran includit. 
203). Spleyro valde similis, sed discrepans alis adhuc brevioribus posticisque in regione anali magis productis. Specimen masculinum in collectione habemus incertac originis, quod candas valde abbreviatas gerit, fascias supernas in fu'vescentem colorem vergentes, alas anticas apice multo latiores et minus productas, margine externo rectas et pusticas levissime sinuatodentatas (levius quidem, quam in Mospitone).

${ }^{20}$ ). Minime varietas $P$. Machuonis, ut Dom. Weidemeyer Proc. of the ent. Soc. of Philad. Vol. I. p. 149 voluit. $\Lambda$ bdominis color jam diversus, vitta ventralis ochracea enin abest et valva analis nigra apparet. Alarum forma aliena. Cellula alarum posticarum angustior.

De distributione geographica cf. Weidemeyer l. c. p. 148. Dom. Koch Geogr. Verbreitg. der europ. Schmett. in and. Welttheilen p. 3' speciminis Machaonis ad fl. Missuri capti mentionem facit. Fortasse ad hano speciem referendum est.

20.5). Clava antennarum paullo angustior, quam in subsectione anteriore. Venula discocellularis alarum anticarum obliquior. Ramus subcostalis quartus et quintus e petiolo multo longiore emissi. Rami mediani earum deflexi, secundus et tertius ad basin magis convergentes. Alae posticae saepe brevissime caudatae, venula discocellulari superiore, ut in subsectione $\Lambda$, multo obliquiore, quam in subsectione praceedente. Occiput flavo hinaculatum. Thorax fasciolis binis scapularibus tlavis. Abdomen maculis lateralibus rotundatis biseriatis concoloribus.

$\left.{ }^{206}\right)$. Rami duo primores subcostales alarum anticarum sat longe inter se distantes, vena subcostalis primaria apud rami secundi originem distincte fracta, ramus quartus et quintus e petiolo paullo breviore nati, quam in subsectione priore. Occiput et thorax maculis duabus flavis, hic subtus immaculatus. Abdomen maculis lateralibus rotundatis biseriatis ochraceis. Cellula alarum posticarum, ut in Machaone.

$\left.{ }^{207}\right)$. Specimina insularia fascian macularem habent latiorem. Museum Caesareum aberrationem maris continet fascia alarum posticarum unulto latiore, et alteram serie interiore macularum flavescentium in alis anticis nulla, in posticis obsoleta.

203). Antennae graciliores, quam in sectione praecedente, clava arcuata, sed multo ancustiore. Alac latiores, anticae vena subcostali magis arcuata, venula discocellulari superiore obliquiore. lami mediani ut in Asteria. Alae posticae leviter siluato-dentatae, subspathulito caudatae, margine anali inter ramos medianos distincte bisinuato.

${ }^{203}$ ). Antennae gracillimae, in clavam tenuem acutam submucronatam excurrentes. Caput flavido bipunctatum. Occiput maculis duabus grossis flavidis. Collare supra maculis totidem concoloribus, subtus ad latera antica flavidum. Thorax subtus maculis humeralibus flavidis. Abdomen maculis lateralibus cingularibus serieque duplici macularum ventralium ochraceis. Valva analis masculina multo brovior, quan in pracecedente. 
210). Simillimus Troilo et ab omnibus auctoribus cum eo confusus, at constanter discrepans statura minore, cellula discoidali alarum anticarmu longiore et multo angustiore, costa alarum posticarum longiore, minus decliva, cellula earum angustiore, venula discocellulari inferiore breviore, plaga atomaria grisea in earum pagina superiore fere usque ad lunulas submarginales extensa, maculis atomariis plumbeis in harum loco subtus apparentibus fere totum intervallum inter maculas extracellulares et submarginales implentibus. Regio tota postica in plurimis speciminibus minus porrecta est (i. e. vena discoidalis et rami mediani multo breviores sunt). Nescimus, utrum forma geographica sit an juxta sequentem proveniat. Observari debet analogia cum $P$. Philenore $\mathrm{L}$. eandem terram incolente.

211). Figura Crameriana bene diversitatem a praecedente demonstrat. Cellula alarum anticarum ut in P'ulemerte. Fascia posticarum magis distincta. Quam specicu Linnaeum sub Troilo suo intellexisse, nescimus, hanc ob rem ch. Batesii exemplum: Journal of Entom. 1861 p. 239 (C. Eulule) secuti sumus.

213). Antennae multo crassiores, fulvescentes. Alae latiores, anticae vena mediana magis sursum flexa. Thorax vittis duabus flavidis, ultra caput et pectus extensis. Abdomen vittis duabus lateralibus, per valvau analem ductis, luac valde elongata.

213). Antenuae longiores, quam in sectione antecedente, gracillimac, clava adhuc angustiore, quam in Troilo. Thorax supra vittis duabus male distinctis, sulphureis, subtus ochrace fasciatus. Ablomen gracilius, quau in sectione priore, valya anali latiore, ochrace quadrifasciata. Alae anticae angustiores, apice magis productae, in mare supra a margine interno ultra ramum medianum tertiun areolis antice lunatim excisis, longitudine increscentibus, lomentosis tectae, vena subcostalis earum minus arcuata, ramus tertius ejus multo magis arcuatus, vena mediana leviter sursum flexa. Alae posticae cauda spathulata, costa multo breviore, quam in sectione prore, angulo apricali vix distincto, trunco subcostali longiore, vena ad origines ranorun duorum magis fracta, venula discocellulari multo magis arrecta, praestim superiore. Thorax, abdomen, cellularum discodalium forma, color (ct signaturite multum I'. Demoleum revocant, a quo sectio latec antennis jan longe discedit.

21'). Autemane multo validiores, quam in praecedente. Caput et collare albido prunctata. Thorax niger. Abdomen robustius, valva anali masculina breviore, sed multe latiore. Vena subcostalis alarum anticarum magis arcuati, discuilalis superior infra mediun venulae discocellularis exiens, rani mediani multo magis sursum directi. Truncus subcostalis alarum postirarmu brevior, renula earum discocellularis inlerior magis arrecta, quan in Hemesthen. Margo, internus carum leviter plicatus, in utroque sexu subplanus.

21.5). Alae posticae ad ramum mediannu tertinm brevissime caudatae wel regione tota anali lobi instar producta. 
${ }^{216}$ ). Facile differt a Nireo cellulis discoidalibus alarum distincte angustioribus anticarumque rena subcostali minus arcuata.

217). Alae canda distincta subspathulatid. An melius sequenti sectioni adjungenda?

${ }^{215}$ ). Antennae (in omnibus?) graciliores adhuc, quam in Menesthro. Caput et thorax supra flavido punctata, lic subtus fulvo fasciatus. Abdomen sat gracile, valva anali valde elongata. Truncus subcostalis alarum posticarum longior, venula discocellularis inferior multo minus arrecta. Ramus subcostalis quartus et quintus anticarmm longius petiolati. Ramus medianus primus earumdem ad apicem leviter sursum flexus.

$\left.{ }^{219}\right)$. Alac anticae margine externo concavo, posticae cauda mediocri spathulata. Cellula alarum auticarum sat angusta. Venula discocellularis earum liaud fracta, sed arcuata, extrorsum convexa, minus obliqua, quam in sectione LIII, inferior siperiore longior, cellula angulo superiore quare paullum producta. Abdomen supra fuscum, subtus vitta ventrali alboochracea.

2:11). Cellula alarum anticarum (secundum iconem) multo latior, venula earum discocellularis multo longior, quan in subsectione anteriore.

221). Alae anticae vena subcostali multo magis arcuata, quam in pracedente. Tenula earum discocellularis multo oJliquior, quam in sectione LIII, distincte fracta, inferior multo brevior, quam superior.

${ }^{322}$ ). Cum $P$. Merope simillimo ab omnibus auctoribus confusus, sed constanter recedens alis angustioribus, posticarum caudis longioribus, angustioribus, immarginatis cellulaque discoidali earum angustiore. Formam geographicam putassemus, nisi icones Cramerianae secundum specimina occidentali-africana confecta optime cum Merope Africae australis congruerent.

223). Yalde affinis praecedenti. Alae posticae ecaudatae, costa longiores, in regione anali vero breviores. Cellula anticarum propter venam subcostalem minus arcuatam latior, quam in sectione priore. Rami mediani venae discoidali inferiori haud paralleli, primus et secundas leviter deorsum llexi. Thorax supra flavido, subtus grosse albo maculatus. Petiolus rami subcostalis quarti et quinti alarum anticarum longior.

Specimen unicum Zenolii antennis carens ante nos habemus.

Fortasse subsectionem vel etian sectionem propriam constituit $I^{\prime}$. Conea.

22\%). Antennae tenuissinae. Alae sat clongatae, anticae marum in dimidio interno, fere ut in Menestheo squamis tomentosis tectae, tomento vero ulira renam medianam et discodalem superiorem extenso. Alae anticae rena mediana mugis sursum llexa, cellula ideo extimum rersus altenuata. Rami mediani earum stricti, cum rena discoidali inferiore paralleti. Cellula alarum posticarum angustiur.

2?.í). Vena subcostalis alarum anticarum apud ramum secundum for- 
titer fracta, venula discocellularis distincte fracta, superior brevior, quam inferior.

226). Magnam analogiam cum Acroeis quibusdam in eadem regione volantibus e. g. Carmentide, Jodutta luabet.

227). Venula discocellularis alarum anticarum multo magis obliqua hand fracta, superior multu longior, inferior subarcuata. Cellula alarum posticarum longior. Abdomen griseum, vitta dorsali, seriebus binis lateralibus punctorum, striga laterali duabusque ventralibus interuptis nigris.

$\left.{ }^{224}\right)$. Antennae tenues, sed clava vix scuta. Caput et collare indistincte albido maculata. Abdomen dimidium alarum posticarum marginis interni aequans, valva anali obtusa. Alae anticae elongatae, cellula fere ut in Zenolio, vena autem subcostali magis arcuata, venula discocellulari superiore longiore, quam inferiore, venis discoidalibus malto longioribus, quam in sectione dicta, inferiore cum ramis medianis omnino parallela. Alae posticae repando-dentatae, dente ad ramum medianum tertium acuto, prominulo, margine interno maris distincte plicato, costa multo breviore, quam in Zenubio, rena subcostali magis fracta apud rami primi originem, venula discoceliulari magis arrecta, regione anali minus porrecta (i. e. ramis medianis multo brevioribus). Praecedentes sectiones cum sequentibus conjungere videtur.

$\left.{ }^{229}\right)$. Antennae sat longae, tenues, clava acuta. Collare supra indistincte bivittatum. Thorax subtus sulplureus. Abdomen breviusculum, pilosum, strigis tribus lateralibus, duabus ventralibus vittaque rentrali sulplureis. Valva analis marum ut in sectione praecedente sed plus minus sulphureo colorata. Alae anticae sat elongatae, posticae abbreviatae, leviter sinuato-dentatac, spathulato-caudatae, angulo apicali bene projecto. Alae anticae angustiores, quam in sectione praecedente i. e. rami mediani multo breviores et magis deorsum directi. Plicae cellulares earum subtus distincte sulphureac. Forma alarum et signatura paginae superioris sectionem XLII paullum revocant, paginae autem inferioris color ei Demolei et Menesthei similior.

${ }^{230}$ ). Alae anticae costa et ideo vena costali et subcostali optime arcuatis, venula discocellulari sat obliqua, ramis medianis leviter deorsun arcuatis. Nlae posticae cauda brevissima, bene spathulata, trunco subcostali sat longo, cellula discoidali de caetero ut in sectione praecedente.

${ }^{231}$ ). Alae anticae costa in dimidio basali haud convexa, vena costali et subcostali ibidem hanc ob causam liaud arcuatis, venula discocellulari multo magis arrecta, rami mediani earum strictissimi. Alae posticae cauda longiore, angustiore, cellula longiore, dimidium alae attingente, interstitio ramorum subcostalium longiore, quam truncus subcostalis, renulit discocellulari inferiore multo magis arrecta.

232). Antenna validiores, quam in sectione pracedente. Occiput et thorax supra albido maculata, hic subtus albo rel ob-olete sulplureo macu- 
latus. Alac anticae latiores i. e. venis longioribus, posticae costa multo breviore, bene convexa, angulo apicali vix distincto.

${ }^{233}$ ). Alae posticae subcaudatae vel cauda brevi, subspathulata. Duae formae feminarum (in omnibus speciebus?).

23k). Magnus de sexibus dissensus. Anglici auctores (cl. Gray, Moore, Hutton in Transact. of the ent. Soc. V. p. 46) Polytis L. mares vidisse volunt, sed putamus, eos feminas abdominibus exsiccatione valde compressis ante oculos habuisse. Permulta Polytis inspeximus specimina e diversissimis locis et omnia feminina fuerunt et diversitates geographicas maribus correspondentes praebuerunt.

235). Specimina regionem interiorem montanam incolentia (Rambodde. cl. Nietner) sat discrepant ab indicis et littoralibus (Trincomali. P. Miliani). Lunulae marginales latiores. Fascia latior. Femina supra etian serie submarginali lunularum obsoletarum rufescentium vel ochracearum. Femina Polytis formae alas latiores habet, quam indica, et obscurius coloratas. Aberratio Stichius (absque macula alba in cellula alarum posticarum) hic etiam provenit.

$\left.{ }^{236}\right)$. Alae multo latiores, anticae obtusiores, quam in praecedentibus varietatibus, saepius margine externo sat convexo. Cauda marum et feminarum maris colore plus minus lobiformis.

237). Utraque figura haud omnino quadrat in Polytem, prior infra in alis posticis duas ostendit series macularum submarginalium, posterior nullam.

${ }^{239}$ ). Specimina feminina ternatica caudam multo breviorem, dentiformem gerunt.

239). Facile cum P. Pammone javano confundendus, sed bene diversus fassia maculari alarum posticarum latiore, dente ad ramum medianum tertium multo latiore, vix prominente, maculis submarginalibus in earum pagina inferiore sicut et maculis in sinubus marginis pure albis, illis margini multo magis approximatis.

$\left.{ }^{240}\right)$. Nullum marem adhuc vidimus. Nisi alarum anticarum signaturae ab omnibus Polytis varietatibus tantas praeberent diversitates, facile tertiam formam feminae Polyti adscriberemus.

241). Statura multo major, quam in praecedente. Femina mari conformis. Alae posticae semper spathulato-caudatac, haud fascia sed plaga subapicali supra ornatae.

242). Specimen e paeninsuli Malayica acceptum ab indicis differt tantum lunulis submarginalibus paginae inferioris alarum posticarum angustioribus, obsoletis.

${ }^{243}$ ). Femina a mare differt colore pallidiore, maculis marginalibus alarum anticarum is fasciae subapicalis maculaque interna (supra etiam apparente) multo latioribus plagaque posticarum magis diflusa. 
244). Alae posticae ecaudatae, in mare apud ramum medianum angulatae. Sexus valde discolores. Alodomen seriebus duabus subdorsalibus, una laterali quinisque ventralibus macularum albarum. Facies sectioni P'cnopes subsimilis.

2'.5). Alae posticae rotundatae, plane ecaudatae. Abdomen fuserm. Sexus valde diversi. Feminae Polytem imitantes.

2'ti). Eanden cum P. Ambrace Boisd. speciem olim judicavimus (Wien. ent. Monatsclnift IV. p. 228), sed auctor clare describit paginam inferiorem alarum posticarum albo maculatam. Eodem fere jure species in vicinitatem 1 . Plesti Guér. rejici posset.

${ }^{2} 47$ ). Alae posticae ecaudatac, sed dente ad ramum medianum tertium paullulum prominulo. Vena subcostalis alarum anticarmm minus arcuata, cellula lace ex causa latior. Sexus in colore et signaturis valde discrepantes. Femina in duabus (vel pluribus?) formis a mare acque diversis, una Polytem imitans. Statura major, quam in praecedentibus.

24s). Cel. Wallace nobis scripsit, $P$. Onesimum II w. benigne ab eo nobiscum communicatum, secundam esse Ormeni feminam. Hand possumus dubitare, $P$. Amengu Boisd. etiam hic pertincre et geographicam varietatem Onesimi esse, similiter ut 1'. Anceum Cram. I'. Laomerlontis, quac ambae cum $P$. Ayenore L. sccundam femininan I'. Memoronis formam constituunt. Specimina masculina e litore occidentali-australi Novae Guincae maculas colore dilute ochraceo-fulvo exhibent, sicut $P$. Ambrax et Euchenor in hac regione. - Specimen in collectione nostria, a cel. Wallace in insulis Arru captum diflert ab illis Novae Guinene fascia alarum posticarum angustiore, maculis ejus extus inaequaliter sinuatis fasciolaque maculari in limbo apicali alarum anticarum optime distincta.

249). Specimen masculinum in Museo Caesareo Viennensi maculam intra cellulam alarum posticarum et supra is iis maculam secundam in regione anali rufam, inter samum medianum primun et secundum exhibet. Aliud specimen in eaden collectione sat parvum est, lunulas marginales fulvo coloratas et subtus in alis posticis fasciam distinctam macularum grisearum habet.

$\left.{ }^{250}\right)$. Differt a sectione pracedente antemis multo longioribus, capite majore, corpore multo robustiore, sexibus multo minus discrepantibus, collari supra obsulete ochraceo bivitato, thorace et abdomine subtus omnino ochraceis, valva anali marum latiore et multo obtusiore, venula discocellulari alarum anticarum multo magis obliqua, vena discoidali superiore infra ejus medium oriente magis deorsum directa cellulaque posticarum angustiore usque in alac mediun extensi.

251). Eemina a mare diflert colore pallidiore, fascia alarnm anticarum rammm nedianum secundum haud attingente, a parte enim inferiore cjus macula inter ramos primores medianos diminuta, clongato-elliptica of ma- 
cula interna infra venan internam solis relictis, fircial allinum posticarum multo angustiore, extrorsum decreserente, acute inciso-dentata maculisque duabus irregulariter rlombicis terminata, primore infra ramum subcostatem cum macula secundir fasciale connexal.

252). Alate anticae longiores, apice multo magis produrtace, cellula angustiore, renula diseocellulari mperiore obliquiore, rena subcostali levissime arcuata. ramis cjus duobus primuribus a cellulae extimo multo remutioribus, petioln rani quarti et quinti longiore, vena mediana multo mans sursum directa, ramis ejus et venis discoilalibus longioribus et margini interno multo magis parallelis. Alac posticae angustiores, paullo prolundius sinuatae, cauda brevi, spathulati, costa multo breviore, quilin in subsections antecedente, sat areuata, trunen subcustali breviore, venta subcostali apuch ramum primum magis fracta, renuld discocellulari inforiore nulto breviore, ramo mediano secundo et tertio nulto magis remotis, regione anali multo magis producta.

25ia). Nomen auctoris mutandum fuit, quia longe antea jam applicatum fuerat (ef. nr. 330 ). Collectio Musei Cacarei specimen unicum retus et rat abstersum lujus venusti et rarissimi l'apilionis continct, ut dicitur, ex Anglia phura decennia ante acquisitum. Facile loc specimen typicum esse potest. Cauda autem alarum posticarum multo latior est, quam $j_{\text {il }}$ icune cl. Donnorani.

2:4). Antennae breviores, quam in sectione praceclente, clitra crassa elongata contorta. Frons capitis magis comosa, lulvo livittata, sicut ct pectus. Statura multo ninor. Abdomen maculis duabus basilibus cingulieque posticis confluentibus ochraceis. Alae anticae multo angustiones, quam in sectione praecedente, margine interno breviores, graciliter sulfalcatiac, colIula discoidali multo angustiole, renula discucellulari magis fratat, superiore enim magis arrecta, inferiore obliguiore, ramis medianis deornuln thexis. Alae posticae multo breviores. quam in sectine anteriore, pratentim margine costali et ideo rena costali multo brevioribus, cellula dincoidali latione, alae medium fere attingente, margine interno muto magis plicato. Signatura et color alarum ut in subscetione E sectionis pracectentis, alde amieate autem serie distincta submarginali maculaum maculisque dualus cellu-

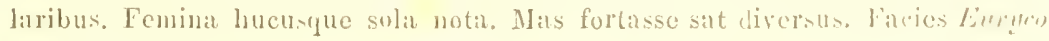
haud absimilis.

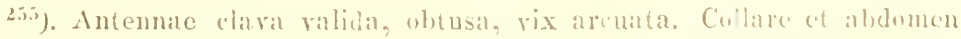
breviora, quam in sectionibus duabus pracedentibus, therax ct abdomen

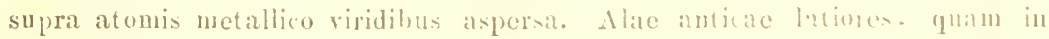

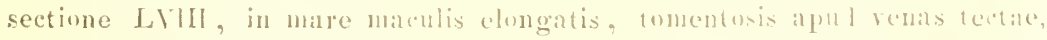
cellula discoidali breviore, rom subcostali multo misus areata. Alate po-ticae remote sinuato - dentatac, cauda phos minus longa et spathulata, collulat discodali multo berviore, guan in sectione dicta, renuly dis ocellulari inle- 
riore multo magis arrecta, cellula quare angulo superiore multo magis determinato, trunco subcostali multo breviore. Alarum pagina superior ares; dilute cyaneis.

2.iti). Vena subcostalis alarum anticarum a vena costali sat distans. Interstitinm venae discoidalis inferioris earum et rami mediani tertii interstitiaque ramormm medianorum sensim increscentia. Alae posticae cauda spathulata, sat longe petiolata, petiolo subaequilato, margine ejus externo recto, introrsum leviter concaro. Truncus subcostalis alarum posticarum brevior, quam interstitia ramorum subcostalium.

257). Nomina a cel. IVestwood proposita valde confusa sunt a cel. Lucas, Bulletin de la Soc. d' Ent. de France p. 23.

2.59). Statura multo minor. Cellula discoidalis alarum anticarum longior, quam in subsectione praecedente, costac bitrientem subaequans, vena earum subcostalis renae costali magis approximata, a rami secuudi origine subito arcuata, fere fracta, interstitium renae discoidalis inferioris et rami mediani tertii interstitiaque ramorum medianorum sensim decrescentia. Cellula alarum posticarum brevior, truncus subcostalis longior, quam interstitium ramorum. Alae anticae margine externo undulato, magis concavo, posticae cauda hrevi, orato-spathulata, brevissime petiolata. (In icone $P$ '. Chaudoiri I. c. cauda filso expressa est.) De tertia specie (Ulysello West.) levem indictionem de abentia (?) macularum tomentosarm solum hahemus.

25!1). Sat affinis sectioni priori, facile tamen dignoscenda antennarum clava multo graciliore, acuta, submucronata, collari magis exserto, vena subcostali alarum anticarum venae costali multo magis approximata, ramo ejus secundo a cellulate extimo multo minus distante, renula discocellulari a'armm posticarum nulto magis obliqua (collulae quare angulo superiore multo magis prominente), inferiore multo minus arrecta et valva anali mascnlina multo minore et obtusiore. Sexus (omnium?) subconcolores.

2(sio). Alace anticae marum maculis sat magnis tomentosis apud plicam internam et duas primores medianas, vena discoidali superiore in medio venulae discocellularis emissa, posticae in regione anali sat porrectate. Alae supra area hasali metallico-viridi.

261). Alac multo latiores, anticae maculis nullis tomentosis, cellula breviore ct latiore, vena discoidali superiore supra venulae discocellularis medium emissa, hac magis obliqua. Alac posticae apud costam longiores, caula semper late spathulata inaequilatera. Alae anticae supra striga, posticae fascia metallien-viridi, canda plus minus metallico-riridi atomosa.

262 ). Diftert a speciminibus in tera littorali (Trincomali) propenientihus fascia alarum posticarum latiore (praecique in femina) laetiusque culorata. Mares littorales apud ramm medanum secundum strigam tomentosam gerunt, montani vero (num plane nudum habent, ut species subsectionis tertiac. 
2633). Vena subcostalis alarum anticarum apud rami secmli originem magis fracta, venula discucellulari magis adhuc obliqua, guam in subsectione B. Alae supra fascia communi metallico-viridi, posticale cinda multo graciliore, longius petiolitir.

26't). Antenuarum clara multo longior, quam in sectione praecedente. Collare magis adhuc exsertum. Cellulat alarum posticarum angustior et longior, nsque in alae medium extensa. Valva analis masculina multo longior. Latitudo celludarum, positio venae discoidalis superioris alarum anticarum at venulae discocelluaris in alis posticis pro speciebus diversil.

265). Antennac iis sectionis LIX plane conformes. Alae posticae in plulimis supra plaga apicali metallico - viridi vel caerulea ornatae, cauda dilatata, spathulata.

26iti. Sat variat haec species. Specimina nostra multo majora sunt, quan. figura in cl. Grayi Catalogo, plaga apicalis alarum posticarum extu. multo profundius sinuata, alae anticae supra fascia distincta atomorum viridiun ct lunulae submarginales rufae pagine inferioris alarum posticarmu multo latiores.

Facile distinguuntur haec et sequentes duae a reliquis subsectionis hujus speciebus vena et plica interna ramisque duobus medianis primoribus alarum anticarum in mare supra tomentosis.

267). Intennarum clava paullo cras-ior. Alarum anticarum vena subcostalis a rena costali magis distans, venula dicocellularis inferior obliquior, cellula ipsa angustior. Alac posticae canda subacquilata, hand spathulati.

26s). A Bianose Cram.g cum quo cl. De II a an colure et signaturis fortasse deceptus confudit, longe diversus et P'. Marukii Ménétr. valde similis, facile tamen dignoscendus lunulis submarginalibus paginae inlerioris alarum posticarum a margine multo magis remotis.

Vena et plica interna ramique me liani alarum anticarum maris in $I^{\prime}$. Mrackir valde tomentosi apparent, et maculae tres inleriores tomenti in unam fere conjunctac sunt. Specimen nostrum I'. Rueduci lirem. ibidem parce tantum tomcntosum est.

$\left.{ }^{269}\right)$. Antennae ut in subsectione 1 sectionis pracedentis. Caput et collare albido maculata. Prons brevius hirsuta, quan in sectione pracedente. Thorax et abdomen supra nigra, atomis nullis metallico-riridibus.

Vena subcostalis alarum anticarum magis areuatio. Alate ponticate sappe caudatae, venula discocellulari inferiore multo minus arrecta, magis longitudinali. Sinus analis multo levior, quam in sectione auteriore. Venula discocellularis alarmu anticarum multum pro specicbus rariat.

270 ). Stitura multum robusta. Antennate validiores, valra analis masculina obtusior, quam in sulsectione sequente. Celfula discoifalis alarum

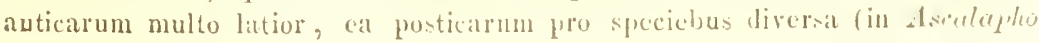


multo longior). Tenula discocellularis alarum anticarum prospeciebus diversa (in Deipholo multo magis fracta, superior multo magis obliqua), sicut ct Jongitudo venulae discocellularis alarum posticarum (in Polymestore haec nulto brevior, yuam in reliquis).

271). Sexus hujus speciei concolores. Femina unicam videtur habere formam, sicut et reliquae subsectionis species, Emalthione excepto.

272). Facies Polymnestoris, alae autem anticae (scilicet cellula earum) multo angustiores, quam in subsectione priore, venula discocellulari superiore alarum anticarum multo magis arrecta, alae posticae multo angustiores, costa breviore, cellula discoidali sat longa et angustiore, renula discocelluIari breviore, quam in P'olumestore. Abdomen maris striga laterali ochracea. Specinen motrum ranum medinum secusdum alae dextrae a medio bifucatum exhibet. Similitulo cum $P$. Priapo $\mathrm{B}$ ois d. primo intuitu valde decipit.

273). Alae anticae margine interno, posticae margine costali longiores, quam in subsectione anteriore. Tenula discocellularis alarum anticarum magis fracta. Alae posticae multo latiores, cellula discoidali breviore, venula discocellulari inferiure multo longiore, quam in Lampateo, sed breviore, guam in Deiplotho, Areulapho. Abdomen ommino nigrescens.

$\left.22^{2}\right)$. Feminae tres vel potius duo exstant typi, primus mari acedit, sccundus longe discrepat. Venula discocellularis superior aliarum anticarum in feminis multo obliquior, quam in maribus.

27.5). Venula discocellularis alarum anticarum magis arecta, iuferior rero oblicuior, cellula angustior et extimum versus magis attenuata, quam in Memme. Celiula alirum posticarum brevior. Observanda analogia feminae cum I'. Livide eanden insulam incolente.

2:6i). Alae anticae fere ut in subsectione b, set cellula discoidali cartum latiore, remula discocellulari superio: e magris arecta, in longitudine pro specicbus valiat in l'rotenore multo breviore, (quam in Rhetenore), cellulac angulu superiore quare magis prominente, pouticae corta adhat breviore, quam n Lerimpseren, valke declivi, vena contali hane ob rem magis areuata, in cxitu multo magis cam ramo sulementi primn convergente, venula discocellutari inferine in plericque speciminibus magis longitudinali, quam in subsectionibus pracedentibus. Femina mari fere concolor.

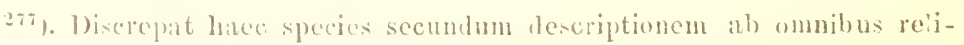
quis hujus sectionis ramis duobus medianis renague interna alarum anticarum supra in mare tomentusis, ut in speciebus nomullis sectionis praceedentis. An propria sectio?

27\%, Antenuac ralidiores, quam in sections Memmonis, clarat haud subuncronatil, sed obturid. Coblare rubro cingulatum. Thorax maculis lumeralibus rubris. Ablumen bitrientem margins intermi alarum posticarum 
a quans, subtus rubrum, stigmatibus fasciolicque rentralibus nigris, valva anali masculina multo minore, obtura rotundata. Frons capitis longius pilosil, multo angustior, quam in sectione IxHi. Alarum forma lere ut in subsectione D sectionis dictae, anticae vena subcostali a costali nulto magis distante, haud arcuata, sed pone ramum secundum dellexir, ramo primo et secundo ejus etiam multo magis inter se distantibus, venula discocellulari sat recta, inferiore l'exili multo longiore, quam superior, vena discoidali inferiore ramoque mediano secundo et tertio multo magis sursum directis, quam in sectione Lemmis. Nae posticae in mare anguntiores, margine interno in utroque sexu valde dilatato, in sare bis involuto, cucullato, involucro secundo extus dense albido squamato, in margine revoluto plicato et juba pilorum brumeorum obsito, in femina profunde plicato, fere canaliculato. Margo earun costalis in utroque sexu valde declivis, omnino in marginem externum transiens, angulo apicali quare nullo et rena costali brevissima. Rami subcostales aeque abbreviati, subflexiles, primus a basi multo magis remotus, quam in sectione Memnonis, venula discocellularis sllperior multo magis longitudinalis, vena discoidalis unacum cum ramo mediano tertio oriens, truncus medianus multo longior, quam in sectione fxill, ramus medianus secundus et tertius margini approximati, primus sat flexili.

Facies hujus sectionis distinctissimae plane P'. Protenoris et afluniun.

273). Valde aftinis sectioni praecedenti facile autem dignoscenda alarum anticarum vena subcostali minus deflexa, venula discocellulari superiore longiore, interstitio renae diseoidalis inferioris et rumi mediani tertii (i. e. renula discocellulari intima) breviore, magis sursum directa, ramo mediano primo et secundo magis inter se distantibus, alis posticie breviuribus, rena costali autem multo longiore, angulo apicali subelistincto, rano subeostali primo basi valde approximato, trunco subcostali ideo brevisimo. venula discocellulari superiore minus longitudinali, inferiore brovi sed optime distincta, vena quare discoidali a ramo nediano tertio bene remota, ramo modiano sceundo et tertio multo magis approximatis, abdomine (feminino) robustione, alartum posticarmm marginis interni bitrientem superante, ntringue nigrolusco, seguento tantum pacultimo infra et anali undiene rubro cingulatis, margine interno alarum posticarum (lembe) angustiore, minime plicato, sinu anali multo breviore antennirque paullo gacilius claratis.

leminam solum noseinus.

$\left.{ }^{2 * 0}\right)$. Jiflirt a sectione anteriore, cui vade aftuis, venula discocellulari alarum anticarum obliquiore, vena discoidali sup riore magin deorsum dircta, inferime ot ramo mediano tertio magis inter se dirtuntibus, alis posticis mulus magis porrectis, vena earum costali brevine, rano subcostali primo a basi multo magis remoto, renula discocellulari superione magis arrecta, inferiore brevissima, cellulat ols venam subcostalem multo magis fractan latiore, capitis fronte pilis ochuaceis valde comusa, cingulo collariv hu- 
merisque ochraceis, abdomine multo breviore, rittis duabus lateralibus latissimis ochraceis, margine interno ut in sectione $L X V$ formato, siut anali earum longisimo. Feminam unicam antennis carentem ante oculos habenus. Observanda est analogia cum P. Lampsaco tam diverso.

231). Facile distinguenda a sectione praecedente capite minore, fronte, cingulis collaris et ventralibus coccineis, ramo subcostali primo longius ante cellulae extimum ascendente, alis posticis sat angustis et in regione anali valde porrectis, multo profundius sinuato-dentatis, angulo carum apicali plane nullo, caula brevi dilatata, lobiformi apud rami mediani tertii extimum cellulaque discoidiali earum multo angustiore. Margo interuus alarmm posticarum in mare, nt in sectione LXV, sed multo minus dilatatus. Antennac breviores, quam in sectione LXV et LAVI. Abdomen multo brevius, quam in sectione 1 XIV et LXV. Venula discocellularis superior alarum anticirum sat variat pro specielus. In $P$. Ráuma M o o r e multo magis obliqua cst, quam in reliquis. Non minus mutabiiis cellula discoidalis alarum posticarun. In P. Dasararla Moore multo angustior et longior apparet, quam in reliquis. In $P$. Philoxeno vena subcostalis alarum posticarum multo magis faacta est, qua re cellula latior et brevior eflicitur.

233). Discrepat a sectione praecedente statura graciliore, antennis multo tenuioribus, alis posticis cauda multo longiore, vix spathulata, subaequilata instructis, sinu anali lerissino, margine interno unlto angustiore, in mare sub involucro tomento multo albiore tecto renulaque discocellulari superiore carumdem alarum multo longiore. Cellulace alarmm posticarum latitudo et longitudo pro speciminibus diversa.

293). Feniuam possidemus Alcinoi, in qua lunulue paginae inferioris alarum posticarum, maculae thoracis et vittae abdominales rubrescunt et marem, in quo ochriaccac apparent.

24t). Antenna longiores, clara crassiore, quam in sectionibus sex praeredentibus. Ablomen masculinum longius, marginis interni alarum posticarum bitrientem bene superasis, dinidio toto posijeo ochraceo, valva anali multo latiore et acutiore. Alace anticae in regione apicali valise porrectae, venula discocellulari inferiore magis arreta, cellulae angulo superiore quare multo magis prominnte; alace posticate leviter sed acute sinuato-dentatae, cauda subrotundata, petiolo longo et angusto insedente, quasi ligulata. Alae posticas multo brevioses ot latiores sunt, quam in sectione pracecente, cellulit earum similis ei $P$. Alcimoi, sed latior. Rami subcostales carumdent alarum nulto longiores, guam in sectione Alcinoi.

24.i.). Falso ridetur abdomine instructa figura in opusculo Delessertii.

$\left.2{ }^{2}\right)$. Valcle alfinis pracedenti, antemae autem longiores, crassius clavatae, valva analis masculina abduminis major, quan et in subsectione demiconis, alarum anticarum magn internus valde abbrevialus, alac (prae- 
sertim marum) quam angustissimae, venula discocellularis superior multo longior, interior minus arrecta, plica discoidalis superior valde distincta, alae posticale valde porrectae, collula discoidalis et ramorum subcostalium directio in is fere ut in sectione $\mathrm{LXT}^{\mathrm{T}}$, sinibus marginis ut in sectione LXVIII, cauda ligulata, sed magis dilatata et ovali, in femina brevins petiolata. Observanda est analogia in colore et ignaturis cum Memnonis feminini forma tertia (Achate etc.).

237). Ab omnibus congeneribus praecedentibus discrepat genitalibus masculinis onnino denudatis, valva enim anali nulla et ejus instar corona pilorum rubrorum, qua re Euryco generi jam accedit, quod facies etian rerocat.

Antennae sat validae, paullo longiores, quam in sectione Alcinoi, cui proxime accedit laec, clava arcuata bene distincta. Abdomen longius, cullare magis exsertum, statura nulto robustior. Cellula alarum anticarum ei sectionis Alcinoi conformis, renula tantum discocellularis inferior magis alrecta (praesertim in l'olydoro). Alae posticac ecaudatac vel cauda brevi spathulata, cellula multo latiore, sinu anali vix ullo, margine interno in mare a rena tantum interua simpliciter involuto, involucro extus juxta renam inte:mam breviter jubato piloso, margine ejus ad basin revoluto.

${ }^{2 \varsigma x}$ ). Valde affuis sectioni priori, diver:a tamen antennis validioribus, ramis duobus primoribus subcostalibus alarum anticarum deflexis, cellulac cxtimo magis approximatis, venula discocellulari superiore earum longiore, inferiore autem alarum posticarum breviore et praecipue margine interno harum alarum in scxibus conformi i. c. in mare magis tantum plicato, quam in femina, minime inroluto.

Tarsorum articulus ultimus in hac et tribus antecedentibus sectionibus longior, quan in congencribus, subtus longe et dense spinosus ungulisque multo majoribus nunitus, quae res affinitatem cum Euyco genere clare demonstrat. Alae feminae in omnibus lis sectionibus latiores, quam illate marum.

2ख9). Facies sectionis pracedentis. Alac anticac sat angustae, posticac cauda sat lati, subspathulata.

290). Antennae breviores, clava crassiore, quam in subsectione priore. Alac anticae multo latiores, margine interno longiore. Cellula discoidalis alarum anticarum latior, renula discocellularis multo rectior. Alae posticae cellula angustiore, venula discocellulari longiore et multo magis arrecta. Sinus earum marginales profundiores, canda brevis, angusta, apicem versus attenuata. - Observanda est magna analogia cum $I$ '. Afaco in antennaruu, alarum et ccllularum discoidalium forma, sicut et in colore, non minus quam similitudo larvae cum iis Ginithoperarem. 
291). Valde incerti sumus de vera eximiae hujus speciei sede. Alarum forma secundum icones species nonnullas sectionis Memonis paullum revocat, thoracis et antennarum forma sicut et color abdominis affinitatem cum sectione praecedente et ricinis indicare videtur. Facies tota P. Menestheo haud absimilis.

292). Genus Pupilioni certe proximum, sed aeque distinctam affinitatem cum Euryco praestans. Facies sectionis X et Xl Papilionis, antennae etiam similes, sed paullo breviores et multo validiores, clava crassior. Caput minus (nigro) pilosum. Abdomen maris brevius, paullo crassius, quan in Hectose, glabrum, maculis bifariis lateralibus juxta rentrem ochraceis, maculis ventralibus cinguloque anali coccincis, annulo ultimo nudo, absque ulla corona pilorum, genitalibus plane denudatis, ut in Euryco, in femina secundum obserrationem cel. Westwoud apud Doubleday Genera of the diurn. Lep. p. 21 appendice magno corneo munitum, ut in Euryco. Cellula alarum anticarum ei $P$. Hectoris similis, rami duo primores subcostales, ut in eo, sat deflexi, rena primaria autem pone secundum nulto magis deflexa, ramus tertius nulto magis arcuatus, paullulum ante cellulac clausum exiens, petiolus rami quarti et quinti longior, strictissimus, ramus quartus ipse multo magis arcuatus, renula discucellularis multo obliquior (cellula angulo superiore quare multo magis retracta), superior multo brevior (vena discoidalis superior hanc ob causam venae subcostali multo magis appruximata), interior magis flexilis, vena discuidalis superiur cum vena subcostali sat divergens, rena mediana apud ramorum origines nagis fracta, rena interna in dimidio terminali strictissima. Alae posticae margine costali longiore, trunco subcostali multo longiore, quam in Hectore, interstitio ramorum subcostalium multo longiore, magis deorsum directo, breriore, sat arrecto, inferiore multo obliquiore, breviore, ramo mediano primo multo longius a sceundo distante, cellula hanc ob causam ci Euryci similio:e et illi $P$. Agentoris Gray hand absimili. Alae anticae (in nostro specimine) paullum pellucidae. Margo internus alarum posticarum (in mare) plicis distinctis, sed nihilominus subplanus, nec canaliculatus, ante sinum analem bene distinctum fortiter complicatus. Tarsi pedum densius spinosi, ungulis ralidioribus armati, guam in 7lectore.

Hocee genus, si non e Prpilionum serie eximas, Eurveum ctian in cam includere debes. Ab hoc multo magis discrepat, duam a I'upilione. Antemae, renarum alarum anticarum conditio, cellulia alarum posticarum latior, brevior et magis oralis, margo internus carmm multo magis dilatatus, apud angulum analen distincte sinuatus, genitalia magis denudata, annulus ultimus abdominalis enim pilorem cingulo omnino carens et laminae hypopygiales maris multo breviores, fortiter carinatac, minus hirsutale, postice triangulum acuminatum constituentes. 


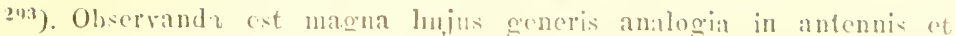
cellulae discoidalis alarum anticarmm forma cum sectione VIll, non minns quam similitudo abolominis, formatalan at venarum subcostalium in alis

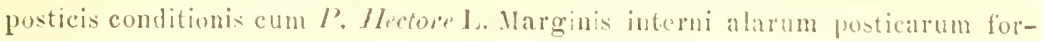
matio corte alfuitaten cum P'arnasiis demonstrat.

2"7). Intemmae ommino nigrac. Cellula alorum posicanum in pierisque speciebus alac medimn attingens. Venae discoidalis superioris alarum anlicarum positio, ramorum subcostalium et renac costalis dircetio et longitudo pro peciebu; diversae. Positio rami subcostalis secundi ct renace discoidalis superioris alarm anticarum et venulae discocellularis inferioris alarum posticarum pro specininibus mutabiles. Ramus subcostalis secundus alartum anticarum in nommllis speciminibus in medio suo cursu ramum primum stringens, fere cum eo connatus.

29.5). Specimen in collectione nostra in Sicilia captum mimus est indigenis, alae breviores et latiores, limbus terminalis hyalinus alarum anicarum fasciola maculari fundi colore divisus et limbus internus atomarius niger alarum posticarum angustior.

2!(i). Specimina e territorio Utah calitornicis minora sunt.

2!7). Antennae validiones, clava longior, scapus totus supra albo annulatus, annulis saepe conlluentibus (e, $g$. in Nomime, alpolline). Cellula alarum posticarum in plerisque speciminibus brevior, alae medium lanud ittingens.

2!18). Specimen in collectione nostra in valle Ilasli superiore alpium Bernensium captum discrepat alis angustioribus, is Delii similingibus, limbo hyalino alarum anticarum latiore posticarumque striga maculari submarginali atomaria nulto angustiore. Antemac autem onnino ut in ifpelline coloratie sunt.

299). Cel. Lederer Wien. ent. Munatschrift V p. 392 grencris hujus jura in dubium rocat, distinguitur vero a Pumessies, calcteris characteribus practermissis, antennarum clava areuatil remaque subenstali carum quinquerimosa. I'arnassios cum Thuilibes conjungit.

:mos). Femina sat variat, prosertin in latitudine lumnlarum submarginalium alaum posticarum.

an). Genus distinctissinum, neque cum l'umusciis, nee cum lmilite vel Therdibes confundendum, antennis solis jam longe diversmm. Antemnarmu clava enim brevis, optime abrupta, subovala, contortil. P'alpi lore ut in Pamessio. Abdomen (maris) gracilius, ham pilosmm, ammlo ultims plane clauso, corma pilorum obsito. Alae unmino ventitite, voua subcontalis anticarum costali valle approximatam (quadribmosal ut in l'urumsion. cellulal discoidalis latior, ramus medianus secundus et tertius multo magis di tilutes, 
quam ille et primus, hi sat deorsum flexi, renula discocellularis (inferior sc.) nulto magis ohliqua. A lae posticae in regione anali longiores, quam in generibus menomatis, vena costali brevi, in costae medio desinente, ramo subcostali primo fere in apice marginis costalis excurente, venula discocellulari magis obliqua, interstitio rami mediani secundi et tertii fere longitudinali, ramo nediano primo et secundo multo magis approximatis. Margo earum internus bene plicatus (fere ut in Sericino).

Signatura alarum anticarum Pamassios revocat, posticarum vero pagina inferior, sicut et facies tota, Picriderum Anthochurides. 


$\forall$

$\infty$

$\infty$

, 

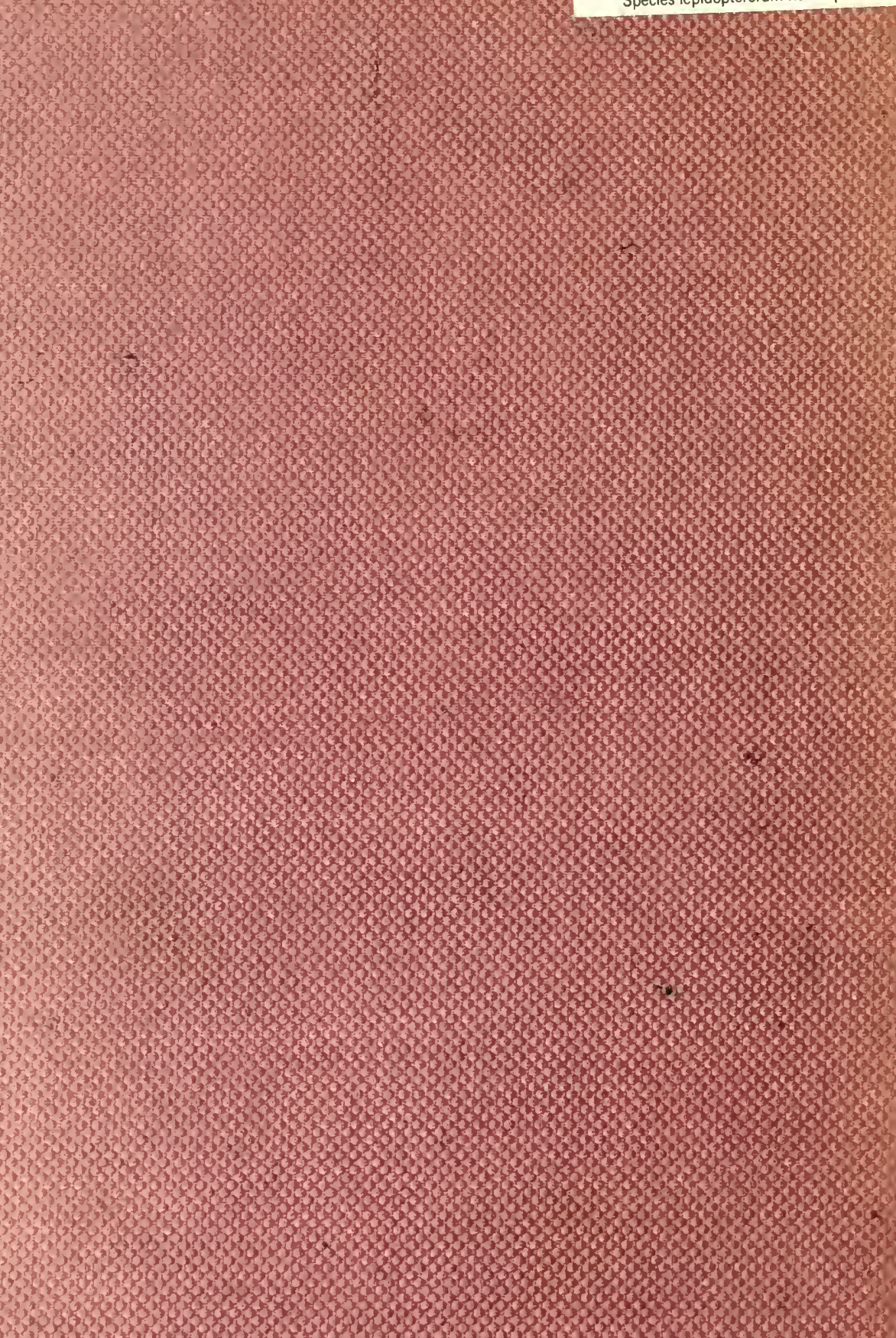

83 803

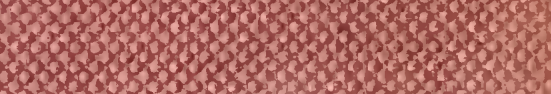

